\title{
THE EFFECTS OF COACHING ON TEACHERS' USE OF FUNCTION-BASED INTERVENTIONS FOR STUDENTS WITH SEVERE DISABILITIES
}

\author{
by
}

Keri S. Bethune

A dissertation submitted to the faculty of the University of North Carolina at Charlotte in partial fulfillment of the requirements for the degree of Doctor of Philosophy in Special Education

Charlotte

2012

Approved by:

Dr. Charles L. Wood

Dr. Fred Spooner

Dr. Ya-yu Lo

Dr. Charlie Reeve 
(C)2012

Keri Stevenson Bethune

ALL RIGHTS RESERVED 


\begin{abstract}
KERI STEVENSON BETHUNE. The effects of coaching on teachers' use of functionbased interventions for students with severe disabilities. (Under the direction of DR. CHARLES L. WOOD)
\end{abstract}

The purpose of this study was to evaluate the effects of coaching on special education teachers' implementation of function-based interventions with students with severe disabilities through the use of a delayed multiple baseline across participants design. This study also sought to examine if teachers could generalize the ability to implement function-based interventions to different situations with their students. Additionally, this study examined the effect of the function-based intervention on the students' problem and replacement behaviors. After an initial training on completion of FBAs and implementation of function-based interventions, coaching was provided by the researcher to each teacher. Results indicated that there was a functional relationship between implementation of the coaching procedure and an increase in teacher fidelity scores. Teachers demonstrated the ability to generalize the strategies to another situation with the target student. While some improvement in student behavior was noted upon teachers implementation of the function-based intervention without coaching (e.g., teacher baseline), this improvement was not consistent for all students and across the replacement behaviors. A functional relationship was found between accurate implementation of the function-based interventions (e.g., the coaching phase) and an increase in the students' primary replacement behaviors. 


\section{DEDICATION}

I would like to dedicate this dissertation to all of the people in my life who love me and have contributed to my success. Completing this doctoral program required sacrifices from everyone in my life. My wonderful husband, John, who I met during the doctoral program, thank you for your support, love, and understanding of my drive to help students with disabilities. Thank you for choosing to go on this ride with me. To my parents, thank you for your teaching me to reach for my dreams and then understanding what it took to get there. To my siblings and their wives, Greg, Laura, Brad, and Tiffany, who I could always count on for compassion and friendship. To their children, Maddie, Ben, and Emma, I hope you always look up to your Aunt Kiki with pride and see what is possible in your own lives. To my sister Stephanie, for showing me that individuals with disabilities never stop growing, I am as proud of you as you are of me. Thank you to my Aunt Amy, her crew, and all my aunts, uncles, and cousins for supporting me on this journey. Thank you to my mentors at Melmark New England, who taught me what it means to provide great services to students with disabilities. Thank you to every student I ever worked with at Melmark New England, for teaching me compassion and what it means to earn your success; Erik, Andrew, Cassie, Jackie, Isaac, Elizabeth, Michael, Tommy, Chuck, Brendan, Tatiana, Kate, Billy, Evan, Brian, and so many more. I will always remember the lessons you taught me. Finally, thanks to everyone at New Town Elementary for supporting me when I chose to come back to school and throughout my dissertation for allowing me to have access to your amazing teachers and students. 


\section{ACKNOWLEDGMENTS}

I would like to acknowledge the many people at UNC Charlotte who have guided me on my path to completing my dissertation. First, I would like to thank my advisor, Charlie Wood. His unwavering support and encouragement has pushed me to grow as a student and professional. His guidance was irreplaceable. I would like to thank Diane Browder for the opportunity to work with and learn from her. I would like to thank Nancy Cooke for identifying my strengths early in the program and encouraging me to push myself. I would like to thank Fred Spooner, for supporting me throughout my time at UNC Charlotte, as a teacher, as part of my portfolio committee, and on my dissertation committee as well. To my other departmental committee member, Ya-yu Lo, thank you for all of the thoughtful feedback throughout this process. To my outside committee member, Charlie Reeve, thank you for your time and insightful perspectives. Thank you to Bethany Smith and Alicia Saunders to helping me keep my sanity. Thank you to Christy Hicks for being my academic "big-sister" and providing me such a strong model to follow. Finally, thank you to the UNC Charlotte Graduate Assistant Support Plan for funding my dream to become a reality. 
TABLE OF CONTENTS

CHAPTER 1: INTRODUCTION 1

CHAPTER 2: REVIEW OF THE LITERATURE 13

CHAPTER 3: METHOD 48

$\begin{array}{ll}\text { Participants } & 48\end{array}$

$\begin{array}{ll}\text { Setting } & 51\end{array}$

$\begin{array}{ll}\text { Materials } & 52\end{array}$

$\begin{array}{lr}\text { Experimenter } & 53\end{array}$

Data Collection Procedures $\quad 54$

Dependent Variables $\quad 54$

Experimental Design $\quad 58$

$\begin{array}{ll}\text { General Procedures } & 60\end{array}$

Initial Observation $\quad 60$

$\begin{array}{lr}\text { Inservice } & 60\end{array}$

$\begin{array}{ll}\text { Student Baseline } & 61\end{array}$

$\begin{array}{ll}\text { Functional Analysis } & 62\end{array}$

$\begin{array}{ll}\text { Teacher Baseline } & 63\end{array}$

$\begin{array}{ll}\text { Coaching } & 63\end{array}$

$\begin{array}{ll}\text { Generalization and Maintenance } & 64\end{array}$

$\begin{array}{ll}\text { Procedural Reliability } & 65\end{array}$

CHAPTER 4: RESULTS 66

$\begin{array}{ll}\text { Interobserver Agreement } & 66\end{array}$

$\begin{array}{ll}\text { Procedural Fidelity } & 67\end{array}$

$\begin{array}{ll}\text { Results for Research Question } 1 & 68\end{array}$ 
Results for Research Question $2 \quad 72$

Results for Research Question $3 \quad 76$

Results for Research Question $4 \quad 85$

CHAPTER 5: DISCUSSION 89

$\begin{array}{ll}\text { Discussion for Question } 1 & 89\end{array}$

$\begin{array}{ll}\text { Discussion for Question } 2 & 91\end{array}$

Discussion for Question $3 \quad 92$

Discussion for Question $4 \quad 96$

$\begin{array}{ll}\text { Specific Contributions of this Study } & 97\end{array}$

$\begin{array}{ll}\text { Limitations and Recommendations for Future Research } & 100\end{array}$

$\begin{array}{ll}\text { Implications for Practice } & 102\end{array}$

$\begin{array}{ll}\text { REFERENCES } & 104\end{array}$

APPENDIX A: FUNCTIONAL ASSESSMENT INTERVIEW FORM 111

APPENDIX B: FUNCTION MATRIX 119

APPENDIX C: BUILDING A SUPPORT PLAN 120

APPENDIX D: POWERPOINT SAMPLES 121

APPENDIX E: FUNCTION-BASED INTERVENTION PROCEDURE 122 FIDELITY CHECKLIST

APPENDIX F: TEACHER SPECIFIC FUNCTION-BASED INTERVENTION 123 PROCEDURE FIDELITY CHECKLIST

APPENDIX G: PARTIAL INTERVAL RECORDING SHEET FOR STUDENT 124 BEHAVIOR

APPENDIX H: COACHING FIDELITY CHECKLIST 125

APPENDIX I: STUDENT DATA COLLECTION 126

APPENDIX J: SOCIAL VALIDITY QUESTIONNAIRES 127 


\section{CHAPTER 1: INTRODUCTION}

Statement of the Problem

Research has shown that the prevalence of challenging behaviors is higher among individuals with disabilities compared to challenging behaviors of their typically developing peers (Sigafoos, Arthur, \& O’Reilly, 2003). Emerson et al. (2001) determined that as many as $10-15 \%$ of the total population of individuals diagnosed with intellectual disability display challenging behaviors. Additionally, individuals who have a dual diagnosis of autism spectrum disorder (ASD) and intellectual disability (ID) are at even higher risk for exhibiting challenging behavior (Blancher \& McIntyre, 2006; Rojahn, Wilkins, Matson, \& Boisjoli, 2010). More specifically, individuals with ASD and ID are more likely to exhibit self-injurious behavior and stereotypic behaviors than individuals with ID alone (Rojahn et al., 2010). The rates of ASD are projected at one in 110 with 730,000 children between 0 to 21 years old being estimated to have ASD (Centers for Disease Control, 2006) with research indicating that rates of autism are increasing (Loiacono \& Valenti, 2010).

Not only are students with disabilities more likely to exhibit challenging behaviors, but they are also at higher rates of expulsion and suspension (Evanson, Justinger, Pelischek, \& Schulz, 2009). Students with disabilities are the recipients of reactionary consequence strategies, such as suspension and expulsion, at higher rates than typically developing peers (Evanson at al., 2009). Students with disabilities are $11 \%$ of 
the total school population; however, they account for $20 \%$ of total school suspensions (Evanson et al., 2009).

Challenging behaviors negatively impact the student's school progress, progress of other students, educational planning, and the well being of caregivers (Blacher \& McIntyre, 2006; Chandler \& Dahlquist, 2006). Some of the negative effects of challenging behavior for students include (a) failure to reach their academic potential, (b) increased school suspensions and increased school absences, (c) higher rates of peer rejection accompanied by a lack of an appropriate social network, (d) disruption of other students' learning, and (e) an increase in the time required for planning from the entire educational team which negatively impacts the time teachers can spend on academic planning (Chandler \& Dahlquist, 2006). Caregivers of individuals who have a disability and demonstrate challenging behavior self report lower personal well-being and increased stress when compared to caregivers of individuals with a disability but who do not exhibit challenging behavior (Blacher \& McIntyre, 2006). For students with severe disabilities, peer rejection, safety, and caregiver stress can be especially challenging and lead to more restrictive placements.

Functional Behavior Assessment and Function-Based Interventions

Functional behavior assessment (FBA) is a process that allows teachers, researchers, psychologists, and other practitioners to create hypotheses regarding the potential relationship between the environment and a student's challenging behavior (O’Neill, Horner, Albin, Storey, \& Sprague, 1997). FBA is a broad term that includes a set of processes to identify the relationship between the challenging behavior and the environment. FBA includes interviews, rating scales, direct observations, and functional 
analysis (FA) where the variables are systematically and experimentally manipulated (O’Neill et al., 1997). Behavior interviews (e.g., Functional Assessment Interview) and behavior rating scales (e.g., Motivation Assessment Scale and Functional Analysis Screening Tool) are part of the process of developing FBAs called indirect strategies, which focus on gathering qualitative information from informants (Alberto \& Troutman, 2009). After conducing behavior interviews, the student's challenging behavior is then analyzed using direct observation methods (e.g., scatterplots, $\mathrm{ABC}$ descriptive data) to look for patterns among antecedents, behavior, and consequences (Alberto \& Troutman, 2009). This may be followed by conducting an FA to (a) verify the hypothesis developed from the direct observation, (b) further refine the hypothesis, (c) clarify uncertain results from the functional behavior assessment, or (d) drive initial development of a hypothesis about the function of the challenging behavior (Alberto \& Troutman, 2009).

The FBA is then used to create and implement function-based interventions. Function-based interventions are positive interventions used to target challenging behavior and increase a functionally appropriate alternative behavior (Horner, 1994). These plans typically include a range of environmental manipulations (e.g., changes to motivating, antecedent, or consequence variables) that create an intervention package that includes teaching replacement behavior, altering the environment, and adjusting student contingencies and consequences (Umbreit, Ferro, Liaupsin, \& Lane, 2007).

Conducting an FBA and implementation of resulting function-based interventions is an important step in reducing challenging behavior (Umbreit et al., 2007). Challenging behavior can result in injuries to the student, other students, and teachers (Umbreit et al.). Students with challenging behaviors, especially those with severe developmental 
disabilities, often do not have appropriate replacement behaviors, have restricted access to the environment, and have restricted social supports (Umbreit et al., 2007).

The Individuals with Disabilities Education Act of 2004 (IDEA) mandates use of FBA with students who have disabilities and challenging behaviors that interfere with learning and/or participation in school activities. FBAs and resulting function-based interventions have been more successful in reducing challenging behaviors than nonfunction-based interventions (Filter \& Horner, 2009; Mustian, 2010; Umbreit et al., 2007). Function-based interventions are more successful because often teacher “penalties" actually reinforce challenging behavior (Umbreit et al., 2007). For example a teacher may send a student to "time-out" as a punishment for acting out in math class; however, escaping the academic task is actually reinforcing the student's challenging behavior. Furthermore, teacher-selected "reinforcers" may not actually serve as reinforcers for the student (Umbreit et al., 2007). That is, the reinforcing nature of the challenging behavior may be stronger than the identified reinforcer (Umbreit et al., 2007).

Teacher Difficulty Implementing Function-Based Interventions

Although conducting FBAs and implementing function-based interventions are an effective practice in reducing challenging behavior among students with disabilities, and are federally mandated, many school personnel fail to implement this process with the fidelity needed to achieve successful outcomes (Blood \& Neel, 2007; Scott, Nelson, \& McIntyre, 2005). At this time, there is not sufficient research demonstrating that school personnel can use the outcomes of FBAs to develop function-based interventions (Scott et al., 2005). Nahgahgwon, Umbriet, Liaupsin, and Turton (2010) specifically 
recommend additional research to examine the type and intensity of training procedures necessary for school personnel to create sustained implementation of FBAs and functionbased interventions with fidelity.

Schools frequently employ the workshop training method to train school personnel on a range of topics; however, research has suggested that this model alone is insufficient to successfully train school personnel to develop function-based interventions and that school staff continue to rely on punitive and exclusionary strategies that are unrelated to behavioral function (Scott et al., 2005). Scott, McIntyre, Nelson, and Conroy (2004) found that after a one-day workshop, school-based teams were unable to correctly identify the function of behavior from their students when compared to expert's analysis of the function.

Additionally, Van Acker, Boreson, Gable, and Potterson (2004) examined FBAs and behavior intervention forms from teachers across the state of Wisconsin. They found that even after a state-provided one-day training, the FBAs and behavior intervention forms contained substantial mistakes including lack of clear definitions of behaviors, lack of verification of hypothesized functions, and not using the results of the FBA to drive creation of the behavior intervention plans (BIP). Due to difficulty in implementing FBAs and function-based interventions, teachers may need additional support through other training and support methods.

Coaching

Coaching is a model used to increase teachers' accuracy when implementing evidence based practices (EBPs) and has been shown to have promising results towards improved student achievement (Kretlow \& Bartholomew, 2010). Coaching has been 
effective in increasing teacher accuracy in a range of areas including implementation of classwide positive behavior supports (PBS; Filcheck, McNeil, Greco, \& Bernard, 2004), reading interventions (Jager, Reezigt, \& Creemers, 2002; Kohler, Ezell, \& Paluselli, 1999; Lignugaris-Kraft \& Marchand-Martella, 1993; Morgan et al., 1994), explicit math instruction (Kretlow, Cooke, \& Wood, 2011; Kretlow, Wood, \& Cooke, 2011), and teacher praise in an RTI model (Myers, Simonsen, \& Sugai, 2011).

When implementing a coaching model, first an initial training is held on the target procedure or curriculum. This is followed up by individualized observations, feedback, and support which is conducted by an expert in the targeted area and helps teachers implement and sustain the new teaching skills (Kretlow \& Bartholomew, 2010). Throughout the coaching process, the expert prompts the teacher to use the targeted teaching behavior in an actual teaching situation and provides the teacher with immediate feedback on his or her performance (Kretlow \& Bartholomew, 2010).

Coaching has been found to have strong evidence as an effective practice for improving the performance of both preservice and current teachers (Kretlow \& Bartholomew, 2010). Coaching may be a successful model to teach teachers how to implement function-based interventions; however, there is no research on coaching and teachers' implementation of function-based interventions at this time.

Purpose

The purpose of this study was to evaluate the effects of coaching on special education teachers' implementation of function-based interventions with students with severe disabilities. This study answered four research questions. 
1. What are the effects of coaching on special education teachers' accuracy of implementation of function-based interventions?

2. What is the effect of coaching on teachers' ability to generalize a function-based intervention (developed using the same process) to a second identified challenging behavior and/or setting with their students?

3. To what extent do students' challenging behaviors decrease and replacement behaviors increase as teachers implement function-based interventions with increasing fidelity?

4. Do teachers and administrators find the use of coaching appropriate and efficient? Dependent Variables

The first dependent variable was percent accuracy of teacher implementation of the function-based intervention as measured by a procedural fidelity checklist. Fidelity checklists were standardized to the use of function-based interventions; however; each checklist was tailored to the individual student's behavioral function. Each checklist included items such as engaging students in an appropriate work task as previously specified, providing appropriate instruction (e.g., least to most prompts) on targeted replacement behavior, reinforcement of correct responses (either appropriate task completion or demonstration of targeted replacement behavior), and reacting as specified to targeted challenging behavior. Data were graphed as percentage of steps completed correctly.

The second dependent variable was frequency or percentage of intervals of each student's challenging behavior. Target students' challenging behavior was identified and defined upon completion of each student's FBA. The researcher tallied the frequency or 
percentage of interval of specified challenging behaviors that occur during the same teacher selected activity. The frequency or percent interval of targeted challenging behaviors displayed was graphed on an equal interval graph.

The third dependent variable was frequency, duration, or percentage of intervals of each student's replacement behavior. Target students' replacement behavior was identified and defined upon completion of each student's FBA during the inservice training. The researcher tallied the frequency or percentage of interval of specified replacement behaviors that occur during the same teacher selected activity as the problem behavior. The frequency or percent interval of targeted challenging behaviors displayed was graphed on an equal interval graph.

Significance of Study

This study has the potential to contribute to the literature on implementation of FBAs and function-based interventions in a number of ways. First, this study provides a model for a successful method for increasing teachers' fidelity of implementation of function-based interventions with students with severe disabilities and ASD. This can be used to design future studies and training protocols that will increase the efficacy of training for function-based interventions by public schools. This study also provides a template for public school administrators to use when planning district or classroom trainings on function-based interventions to include classroom follow up and coaching by an expert. Furthermore, because the study focused on teacher implementation of the function-based interventions, this study can provide support that teachers can be trained to use function-based interventions with fidelity. 
Additionally, this study used coaching to examine teacher fidelity of functionbased interventions to report on both teacher fidelity data and data on student challenging behavior. Reporting on both sets of data in this manner will advance the literature in two ways: (a) it will add to the literature on FBAs and function-based interventions by examining the training process, and (b) it will add to the literature on coaching by showing that coaching works to increase teacher fidelity of implementation for FBAs and function-based interventions.

Limitations/Delimitations

This study examined the effects of coaching on fidelity of implementation of function-based interventions with teachers of students with severe disabilities and ASD and measured the effects of the function-based intervention on student behavior. It is important to provide accurate limitations of this study to help readers accurately interpret the results.

First, this study utilizes a single-case research design. A limitation of singlesubject research is a potential lack of generalization to populations other than those specifically targeted in the study. This limitation can be addressed through systematic replication of this study with additional participants, different researchers, and in a range of locations (Cooper, Heron, \& Heward, 2007).

Second, initial expert support was provided during the one day inservice and was used to assist in completion of the FBA process. This study did not examine fading of expert support through conducting the FBA itself, instead taking a collaborative approach. Therefore, methods of fading expert support during completion of FBAs cannot be determined from this study. 


\section{Definitions}

The following definitions of terms are used throughout the proposed study to describe related literature and the methodology. Consensus on use of these terms is key to understanding the purpose of this study and in identifying potential contributions to the literature.

Autism spectrum disorder (ASD). A neurobehavioral disorder marked by deficits in social interaction, communication, and restricted, repetitive, and stereotyped behavior (Heward, 2009).

Challenging behavior. Also called problem behavior. This is a behavior that is exhibited by a student that interferes with the learning of the student himself/herself or the learning of other students. Additionally, this behavior is technically described in measurable and observable terms and is specifically identified for reduction through the selected intervention package (Umbreit et al., 2007).

Coaching. A process of teacher training that is comprised of an initial training (e.g., in-service) that is followed by the expert providing individualized feedback and support to help teachers implement and sustain the new teaching behaviors with the purpose of coaching of increasing teachers' accuracy when implementing evidence based practices (EBPs), (Kretlow \& Bartholomew, 2010).

Direct observation. A process of direct and repeated observation of the students' behavior in the natural environment (e.g., $\mathrm{ABC}$ recording) resulting in an overall description of students' behavior patterns (Cooper et al., 2007). 
Fidelity. The extent to which independent variable is applied exactly as planned and described without deviations that could lead to extraneous variables that could influence data (Cooper et al., 2007).

Function. The purpose the behavior serves which is developed by a past history of consequences (Umbreit et al., 2007). Functions are typically described in terms on positive reinforcement (social, tangible, and automatic) and negative reinforcement (escape and automatic; Cooper et al., 2007).

Functional behavior assessment (FBA). A set of strategies designed to identify the function of a given behavior through identification of altering antecedent variables, altering consequence variables, and alternative behaviors (Cooper et al., 2007). FBA methods fall into three categories (a) functional analysis, (b) descriptive assessment, and (c) indirect assessment (Cooper et al., 2007).

Functional analysis (FA). Also known as experimental analysis. When the antecedent and consequences in a person's environment are systematically arranged in a way that allows researchers to identify, observe, and measure their separate effects on the problem behavior. (Cooper et al., 2007).

Function-based intervention. Interventions and intervention packages that are developed from the FBA data that address the identified function of the challenging behavior (Umbreit et al., 2007).

Problem behavior. Also called challenging behavior. This is a behavior that is exhibited by a student that interferes with the learning of the student himself/herself or the learning of other students. Additionally, this behavior is technically described in 
measurable and observable terms and is specifically identified for reduction through the selected intervention package (Umbreit et al., 2007).

Severe disability. A term used to describe students with significant disabilities in the area of intellectual, physical, and/or social functioning including students diagnosed with multiple disabilities, deaf-blindness, severe intellectual disability, severe emotional disturbance, and/or severe health impairments (Heward, 2009).

Side-by-side coaching. A process where an expert, but not a direct supervisor, observes the teacher implementing the target practice, provides feedback in vivo, and may model the practice with the students while the teacher observes (Kretlow \& Bartholomew, 2010).

Topography. The physical form or shape of a behavior, which is both measurable and can be shaped (Cooper et al., 2007). 


\section{CHAPTER 2: REVIEW OF LITERATURE}

This chapter includes a brief description of students with intellectual disability and autism, an overview of the process of conducting a functional behavior assessment, and a review of relevant literature on FBA, function-based interventions, and coaching. The chapter includes a summary of each topic (FBA, function-based intervention, and coaching) which, together, supports the significance and purpose of this study. The chapter starts with a description of the FBA process, which leads to development of the function-based intervention. The chapter then includes research on teacher involvement in FBAs, then research on function-based interventions and difficulties with teacher implementation of these interventions (the dependent variable in this study). Finally, the chapter ends with a review of coaching (the independent variable in this study). In the current study, the effects of coaching on teachers' accurate implementation of functionbased interventions were analyzed.

Students with Intellectual Disability and Autism

Intellectual disability. Under IDEA (2004) students are considered to have an intellectual disability (ID) when their intellectual ability score (IQ) is below 70 with correspondingly similar adaptive and academic skills. Most students with ID are affected throughout their lifetimes (Heward, 2009). Students with severe to moderate ID may be diagnosed early in childhood, while students with mild ID may not be diagnosed until second or third grade (Heward, 2009). Students with ID may have lower functioning in 
the areas of cognitive functioning (e.g., memory, learning rate, attention) and adaptive behavior (e.g., daily living skills, social skills, behavioral challenges; Heward, 2009).

Educational approaches for students with ID often include academic and functional curriculum and self-determination training (Heward, 2009). Traditionally, students with ID were instructed in self-contained classroom; however, more recently more students with ID have been educated in general education classrooms with support (Heward, 2009).

Autism spectrum disorders (ASD). ASD is defined as a neurobehavioral syndrome with impairments in social interaction, communication, and restricted, repetitive, and stereotyped behaviors (Heward, 2009). ASD encompasses a group of conditions including autism, Asperger syndrome, Rett syndrome, childhood disintegrative disorder, and pervasive-developmental disorder-not otherwise specified (PDD-NOS) (Heward, 2009). Students with ASD can vary significantly with some being very significantly impacted across domains and other students demonstrating mild impacts towards academic, social, and behavioral domains (Heward, 2009).

Educational approaches for students with ASD often include teaching methods derived from applied behavior analysis (Heward, 2009). Early intervention with students with ASD can greatly improve their social, communication, and cognitive function and may lead to increased placement in general education settings (Heward, 2009). Students with ASD are educated in a range of educational settings, including separate schools, separate classrooms, and increasingly in general education settings (Heward, 2009).

Problem Behaviors. Individuals with disabilities have higher rates of problem behaviors than typically developing individuals (Sigafoos, Arthur, \& O’Reilly, 2003). 10- 
$15 \%$ of students with intellectual disability display challenging behaviors (Emerson et al., 2003). Individuals who are diagnosed with both ASD and intellectual disability are even more likely to display challenging behaviors, and are specifically at a higher risk of exhibiting self-injury or stereotypic behaviors (Blancher \& McIntyre, 2006; Rojahn, Wilkins, Matson, \& Boisjoli, 2010).

Research has also shown that students with disabilities are the recipients of reactionary consequence strategies (e.g., expulsion and/or suspension) more than their typically developing peers (Evanson at al., 2009). While students with disabilities make up approximately $11 \%$ of the total school population, they account for $20 \%$ of school suspensions (Evanson at al., 2009). In addition to being suspended and expelled more often, challenging behaviors have a negative impact on student's progress in school, the progress of other students, teachers' educational planning, and the well being of caretakers (Blacher \& McIntyre, 2006; Chandler \& Dahlquist, 2006).

Functional Behavior Assessment

This section discusses the process of conducting FBAs, which were conducted in this study as part of the inservice completed by teachers with the support of the researcher. Conducting FBA in a school system is often a team effort, involving the special educator, the school psychologist, general educators, and at times school administrators. FBA is a process that enables researchers and teachers to develop and test hypotheses regarding environmental events and behavior (Cooper et al., 2007). FBA is derived from the principles of applied behavior analysis (ABA), which states that all behavior has a function (Cooper et al.). FBA is designed to identify the function of a challenging behavior and the antecedent conditions that predict occurrence of the 
behavior for that individual (Sugai et al., 2000). Identification of these antecedent conditions also allows the researcher or teacher to identify any modifications that can be made to the environment to decrease the occurrence of the behavior in the future (Umbreit et al., 2007).

Functions of behavior (including desirable and challenging behaviors) have been categorized in a number of ways; however, when broken down into the most basic behavioral principles, the functions of behavior fall into two categories: (a) positive reinforcement (e.g., to get something) and (b) negative reinforcement (e.g., to get out of something; Cooper et al., 2007). Positive reinforcement is defined as the contingent presentation of a stimulus following the occurrence of a behavior that increases or maintains the frequency, duration, of intensity of the behavior (Skinner, 1938). Negative reinforcement is defined as the contingent removal of a stimulus following the occurrence of a behavior that increases or maintains the frequency, duration, of intensity of the behavior (Cooper et al., 2007).

Functions of behavior can be further broken down within the categories of positive and negative reinforcement. For example, Carr (1994) lists social attention, access to tangibles, and gaining internal/sensory stimulation under the umbrella of positive reinforcement. Furthermore, he lists escape or avoidance of tasks and escape or avoidance of individuals as negative reinforcers. Cooper et al. (2007) also include social positive reinforcement (attention), tangible reinforcement, and automatic reinforcement as positive reinforcement. However, they add automatic negative reinforcement in addition to social negative reinforcement to the category of negative reinforcement (escape; Cooper et al.). 
The reinforcers can also be broken down into a number of categories, but all fall within one of two broad categories of reinforcers: primary reinforcers or secondary reinforcers (Umbreit et al., 2007). Primary reinforcers are those that fulfill a basic biological need and are further broken down as either consumables (e.g., food and liquids) or sensory reinforcers (e.g., heat and touch; Umbreit et al., 2007). Secondary reinforcers are items/activities that acquire their reinforcing value through repeated association with primary reinforcers (Umbreit et al., 2007). Umbreit et al. (2007) break down secondary reinforcers into four categories: (a) tangible reinforcers (e.g., toys or clothes), (b) activity reinforcers (e.g., events such as reading or watching TV), (c) social reinforcers (e.g., social activities such as attending a dance or party), and (d) exchangeable reinforcers (e.g., items that can be exchanged for other primary or secondary reinforcers such as money or tokens).

According to Cooper et al. (2007) the process of conducting an FBA includes four primary steps:

1. Gathering information through the use of indirect and direct assessments.

2. Developing a hypothesis about the function of the behavior.

3. Testing the hypothesis.

4. Developing intervention strategies based on the function of the challenging behavior.

Gathering information. There are a number of methods used to gather information on the problem behavior; however, these methods fall into two categories: (a) indirect functional behavior assessment and (b) direct observation functional behavior assessment (Umbreit et al., 2007). Indirect functional behavior assessment can include structured interviews (of caregivers, teachers, individuals, etc.), record reviews, checklists, rating 
scales, and/or questionnaires (Cooper et al., 2007). The goal of these types of assessment is to obtain information about the behavior and the environmental conditions surrounding the behavior (Cooper et al., 2007). A number of structured interview forms have been published to help teachers and clinicians with this process, including the Functional Assessment Interview (O’Neill et al., 1997) and the Preliminary Functional Assessment Survey (Umbreit et al., 2007).

Indirect forms can be convenient and can guide further direct observation methods (e.g., if the teacher reports that the problem behavior occurs more frequently during a specific time of day, observations can be scheduled during those times; Cooper et al., 2007). While indirect forms can be an important first step, there are some disadvantages of indirect methods. One major concern is the accuracy of the information provided by the informant, who may have unclear descriptions or interpretations of the behavior (Cooper et al., 2007). Additionally, little research has been done on the accuracy of interview forms (Cooper et al., 2007). Research that has been completed on the Motivation Assessment Scale found interrater reliability to be low (Cooper et al., 2007).

Direct observation, also known as descriptive functional behavior assessment, occurs when the behavior is observed during naturally occurring observations (Cooper et al., 2007). There are two primary types of direct observation: $\mathrm{ABC}$ recording (continuous or narrative) and scatterplots (Cooper et al., 2007). When using ABC recording, an observer records the antecedents, behaviors, and consequences as they are observed occurring in the environment. These recordings are then analyzed for trends in events that occur in close temporal relationship to the target behavior to develop a hypothesis about the function of the behavior (Cooper et al., 2007). ABC recordings can help identify 
causal relationships to the behavior and provide helpful information about the behavior in the natural environment (Cooper et al., 2007). Some disadvantages of ABC recording are that conditional probabilities indicated in the $\mathrm{ABC}$ recordings may be misleading if the behavior is maintained by intermittent reinforcement and when conducted by untrained personnel they may not be accurate (Cooper et al., 2007).

Scatterplot recording is a method in which problem behavior is observed by recording the relationship to the time of day the behavior occurs (Touchette, MacDonald, \& Langer, 1985). The day is divided into time blocks and coding symbols are used to indicate the frequency of the behavior during each individual time block (Touchette et al., 1985). After the data have been collected for a period of days or weeks, the data can then be analyzed for temporal patterns and correlated to environmental events occurring at the same times (Touchette et al., 1985). The main advantage of using scatterplots is that the observer can easily identify time periods when the behavior is more likely to occur (Cooper et al., 2007). A number of disadvantages to the use of scatterplots have been indentified: (a) there is insufficient research to demonstrate how frequently temporal patterns are apparent, (b) obtaining accurate scatterplots can be problematic, and (c) rating systems can be subjective which may lead to inconsistency in the data (Cooper et al., 2007).

Developing a hypothesis. After completing the information-gathering phase, the collected information is then used to develop a hypothesis statement identifying any antecedent variables and maintaining consequences (Cooper et al., 2007). The first step in creating the hypothesis statement is to determine if the behavior is maintained by positive or negative reinforcement, then to identify exactly what is being gained or avoided 
(attention, tangibles, activities, or sensory stimulation; Umbreit et al., 2007). Umbreit et al. (2007) suggest use of a Function Matrix to help develop the behavioral hypothesis. The Function Matrix is a table with positive reinforcement (access something) listed in the left column and negative reinforcement (avoid something) listed in the right column. These types of reinforcement are broken down further by the following rows: attention, tangibles/activities, and sensory (Cooper et al., 2007). A check is then placed in any box corresponding to the information gathered on the individual's problem behavior, which is then used to write the hypothesis statement of the behavior (Umbreit et al., 2007). The hypothesis statement should include information on the antecedent, student, behavior, and function (Cooper et al., 2007; Umbreit et al., 2007).

Testing the hypothesis. Once the hypothesis statement has been developed, it can be tested to ensure the intervention will be effective. Cooper et al. (2007) state that the hypothesis statement should be tested through the use of a functional analysis (FA). This is a process where the individual is systematically exposed to specific conditions designed to elicit the problem behavior based on the function (Cooper et al., 2007). An FA should always include a play condition where the individual has no demands and continuous attention and access to preferred items (Cooper et al., 2007). FAs should also include any other conditions required to confirm the hypothesis of the function of the behavior and may include contingent escape, alone, and contingent attention (Cooper et al., 2007). Use of an experimental design allowing for demonstration of experimental control (e.g., reversal or alternating treatments) leads to the ability to verify the behavioral function (Cooper et al., 2007). 
Umbreit et al. (2007) take a slightly different approach to confirming the hypothesis. They suggest developing an intervention package, and using an experimental design allowing for demonstration of experimental control (e.g., reversal or alternating treatments) to identify the effectiveness of that particular intervention package, thus confirming the hypothesis statement (Umbreit et al., 2007). This method provides a simple procedure that allows teachers to ensure they are on the right track before full scale implementation of the intervention package begins (Umbreit et al., 2007).

Developing the intervention. Once the previous steps of the FBA have been developed and the function of the behavior has been identified, an intervention that is directly linked to the function of the behavior (function-based intervention) can be developed. This intervention may take the form of an intervention package with multiple components including teaching replacement behaviors, improving the environment, and adjusting the contingencies (Umbreit et al., 2007). Umbreit et al. (2007) indicate that even when FBAs have been correctly completed, school teams still make errors when developing appropriate function-based interventions. They lay out a clear plan for developing function-based interventions using the Function-Based Intervention Decision Model, a flowchart developed to guide practitioners' decision-making (Umbreit et al., 2007). This tool includes a series of yes/no questions such as "Can the student perform the replacement behavior?" and "Do antecedent conditions represent effective practice?" As practitioners answer these questions the flow chart directs them towards whether the replacement behavior needs to be taught, the environment needs improved, and/or the contingencies need adjusted (Umbreit et al., 2007). Use of this method is a clear, 
systematic approach to help school teams appropriately develop function-based interventions from the results of the FBA.

Research on Functional Behavior Assessment

The following studies are reviewed on FBA to provide a brief history of the research in this area, but also to examine the role of the teacher in conducting the FBA and implementation of the subsequent function-based interventions. The use of interventions that are based on the results of FBAs (i.e. function-based interventions) began with Carr (1977) hypothesizing that individuals engage in problem behaviors deliberately to fulfill a purpose. He suggested that as individuals receive reinforcement for challenging behaviors, they learn to exhibit these behaviors under certain circumstances to produce the reinforcement. He then concluded that if his hypothesis was true then these challenging behaviors are operant and can be assessed and treated as such.

Iwata, Dorsey, Slifer, Bauman, and Richman (1982) published a seminal article describing a method for analyzing the function of self-injurious behavior of nine individuals with developmental delays. They exposed participants to eight sessions designed to test the frequency of self-injury under four conditions (i.e., social disapproval, academic demands, unstructured play, and alone). Results were presented in the form of descriptive statistics for all nine participants and alternating treatment design graphs for four participants. Results indicated that there was a high level of both between and within subject variability; however, six of the eight subjects demonstrated high levels of self-injury correlating to a specific condition. The authors conclude that self-injury may, in fact, be a function of a variety of forms of reinforcement and identification of the function could impact treatment design. The authors state that one limitation of the study 
is that there is no function-based intervention phase showing corresponding decreases in self-injury. The authors state that use of their methodology enables clinicians to empirically identify the function of self-injury and avoid designing interventions on a "best guess" (Iwata et al., 1982). While this article establishes that behavior of individuals with disabilities serves a clear function, it was conducted in a medical setting and did not include the participation of teachers.

Carr and Durand (1985) conducted a two-part study to assess the function of challenging behavior of four children with disabilities and then to identify replacement behaviors (using differential reinforcement of functional communication responses) to reduce the challenging behaviors. For the first part of the study, they used a modified reversal design (one for each student) to measure the impact of attention and demand conditions on the problem behavior of the participants. The authors interviewed the participant's teachers to help them develop the hypothesis that led to the creation of the attention and demand conditions. Results indicated the function of the challenging behavior for each participant (e.g., attention and escape from demand). For the second part of the study, they again used a modified reversal design to measure the impact of the functional communication training on the challenging behavior. Results indicated that functional communication training was effective in decreasing problem behavior. The authors concluded that functional communication training, while topographically different from the problem behavior, teaches the child a functionally equivalent appropriate replacement behavior. They also concluded that the study of human behavior will be best advanced through the analysis of function, instead of topography (Carr \& Durand, 1985). In this study, teachers were involved in the initial phases of the 
experiment through an interview process; however, they were not involved in development or implementation in anyway.

Repp, Felce, and Barton (1988) moved this line of study into the school systems. They conducted a study to identify the function of problem behaviors and test functionbased interventions with three students with disabilities and self-injurious or stereotypic behaviors in their classroom settings. With each participant, they used a three-part design. First, they used an alternating treatments design with function-based condition to identify the function of the behavior, then used an alternating treatments design (function-based intervention verses non-function-based intervention) to show efficacy of the functionbased intervention in one setting, and finally applied the function-based intervention across both conditions to observe behavior reduction across settings. Results of the initial alternating treatments revealed a hypothesized function of the challenging behavior of each student. In the second phase, introduction of the function-based intervention lead to decreases in the challenging behavior in one setting, which then was also effective across both settings in the final phase. The authors conclude that use of function-based interventions is effective in treating problem behavior (Repp et al., 1988). While this research was conducted in the classroom, the participants' teachers were not directly involved in the decision making or implementation.

Dunlap, Kern-Dunlap, Clarke, and Robbins (1991) conducted a study with two goals: (a) to test a hypothesis regarding function of a student's problem behavior and (b) see if curricular modifications based on the hypothesis would be effective in reducing the problem behavior of a 12-year-old student with multiple severe disabilities in her separate classroom setting. Two specially hired classroom instructors worked with the participant 
throughout the study; however, data collection and decision-making remained the responsibility of the research team. During the first phase, the authors used standardized tests, direct observations, rating scales, and questionnaires to identify potential variables contributing to problem behavior. This information was used to design a reversal design to identify the function of the student's behavior relating to school specific tasks (e.g., fine motor activities, lengthy activities, nonfunctional activities, presented with no choice in activity selection). During the second phase, the authors implemented a packaged intervention including both curricular modifications and consequence strategies using a multiple baseline across time periods. Results indicated that use of the package intervention was effective in reducing the student's challenging behavior; however, because there are only two tiers, no functional relationship can be definitively established. The authors stated that use of functional analysis was effective in identifying curricular variables influencing behavior and that functional analysis can be successfully implemented in a school setting. They also state that use of the functional analysis creates a direct link to the development of the intervention package (Dunlap et al., 1991). This study moves towards using teacher implementers for research; however, this study did not include teachers in data collection or decision making.

Sasso et al. (1992) examined the accuracy of descriptive analysis and experimental analysis conducted by teachers with two students diagnosed with autism in two public school self-contained classrooms. For each student they used an alternating treatments design to identify the function of the challenging behavior using three methods: (a) functional analysis conducted by the authors, (b) descriptive analysis collected by the classroom teachers, and (c) functional analysis conducted by the 
classroom teachers. Results showed that the function of each student's challenging behavior (negative reinforcement) was correctly identified by the descriptive analysis and the teacher-conducted functional analysis. The authors then instructed the teachers to implement intervention packages based on the results of the functional analysis. Using a multiple baseline across settings (two tiers) design, the researchers showed that the intervention package was successful in decreasing the challenging behavior and increasing the appropriate behavior of each student. The authors concluded that teachers are able to successfully implement functional analysis technologies, that the intervention packages were successful in decreasing the problem behavior, and that teachers found these procedures to be socially acceptable (Sasso et al., 1992).

Foster-Johnson, Ferro, and Dunlap (1994) extended this line of research by measuring the influence preference on the occurrence of problem and desirable behaviors of three students with moderate disabilities; however, they did not include a measure for accuracy of teacher implementation. Teachers were interviewed to identify potential preferences for participants. For each student they used a reversal design to evaluate the impact of the high and low preference activity on the students' behavior. Results indicated that each of the students had higher rates of problem behavior and lower rates of desirable behavior during low preference activities and high rates of desirable behavior and low rates of problem behavior during high preference activities. The authors conclude that preference can be systematically measured and that preference can have a large impact on students' challenging behavior (Foster-Johnson et al., 1994). While the impact of preference is important to the potential effectiveness of function-based interventions, this study did not include teacher implementation. 
Kern, Childs, Dunlap, Clarke, and Falk (1994) examined the effects of conducting an FBA and implementing a subsequent intervention package on the problem behavior of an 11-year-old boy with above average intelligence and severe behavior challenges in a public elementary separate classroom. They used interviews with teachers followed by an experimental analysis implemented by teachers to identify the variables maintaining the student's problem behavior. The researchers then used a multiple baseline across settings design to measure the impact of the intervention package (including self-monitoring) on on-task behavior. Results demonstrated a functional relationship between on-task behavior and the intervention package. The authors stated that the results expanded the literature to students with above average intelligence and support the use of curricular modifications to affect student behavior (Kern et al., 1994). Additionally, implementation of the procedures by teachers adds to the literature suggesting that teachers are capable of implementing FBAs and function-based interventions; however teachers were not involved in decision making process.

Ervin, DuPaul, Kern, and Friman (1998) investigated the effects of classroombased functional and adjunctive assessments and subsequent intervention packages with two students diagnosed with attention deficit hyperactivity disorder (ADHD) and comorbid oppositional defiant disorder (ODD) in a private school setting. For the first student they used an alternating treatments design to assess the variables affecting the behavior followed by a reversal design to assess the impact of the treatment package. For the second student they used an alternating treatments design to assess the variables affecting the behavior. This was followed by a multiple baseline across setting (classrooms) design with embedded reversal in the top two tiers. Results of the teacher- 
implemented functional analysis for both students identified the function of the students' behaviors and indicated that there was a functional relationship between packaged interventions (including curricular modification and self-recording) and increases in ontask behavior. The authors stated that this study added to the literature supporting use of functional behavior assessment procedures by teachers and also reported that teachers found these procedures to be socially acceptable (Ervin et al., 1998).

In addition to the individual studies that have been conducted on functional analysis, Iwata et al. (1994) completed a literature review examining 152 single-subject studies to analyze the effects of functional analysis on individuals who demonstrate selfinjurious behavior. All included studies used systematic manipulation of conditions (e.g., social-positive, social-negative, demand, automatic reinforcement) through the use of multielement, reversal, or combined designs. They found that the maintaining function of self-injurious behavior varied by individual with $31 \%$ maintained by social-negative reinforcement, $26.3 \%$ maintained by social-positive reinforcement, $25.7 \%$ maintained by automatic reinforcement, $5.3 \%$ maintained by multiple variables, and $4.6 \%$ had unclear results. The authors also found that matching treatment to behavioral functions were reported in a small proportion of the studies, resulting in a wide range in the designed interventions. The authors concluded that (a) experimental approaches to behavioral assessment are effective and efficient, (b) self-injury is a learned behavior, and (c) determination of the function of the behavior should guide development of the intervention (Iwata et al, 1994).

More recently, research has focused on teacher implementation of FBAs and function-based interventions by teachers with a range of students, including students with 
ADHD and students considered at risk. Kamps, Wendland, and Culpepper (2006) examined the effects of an FBA and subsequent development of function-based interventions (including reinforcement in the form of teacher praise and a token system and self-management) with two second-grade students in a general educations setting. The teacher implemented the intervention with some coaching provided by the researcher. Results indicated that on-task behavior increased and disruptive behaviors decreased. The authors conclude that such procedures can be implemented by teachers in general education settings (Kamps, Wendland, and Culpepper, 2006).

Summary of function based assessment. Research has shown that FBA is an effective way to identify the function of and contributing variables to problem behavior. A number of themes have arisen from the literature including (a) problem behavior is learned behavior that is maintained by reinforcement (Carr \& Durand, 1985; Dunlap et al., 1991; Iwata et al, 1982; Iwata et al., 1994; Repp et al, 1988), (b) FBAs can be implemented accurately in school settings (Ervin et al., 1998; Kern et al., 1994; Sasso et al., 1992), (c) function-based interventions are effective in decreasing problem behavior (Carr \& Durand, 1985; Dunlap et al., 1991; Kern et al., 1994; Repp et al., 1988), and (d) a lack of research on function-based interventions (Iwata et al, 1982; Iwata et al., 1994). Research on Function-Based Interventions Developed by School Personnel

Although research has been published on the effectiveness of FBAs and functionbased interventions, there is a general lack of research of function-based intervention development and accurate implementation (Iwata et al, 1982; Iwata et al., 1994). School personnel, including teachers, frequently fail to implement function-based intervention with the fidelity needed to achieve successful outcomes (Blood \& Neel, 2007; Scott, 
Nelson, \& McIntyre, 2005). In 2005, Scott and colleagues found that there is not sufficient research demonstrating that school personnel can use the outcomes of FBAs to develop appropriate function-based interventions (Scott et al., 2005). A gap also remains in the application of this process into school systems and school teams can struggle with appropriate development of function-based interventions even when FBAs are completed (Umbreit et al., 2007). In recent years, a number of studies have been published that address this gap.

Liaupsin, Umbreit, Ferro, Urso, and Upreti (2006) examined the effectiveness of a system for organizing FBA data and developing intervention components with a middleschool 14-year-old typically developing student with challenging behavior in a charter school specializing in students with low academic performance and challenging behavior. They used a multiple baseline across settings design to measure the impact of the function-based intervention developed from an FBA on off-task and on-task behavior. Visual analysis of the graphs suggests a functional relationship between the functionbased intervention and the off-task behavior; however, this analysis was not as conclusive. That is, the on-task behavior during science class in baseline was too high, prompting the researchers not to implement the intervention in this class. The authors identified the following limitations: (a) there was no functional relationship because the intervention was implemented in only two tiers, (b) there was a lack of maintenance data, and (c) social validity was not assessed. The authors state that future research is needed with additional subjects, with treatment integrity included, and additional research is needed that compares function-based and non-function-based interventions (Liaupsin et al., 2006). 
Turton, Umbreit, Liaupsi, and Bartley (2007) examined the effectiveness of a model for organizing FBA data and developing FBI with a student diagnosed with EBD. They used a reversal design to measure the impact of function-based interventions created using the results of FBAs on profanity use and appropriate responding of a 16year-old female attending an alternative high school for students with significant behavior challenges. Visual analysis shows a functional relationship between functionbased intervention and appropriate responding. Limitations were that the study included only a single participant which limits generalization and that no maintenance data were collected. The authors stated that future research should consider the degree to which FBA can be used within a school or Local Education Agency to observe for results across a range of students (Turton et al., 2007).

Lane, Smither, Huseman, Guffey, and Fox (2007) evaluated the effects of function-based interventions, self-monitoring, and differential reinforcement on the classroom behavior of a typically developing 6-year-old male. They used a multiple baseline across settings design to measure the impact of the function-based intervention, differential reinforcement, and self-monitoring on the total disruptive behavior (TBD) and academic engaged time (AET) during general classes and specials classes. Results showed evidence of a functional relationship between the intervention package and changes in behavior; however, the multiple baseline included only two tiers, limiting the ability to definitively demonstrate a functional relationship. The authors stated that future research is needed with sufficient tiers to demonstrate a functional relationship and to examine what level of teacher fidelity is required to generate positive effects on challenging behavior (Lane et al., 2007). 
Filter and Horner (2009) compared the effects of function-based interventions with non-function-based interventions for fourth-grade students whose problem behaviors were maintained by academic variables in a general education classroom. They used a single-subject A-B-C-B design to compare the impacts of the function-based intervention verses the non-function-based intervention on percentage of problem behavior and task engagement. Results showed that the function-based interventions were more effective in reducing problem behavior than the non-function-based interventions. The authors stated that limitations of their study included a small sample size and the short phase lengths for one participant. The authors stated that future research is needed that includes fidelity of implementation of the interventions (Filter \& Horner, 2009).

Nahgahgwon, Umbreit, Liaupsin, and Turton (2010) examined the effectiveness of function-based interventions with young children at risk of emotional behavioral disorders (EBD) in an inclusive setting. They used a multiple baseline across participants design to measure the impact of function-based interventions developed after completion of an FBA on the disruptive and on-task behavior of three kindergarteners. Visual analysis indicated that function-based interventions were successful demonstrating a functional relationship for on-task behavior. Limitations included that no post-measures of global functioning were collected (participants had been screened with the BASC-2 prior to implementation), there was no measure of disruptive behavior, and expert support was present when developing FBA and function-based interventions. The authors stated the future research should examine the "type, quality, and quantity of training" to create sustained use of FBA and FBI with fidelity (Nahgahgwon, 2010, p. 555). 
Roscoe, Kindle, and Pence (2010) evaluated the utility of preference and attention analysis to identify the maintaining function of the problem behavior, extended FA that included the modified form of attention, and conducted a treatment assessment to assess development of function-based interventions with a 13 -year-old with autism in a residential placement. The authors used a reversal design to measure the impact of the function-based intervention (including functional communication training) based on results from the FBA including an extended FA on aggressive behavior. Visual analysis of the graph showed a functional relationship between the function-based intervention and aggression. The authors identified the following two limitations of their study: (a) during the FA an unequal number of sessions for each condition were conducted which may have impacted the results and (b) only one class of attention (conversational topics) was analyzed during the preference assessment and attention analysis. The authors stated that future research should include ways to evaluate other forms of attention (Roscoe et al., 2010).

Mustian (2010) compared the effectiveness of function-based and non-functionbased interventions with two elementary students considered at risk for being emotionally disabled (ED). She used an $\mathrm{ABABCBC}$ multiple treatment reversal design to assess the impact of the non-function-based intervention and the function-based intervention. Additionally, she used a training package that included teaching modules and coaching to prepare teachers to implement the interventions with the students and measured teacher performance using fidelity checklists. Results indicated that the function-based interventions were more effective than the non-function-based interventions in decreasing the problem behavior. Additionally, a functional relationship was demonstrated between 
the problem behavior and the function-based intervention. Results of the teacher fidelity checklists showed high percentages of accuracy from the teachers (above 85\%). The author stated that future research should be conducted to replicate the results with additional participants, allow for collection of maintenance data, and include a range of problem behaviors.

Summary of research on function-based interventions. Overall, function-based interventions have been shown to be effective in reducing problem behavior and increasing replacement behavior. Additionally, the research suggests that additional research is needed that addresses the following concerns: (a) development and implementation of function-based interventions in school settings (Turton et al., 2007), (b) inclusion of additional participants (Filter \& Horner, 2009; Mustian, 2010), (c) inclusion of social validity data (Liaupsin et al., 2006), and (d) examination of the "type, quality, and quantity" of training to sustain accurate use of FBA and function-based interventions in schools (Nahgahgwon et al., 2010).

Current Training Methods Used By School Districts

Ongoing teacher training provided by school districts occurs largely though the use of workshops or summer institutes (Yoon, Duncan, Lee, Scarloss, \& Shapley, 2007). Scott and colleagues (2005) found that schools frequently utilize the workshop training method to train school personnel on a range of topics; however, this model alone is insufficient to successfully train school personnel to develop function-based interventions. They also found that teachers and administrators continue to rely on punitive and exclusionary strategies that are not related to the function of the behavior (Scott et al, 2005). Scott and colleagues (2004) found that after being provided with a 
one-day workshop, school-based teams continued to be unable to correctly identify the function of students' behavior when compared to expert's analysis of the function.

Van Acker, Boreson, Gable, and Potterson (2004) found similar results in the state of Wisconsin. They examined FBAs and behavior intervention forms from teachers across the state and found that after a one-day training, the FBAs and behavior intervention forms contained substantial mistakes. These mistakes included some of the following errors: (a) a lack of clear definitions of behaviors, (b) a lack of verification of hypothesized functions, and (c) not using the results of the FBA to drive creation of function-based interventions. Due to difficulty in implementing FBAs and function-based interventions even after being provided with a workshop, teachers may need additional support through other training and support methods. A combination of inservice training paired with follow-up support (e.g., coaching) may be more effective in producing sustained improvement in teacher behavior (Yoon et al., 2007).

\section{Coaching}

Research has shown that FBAs and function-based interventions are an effective way to decrease problem behavior; however, there is not sufficient research on the "type, quality, and quantity" of training needed to ensure accurate use of FBA and functionbased interventions (Nahgahgwon et al., 2010). Also, there is a general need for increased special education support and ongoing training of special education teachers (Jenkins \& Yoshimura, 2010). Coaching is defined as a process where an initial training occurs and afterwards an expert in the targeted area provides individualized feedback and support to help teachers implement and sustain the new teaching behaviors (Kretlow \& 
Bartholomew, 2010). The purpose of coaching is to increase teachers' accuracy when implementing evidence-based practices (EBPs), which have been shown to improve student achievement (Kretlow \& Bartholomew, 2010). Throughout the coaching process, the expert prompts the teacher to use the targeted teaching behavior in an actual teaching situation and provides immediate feedback on his or her performance (Kretlow \& Bartholomew, 2010).

Kretlow and Bartholomew (2010) conducted a comprehensive literature review examining coaching to improve fidelity of EBPs. The studies in this review used supervisory coaching, side-by-side coaching, and some studies used a combination of both supervisory and side-by-side models of coaching. Coaching was found to improve teacher accuracy in all 13 identified studies. They concluded that more research is needed among middle and high school students, on student outcomes, and sustainability of the teachers' behavior change. Additionally, coaching has been found to have strong evidence as an effective practice for improving the performance of both preservice and current teachers (Kretlow \& Bartholomew, 2010; Tschannen-Moran \& McMaster, 2009).

Types of coaching. Coaching can be divided into a number of types including supervisory coaching, side-by-side coaching, and bug-in-ear coaching. Supervisory coaching occurs when a supervisor observes a teacher implementing a new practice, takes notes on the occurrence or nonoccurrence of the desired behavior, and provides specific feedback to the teacher immediately following the observation (Kretlow \& Bartholomew, 2010). Side-by-side coaching is described as a process where an expert, but not a direct supervisor, observes the teacher implementing the target practice, provides feedback in vivo, and may even model the practice with the students while the teacher observes 
(Kretlow \& Bartholomew, 2010). Bug-in-ear coaching is similar to side-by-side coaching; however feedback is provided through wireless headsets to prevent disrupting the flow of the lesson (Scheeler, Congdon, \& Stansbery, 2010). Research on Supervisory Coaching

Supervisory coaching for academics. Supervisory coaching has been found to increase the accuracy of teacher implementation of academic instruction. Powell, Diamond, Burchinal, and Koehler (2010) used a Hierarchical Linear Model to examine the effects of literacy-focused professional development using expert coaching and to determine whether or not there are differential effects of remote versus on-site delivery of coaching. The study included 759 students enrolled in 88 classrooms in 24 Head Start centers in 11 counties in a midwest state. Teachers participated in a semester long professional development consisting of a 2-day workshop followed by seven coaching sessions across a 15 week-period. Investigators measured changes in scores on one measure of teacher behavior: Early Language and Literacy Classroom Observation (teacher assessment). This assessment has a 5-point anchored scale to rate global classroom quality and teachers' instructional practices. They also measured child scores on a number of assessment procedures. Positive results were found for general classroom environment, classroom supports for early literacy and language development, children's letter knowledge, blending skills, writing, and concepts about print. No significant results were found for onsite versus remote coaching. The authors recommend future research examine whether or not remote coaching can be more cost effective than on-site coaching. 
Supervisory coaching for social behavior. Supervisory coaching has also been found to increase fidelity of instruction designed to improve student social behavior. Coaching has been found to be effective in changing parent interactions with children with severe disabilities (Janssen, Riksen-Walraven, van Dijk, \& Ruijssenaars, 2010; Shanley \& Niec, 2010). Janssen et al. (2010) reported two case studies where individual coaching of mothers resulted in positive effects on interaction with their young children who had severe disabilities. The parent behaviors studied included initiatives, confirmations, answers, turns, attention, intensity, affective involvement, and independent acting. Parents and coaches reviewed videos of their interactions with their children and coaches provided specific feedback to improve the quality and number of interactions. Positive effects were reported in all but one category (adequate reacting from the mother) for each of the participants through the use of bar graphs showing parent behavior before and after coaching.

Additionally, coaching has been found to be effective in increasing teacher praise in an RTI model (Myers, Simonsen, \& Sugai, 2011). While the authors of this study do not label their intervention as coaching, instead calling it targeted training support, it meets the definition of coaching by use of a supervisory coaching model where feedback was provided in email and in person directly after a supervisor observation. They used a multiple baseline across teachers design to examine if coaching is effective in increasing teacher praise. They found that coaching was generally effective, but did not yield a functional relationship because some teachers required an additional phase of intervention in the form of an increased level of support. This additional level of support included providing overt scripts for teachers to use and providing post session feedback 
in the form of individual meetings and follow up emails. The authors stated that the lack of a functional relationship indicates the need for future research to determine why some teachers respond to coaching while others require additional support.

Finally, Vismara, Young, Stahmer, McMahon-Griffith, and Rogers (2009) conducted an experimental group design to evaluate the most effective model for training therapists as coaches when coaching parents to implement behavior therapy in children with autism. The study included 10 therapists and 29 children diagnosed with autism spectrum disorders (ASD). Initially, the parents and therapists were provided with a training module called the Early Start Denver Model (ESDM), followed by training the therapists to conduct individualized coaching with the parents. Results indicated that parent implementation of targeted behavior therapy skills changed significantly $(F(3,24)$ $=8.85, \mathrm{p}<.001)$ with the ESDM training. Three of the four measures of child behavior also changed significantly $(F(3,27)=4.59, p<.05$ for verbal utterances, $F(3,27)=6.17$, $\mathrm{p}<.01$ for child attention, and $\mathrm{F}(3,27)=7.87, \mathrm{p}<.001$ for social initiations $)$. Parent implementation of the targeted behavior therapy skills increased significantly again upon implementing the coaching procedure $(\mathrm{F}(3,16.86)=21.88, \mathrm{p}<.001)$, but no significant results were found for child behavior at this stage. The authors suggested this model is an appropriate method for training therapists and parents to implement behavior therapy with children diagnosed with ASD.

Summary of supervisory coaching. Research has shown that supervisory coaching is effective for improving fidelity of academic and behavioral instruction. A number of recommendations for future research arise from the literature regarding supervisory coaching including (a) the need for research to determine if a particular type of coaching 
is more effective than another (Powell et al., 2010), (b) the implementation of supervisory coaching using natural implementers rather than researchers (Myers et al., 2011), (c) research in a wider range of settings and with a wider range of participants (Myers et al., 2011), (d) additional research examining student data in addition to teacher data (Myers et al., 2011), (e) research to examine the level of intensity of teacher support needed to make sufficient gains in teacher behavior (Janssen et al., 2010), and (f) the appropriate and effective use of technology in the coaching process (Powell et al., 2010). Research on Side-by-Side Coaching

Side-by-side coaching for academics. There have been a number of studies that examine side-by-side coaching to increase the fidelity of teachers' implementation of academic instruction. While these studies primarily center on literacy instruction, two studies were found that focused on teacher behavior during math instruction. Rudd, Lambert, Satterwhite, and Smith (2009) found that coaching improved teacher's appropriate use of math-mediated language. They reported on implementation of a coaching program with 12 math teachers in a university, child development center for early childhood education. The researchers used a single-subject method; however, they only reported descriptive statistics due to high variability in the data. Their results indicated that after a 2 hour workshop, there was a $56 \%$ increase in teachers' use of mathmediated language; however, an additional 39\% increase was reported after math teachers received additional coaching. The researchers concluded that the 2 hour training was effective in increasing teacher use of math mediated language, but they recommend following up with the coaching model as this is where the largest increase in teacher use of math mediated language was observed. 
Onchwari and Keengwe (2008) used a qualitative method to examine the effects of a mentor-coach initiative model on literacy in Head Start programs. They conducted one-on-one interviews that resulted in a number of themes. The authors report that $77 \%$ of teachers report that Head Start uses the mentor-coach model in their school. Teachers are trained on literacy; however, the teachers are not appropriately implementing the trained literacy techniques due to being overwhelmed and confused by the provided materials. Often, teachers' direct supervisors acted as coaches, which may pose a conflict between their role as a supervisor and their role as a peer coach. They found that half of teachers stated that the coaching model was helpful. Teacher identified challenges to effective implementation of a coaching included (a) lack of time, (b) lack of resources, and (c) diversity of children in their classes (ages and knowledge level). They also found that teachers reported there was not enough one-on-one time with coaches.

Menzies, Mahdavi, and Lewis (2008) conducted a group study to identify the amount of progress made by first-grade students on specified reading measures and to examine "treatment resisters" individually to identify as special education if needed. They used an ANOVA to examine the Dynamic Indicators of Basic Early Literacy Skills (DIBELS) and Developmental Reading Assessment (DRA) scores of 42 first-grade students who were at risk for reading difficulties. They found that small group instruction on phonemic awareness, decoding and fluency, and guided reading techniques provided by teachers who were meeting regularly with literacy coaches was effective in increasing student scores. ANOVA results show that both at-risk and non-at-risk students showed significant growth over time. The authors reported that $90 \%$ of students reached grade level reading proficiency by the end of the study. Three of the four students who were 
significantly below grade level qualified for special education services (the fourth student had very inconsistent school attendance). The authors state that side-by-side coaching supported fidelity of implementation.

Tschannen-Moran and McMaster (2009) conducted a survey to evaluate the selfefficacy beliefs of elementary school teachers regarding implementation of new reading strategies targeted at beginning readers. Ninety-three teachers responded to the survey and results indicated that the most effective training format was a professional development training followed by coaching. Teachers who attended professional development trainings, but were not provided with coaching reported decreased selfefficacy. The authors concluded that coaching is a valuable support that is needed when asking teachers to implement new reading strategies.

Peterson, Taylor, Burnham, Schock (2009) conducted a mixed method study examining the practices of current successful literacy coaches. From a pool of 24 schools in the Minnesota Reading First Professional Development Program and 48 Reading First Coaches, coaches representing high performing schools were selected. This selection was based on overall school effectiveness rating, overall school reform effort rating, and students' growth in reading. Four schools met these criteria (eight coaches total). Qualitative interviews with these coaches were conducted along with descriptive statistics and direct observation of their coaching sessions. The following types of coaching conversations were observed: using data from lessons to focus on critical pieces of instruction, using questions to elicit conversation, and building bridges between professional development and instruction. The authors concluded that teacher reflection is critical and that teachers benefit from concrete data and feedback from coaches. 
In addition, Lynch and Ferguson (2010) conducted a qualitative study to clarify the specific details of literacy coaches roles, including how to improve coaching to make future professional development of coaches more effective. They interviewed 13 literacy coaches in "primary" or "junior schools" in an urban setting in Ontario, Canada. Through semi-structured interviews, the researchers found themes related to the role of the coach (presenting workshops to teachers, examining grade-level assessments, identifying how to improve teaching and assessments), barriers to effective coaching (low principal involvement, teachers who are resistant, too large a case load, unclear roles, and limited resources), and ways to overcome barriers (improving communication with teacher and principals, increased specificity in job descriptions, and smaller case loads).

Zakierskiy and Siegal (2010) conducted a case study examining the effects of a school-wide reading intervention utilizing coaching to strengthen the skills of literacy teams. They examined reading scores of fourth-grade students enrolled in a public elementary school where a majority of students receive free or reduced-price lunch. The authors reported that after implementing the literacy team approach student scores on state exams rose from $68 \%$ to $93 \%$. The authors concluded that the intensive reading approach involving literacy teams and the side-by-side coaching positively impacted student learning.

Sailors and Price (2010) conducted an experimental group design to compare the effects of a two-day summer inservice where 44 teachers were randomly assigned to receive follow-up coaching or no follow-up coaching. The authors measured the effectiveness of the workshop alone versus the follow up coaching on reading instruction and student achievement measures. They used a Hierarchical Linear Model (HLM) to 
demonstrate that coaching was more effective in increasing a variety of teacher behaviors including opportunities to engage in cognitive reading strategies $(p<.05$ with an effect size of 1.65) and constructed explanations ( $p<.05$ with an effect size of 0.78$)$. They also report that student achievement increased when opportunities to engage increased with an effect size of (Cramer's $V=.86)$.

Additionally, Kretlow, Wood, and Cooke (2011) conducted a study to examine the effects of coaching on teachers' implementation of Direct Instruction strategies during math class. They used elements of both supervisory and side-by-side coaching comprising an initial training, pre-observation meeting, coaching, and follow-up meeting; however, this study is included with side-by-side coaching as it was the predominate method used. They used a multiple baseline across participants design to measure teachers' accuracy on instructional units (multiple-interconnected three-term contingencies) during three kindergarten math classes. Use of the instructional unit as a dependent measure allowed the researchers to accurately capture the entire Direct Instruction sequence, including appropriate praise and error correction. Results demonstrated that side-by-side coaching was an effective method for increasing teacher fidelity of Direct Instruction strategies during math instruction.

Then, Kretlow, Cooke, and Wood (2011) conducted a similar study to examine the effects of a combined method of supervisory and side-by-side coaching on first-grade teachers' performance delivering two types of math instruction (i.e., calendar math lessons and numeracy and problem solving lessons). Coaching was implemented during calendar math lessons, while numeracy and problem solving lessons acted as a measure of generalization. They used a multiple baseline across participants design to show that 
the coaching method was effective in increasing teachers' performance (measured again in instructional units) across both types of math lessons.

Side-by-side coaching for social behavior. Side-by-side coaching has also been reported to be effective for improving students' behavior. Shanley and Niec (2010) conducted a group experimental design to compare the effects of coaching versus no coaching on parent interactions with their children. They randomly assigned 63 mothers to either the coaching or no coaching group and measured their behavior across a variety of measures including the Parent Stress Index-Short Form, Behavior Assessment System for Children, and Dyadic Parent-Child Interaction Coding System. They implemented a side-by-side coaching model where experts provided immediate feedback and modeling to mothers. Their results indicated that mothers in the coaching group significantly improved their use of positive parenting skills as measured from pre-intervention $(\mathrm{M}=15.47, \mathrm{SD}=10.80)$ to post-intervention $(\mathrm{M}=27.93, \mathrm{SD}=16.44), \mathrm{t}(29)=4.46, \mathrm{p}<.001$, compared to mothers in the non-coaching group as measured from pre-intervention $(\mathrm{M}=20.50, \mathrm{SD}=11.51)$ to post-intervention $(\mathrm{M}=16.63, \mathrm{SD}=10.32), \mathrm{t}(29)=2.41, \mathrm{p}<.05$. The authors conclude that coaching is an effective method to improve parent behavior.

Summary of side-by-side coaching. Research has shown that side-by-side coaching is effective for improving fidelity of implementation of both academic and behavioral instruction. Recommendations for future research include: (a) the effects of coaching on student performance (Menzies et al., 2008); (b) the sustainability of the changes in teacher behavior resulting from coaching (Tschannen-Moran and McMaster, 2009); (c) examination of the level of intensity of coaching needed to make sufficient gains (Menzies et al., 2008; Tschannen-Moran \& McMaster, 2009); (d) examination of 
the level of support that is needed when coaching adult behavior (Myers et al., 2011); and (e) if certain types of coaching are more preferred and more effective (Shanley \& Niec, 2010). Research on Bug-In-Ear Coaching

Research on bug-in-ear coaching for academics. Bug-in-ear technology has been shown to be effective in increasing teacher fidelity of academic instruction. Rock, Gregg, Thead, Acker, Gable, and Zigmond, (2009) used a mixed method sequential explanatory strategy to evaluate the effectiveness of bug-in-ear coaching on teacher behavior during reading instruction. Qualitative results indicated that use of the bug-in-ear coaching did not negatively affect instruction, instead teachers reported that it was a useful tool to bridge the research to practice gap. Matched-pairs $t$ tests demonstrated a statistically significant reduction in the number of student hand raises $\left(t(14)=4.58, p=.0005, \alpha_{\text {one- }}\right.$ tailed $<.016, \Delta=.99)$ and student blurt-outs $(t(14)=2.142, p=.025)$. The researchers also found a statistically significant improvement in the number of choral response practices implemented by teachers $\left(t(14)=-2.509, p=.0125, \alpha_{\text {one-tailed }}<.016, \Delta=1.09\right)$.

Bug-in-ear coaching has also been shown to increase teachers' implementation of the successful three-term-contingency teaching units across a range of academic subjects (Scheeler et al., 2010). They used a multiple baseline across participants design to demonstrate that bug-in-ear technology with three general education and special education teacher pairs was successful in improving the percentage of correct implementation of three-term-contingency trials. In a post-intervention survey, teachers responded that they liked using the bug-in-ear technology. 
Summary of bug-in-ear coaching. Research has shown that bug-in-ear coaching is effective in improving fidelity when implementing academic instruction. At this time, no research was found on the use of bug-in-ear technology for behavior instruction. Recommendations for future research include (a) additional research on bug-in-ear technology that uses more precise experimental designs (Rock et al., 2009), (b) collection of student outcome data in addition to collection of teacher data (Rock et al., 2009; Scheeler, Congdon, \& Standsbery, 2010), and (c) which component (e.g., bug-in-ear or coaching) was more effective in changing teacher behavior (Scheeler, Congdon, \& Standsbery, 2010).

Summary

Overall, coaching in a variety of styles (e.g., supervisory and side-by-side) has been shown to increase fidelity across a range of academic and behavior instruction. Bugin-ear coaching has also been effective for increasing fidelity of academic instruction. An additional recommendation for future research on coaching is the need to evaluate the effectiveness of coaching on strategies other than Positive Behavior Supports, Direct Instruction, Learning Strategies, and Active Student Responding (Kretlow \& Bartholomew, 2010). Some recommendations for successful application of coaching include developing a trusting relationship where both professionals are working towards instructional efficacy, scheduling coaching sessions, and reflection on teachers' own practices (Shidler \& Fedor, 2010). 


\section{CHAPTER 3: METHOD}

\section{Participants and Selection Criteria}

The target population of this study was certified special education teachers working with students with moderate to severe disabilities who demonstrate challenging behavior. Convenience sampling was used to identify four teachers/student pairs who met the inclusion criteria. To be included in the study, participating teachers met the following criteria (a) hold a current North Carolina teaching license in special education (either adapted or general curriculum), (b) teach at least one student receiving special education services, (c) agree to attend a one day workshop on FBA, (d) have not previously been involved in a coaching/mentoring program, (e) are not a Board Certified Behavior Analyst or a Board Certified Associate Behavior Analyst, and (f) sign consent to participate in the study. The teachers' exclusion criteria includes inability to meet the inclusion criteria.

The students' inclusion criteria included (a) receiving special education services, and (b) displaying challenging behavior that interferes with participation in school activities. The exclusion criteria included (a) inability to meet the inclusion criteria, (b) inability to obtain parental consent, or (c) inability to obtain student assent.

Mrs. Yacht. Mrs. Yacht (pseudonyms used throughout) taught in an exceptional children preschool classroom. The classroom consisted of both students with disabilities and their typically developing peer models. Mrs. Yacht is a master's level teacher and is licensed as a birth through kindergarten teacher and has 14 years of teaching experience. 
She had been in her current classroom for 5 years. Mrs. Yacht referred Susan as her target student to be involved in the study. The study intervention took place during morning circle time, which was identified by Mrs. Yacht as a time when Susan frequently displayed the problem behavior.

Susan. Susan was a 4-year-old Caucasian girl who attended Mrs. Yacht's pre-K classroom. She was diagnosed with trisomy 9 mosaicism, a disorder associated with failure to grow, severe intellectual disability, facial abnormalities, and joint abnormalities (Accardo \& Whitman, 2011). Susan was nonverbal and communicated through crying, facial expressions, and occasionally pointing to items. She required adapted chairs to maintain her posture during seated activities and was able to walk while holding an adults hand; however, she was unable to walk independently at the time of this study. Susan also wore a patch on one eye due to estropia (turning in of one eye) and glasses to correct her vision. She was referred to participate in this study due to the problem behavior of taking off her glasses, which then lead to her attempting to remove her eye patch.

Mrs. Williams. Mrs. Williams taught in one of the school's resource rooms. She taught small groups of children throughout in math and language arts. She also cotaught part of the day in a $3^{\text {rd }}$ grade inclusion class. Mrs. Williams was a master's level teacher and was licensed as a special education teacher $(\mathrm{K}-12)$ in the area of general curriculum. She had four years of teaching experience; two of those years had been in her current classroom. Mrs. Williams referred Karla as her target student to be involved in this study. The study intervention took place during English Language Arts instruction in the resource classroom, which was identified by Mrs. Williams as a time when Karla frequently displayed the problem behavior. 
Karla. Karla was an 8-year-old Caucasian girl who attended a typical $3^{\text {rd }}$ grade class and received resource support with Mrs. Williams in the areas of math and language arts. Karla had a diagnosis of Down syndrome. Karla was able to vocally communicate in full sentences and read at approximately a second grade level. She was referred to participate in this study due to the problem behavior of noncompliance, refusal to complete assigned classroom tasks by saying no, pushing away work tasks, putting her head on the desk, leaving the designated work area, and physically refusing to move.

Mr. Carlisle. Mr. Carlisle taught in a separate classroom called a "Communication, Behavior, and Social Skills Classroom" that was targeted towards the needs of students with moderate to severe autism. Mr. Carlisle was a licensed special education teacher $(\mathrm{K}-12)$ in the area of general curriculum. He had three years of teaching experience with one of those years in his current classroom. Mr. Carlisle referred Michael as his target student to be involved in this study. The study intervention took place during one-one-one discrete trial instruction with Michael, which was identified by Mr. Carlisle as a time when Michael frequently displayed the problem behavior.

Michael. Michael was a 5-year-old boy with a diagnosis of autism who was a student in Mr. Carlisle's classroom throughout the entire school day. Michael was nonverbal and communicated by grabbing for items and displaying challenging behaviors. Michael was not toilet trained, unable to receptively identify common objects; however, he did respond to simple, one-step directions (e.g., "come here" and "sit down"). Michael's challenging behaviors included screaming, hitting self and others, swiping materials, biting, and dropping to the floor. 
Mrs. Green. Mrs. Green also taught in a "Communication, Behavior, and Social Skills Classroom." Her classroom was designed to meet the needs of students with autism; however, the students in this classroom had higher academic skills and most students were included in general education classes for at least some of their school day. Mrs. Green was a licensed special education teacher $(\mathrm{K}-12)$ in the area of adapted curriculum. She had 15 years of teaching experience. Four of those years had been at this elementary school and this is her first year in her current classroom. Mrs. Green referred Jack as her target student to be involved in this study. The study intervention took place during small group English Language Arts instruction, which was identified by Mrs. Green as a time when Jack frequently displays the problem behavior.

Jack. Jack was a 10-year-old boy with a diagnosis of autism who attended Mrs. Green's classroom for the majority of his school day. He attended specials (i.e., gym, art, computers, music) and recess with a general education classroom. Jack was vocal and was able to communicate his wants and needs using short sentences, phrases, and one word requests. Jack was able to read at approximately a first grade level, could identify numbers, complete correspondence counting, and could complete simple addition problems. Some of his academic goals focused on increasing his reading comprehension skills and completing simple word problems during math class. Jack was referred by his teacher to participate in this study due to his off-task behavior during work time. These behaviors included non-contextual echolalia, refusal to respond, and screaming. Setting

The study was conducted at New Town Elementary School, a public elementary school located in the Union County School District of North Carolina. The school was a 
semi-rural elementary school and served typical students and students with disabilities through a range of services and settings. These included inclusion provided through coteaching or paraprofessional support, pullout resource room services, or separate classrooms for some students. The study occurred in multiple locations throughout the school including the conference room (for the initial FBA training) and the teacher/student's classroom for the intervention. The intervention took place during a teacher identified activity that was part of each student's day, so no additional classroom modifications were required.

Materials

Materials used in this study were both created and aggregated from a number of published resources. During the inservice, teachers completed the Functional Assessment Interview Form (FAI) developed by O’Neill and colleagues (1997; see Appendix A). The experimenter and teachers also completed the function matrix as described by Umbreit and colleagues (2007; see Appendix B). Subsequently, the experimenter and teachers used the Building a Support Plan form also developed by O'Neill and colleagues (1997) which includes a competing pathways summary (see Appendix C). The inservice included PowerPoint presentations training teachers on the basics of $\mathrm{ABA}$ and development and implementation of FBAs and function-based interventions (see Appendix D for an example of PowerPoint presentation). The primary dependent variable was measured through use of a function-based intervention procedure fidelity checklist and reported as percent accuracy (see Appendix E). While the steps of the checklist remained the same, individualized data sheets were created for each student/teacher pair 
that corresponded directly to the function-based intervention for that student (see Appendix F).

Student behavior was included as a secondary dependent variable and data were collected through frequency or interval recording (see Appendix G for an example of a student recording sheet). Finally, fidelity was conducted on the experimenter's implementation of the coaching session, which was tracked through use of a coaching fidelity checklist (see Appendix H). Experimenter

Implementation of this study was conducted by a full time, $3^{\text {rd }}$ year doctoral student in the special education program at the University of North Carolina at Charlotte. The experimenter served as the primary trainer, interventionist, and data collector. The experimenter had over 10 years experience teaching students with severe disabilities and behavioral challenges. The experimenter received a Master of Education in Special Education and held a North Carolina Teaching License (Adapted Curriculum).

Additionally, the experimenter had been a Board Certified Behavior Analyst for approximately 7 years. She had thorough training and experience in implementing functional assessments and developing function-based interventions for students with severe disabilities and challenging behaviors. She had experience training both teachers and noncertified staff on accurate implementation of function-based interventions. As a doctoral student, she had independently taught a course on classroom management, based on the principles of $\mathrm{ABA}$, for graduate special education students.

Treatment fidelity and interobserver reliability was taken by one first year doctoral student in the special education program at the university and also by the school 
psychologist, who has completed the coursework to become a Board Certified Behavior Analyst, but has not taken the exam yet.

Data Collection

Dependent variables. The first dependent variable was percent accuracy of teacher implementation of the function-based intervention during probe sessions as measured by the procedural fidelity checklist (see Appendix E). Fidelity checklists were standardized to the use of function-based interventions; however, each checklist was tailored to the individual student's behavioral function and needs (see Appendix F). Each checklist included items such as engaging students in appropriate work task as previously specified, providing appropriate instruction (e.g., least to most prompts) on targeted replacement behavior, reinforcement of correct responses (either appropriate task completion or demonstration of targeted replacement behavior), reacting as specified to targeted challenging behavior, and collecting data accurately on student behavior. Data were graphed as percentage of steps completed correctly.

The second dependent variable was a measure of the students' problem behavior during probe sessions (as selected and defined by the teacher and researcher during the afternoon portion of the workshop training). Each measurement system was selected to best gain an accurate measure of student behavior based on the topography and definitions (see Appendix I). The researcher calculated the frequency or percentage of intervals of specified challenging behaviors that occurred during the same teacher selected activity for a 10 min observation. The frequency or percent interval of targeted challenging behaviors displayed was graphed on an equal interval graph. Additionally, data were collected on the same behavior in a different setting. This behavior had an FBA 
conducted and function-based intervention developed in the same manner as the primary challenging behavior, but was used to measure teacher generalization.

The third dependent variable was a measure of the students' replacement behavior during probe sessions (as selected and defined by the teacher and researcher during the afternoon portion of the workshop training). The researcher calculated the frequency or percentage of intervals of specified replacement behaviors that occurred during the same teacher selected activity for a 10 min observation. The frequency or percent interval of targeted replacement behaviors displayed was graphed on an equal interval graph. Additionally, data were collected on the same appropriate replacement behavior in a different setting to be used to measure teacher generalization. This replacement behavior was indentified in the same manner as the primary replacement behavior, but was used to measure teacher generalization.

Susan. Susan's problem behavior was taking her glasses off. Taking glasses off was defined as anytime Susan attempted to or actually removed the glasses from their correct position. This was recorded using a frequency count. Susan's chosen replacement behavior was appropriate use of materials, which was defined as interacting with adapted circle time materials. This was tracked using momentary time sampling with 1 min intervals.

Karla. Karla's problem behavior was noncompliance. Noncompliance was defined as anytime Karla left the designated work area without permission, physically pushing away work materials, verbally refusing to complete a teacher-assigned task or request, not starting a task or assignment within 30s of the teacher prompt, or physically refusing to move. This was recorded using partial interval recording with 1 min intervals. 
Karla's first replacement behavior was compliance (e.g., completing assigned tasks and activities without displaying noncompliant behavior). This was recorded using whole interval recording with 1 min intervals. Karla's second replacement behavior was functional communication (i.e., raising her hand to request a break or help). This was tracked using a frequency count.

Michael. Michael's problem behavior was tantrums. A tantrum was defined as anytime Michael attempted to or actually bit others, hits himself/others/objects, threw or swiped objects, banged his head against objects, or dropped to the floor. This was recorded using partial interval recording with 30s intervals. His first replacement behavior was on-task behavior (e.g., absence of tantrums). This was recorded using whole interval recording with 30s intervals. His second replacement behavior was functional communication (i.e., exchanging a photograph of a preferred break item to request a break from the activity). This was recorded using a frequency count.

Jack. Jack's problem behavior was off-task behavior during work tasks. Off task was defined as anytime Jack pushed away work, repeats works/phrases that were unrelated to the activity, screamed (using volume above conversational level), or not responding to a teacher directive within 10s. This was recorded using partial interval recording with 1 min intervals. Jack's first replacement behavior was on-task behavior (i.e., absence of off-task behavior). This was recorded using whole interval recording with 1 min intervals. His second replacement behavior was independently initiated functional communication (i.e., appropriate break requests). This was recorded using a frequency count. 
Interobserver reliability. Interobserver reliability was conducted on $32.2 \%$ of teacher sessions and $31.3 \%$ of student sessions distributed evenly across phases (baseline, post-inservice, coaching, generalization, and maintenance), with a minimum of $90 \%$ agreement being acceptable. If interobserver reliability fell below 90\%, the two people conducting reliability would discuss the disagreements and reach a consensus to resolve the disagreements. The goal of reaching consensus was to improve future reliability scores. Interobserver reliability was taken by one first year doctoral student in the special education program at the university and also by the school psychologist, who has completed the coursework to become a Board Certified Behavior Analyst. Reliability for teacher fidelity was established point by point and calculated by dividing the total agreements by the total opportunities and multiplying by 100 . Reliability for the student challenging behavior was either the gross method for frequency measures or interval-byinterval for interval measures of behavior. Gross method was calculated by dividing the smaller frequency divided by the larger frequency and multiplying by 100 . Interval-byinterval method was calculated by dividing the total number of agreements by the total intervals.

Social validity data. Social validity was collected by asking the classroom teacher and school psychologist to complete social validity questionnaires (see Appendix J). The questionnaire focused on the four main areas: (a) if coaching was an effective method to improve teachers' implementation of function-based intervention; (b) if coaching was a feasible method to improve teachers' implementation of function-based intervention; (c) if coaching was a socially acceptable method for improving teachers' implementation of 
function-based intervention; and (d) if teachers will use function-based interventions with students in the future.

Experimental Design

The study used a delayed multiple baseline across participants design for teachers and a multiple baseline design across participants design (Cooper et al., 2007) for students. The decision to use a delayed multiple rather than a standard multiple baseline was made as a result of practical difficulties encountered after the beginning of student data collection (e.g., one of the teacher participant's wife gave birth, resulting in a paternity leave that made him unavailable to begin the teacher baseline phase immediately). Delayed multiple baseline designs use the same experimental logic as standard multiple baseline designs with the exception that participants enter the baseline phase in a staggered fashion (Cooper et al., 2007). This may present a limitation if baseline periods do not overlap with those of prior phases and therefore cannot be used to verify predictions of the prior phases; however, this can be overcome by ensuring that each baseline period overlaps the previous tier's baseline period by several sessions (Cooper et al.; Heward, 1978).

It is also important to note that although the terms are sometimes used synonymously, the delayed multiple baseline used in this study is not the same as a nonconcurrent multiple baseline as described by Watson and Workman (1981) and Gast (2010). In a non-concurrent multiple baseline design, the baseline lengths are randomly selected and tiers are not implemented concurrently; however, in this study the baselines were started in a staggered fashion, but the tiers of the study were implemented concurrently as described by Cooper and colleagues (2007). Additionally, the baseline 
phase of the second teacher overlaps the baseline phase of the first teacher by two data points, allowing for verification of the prediction made in the first tier. The same is true of the baseline phase of the third tier, allowing verification of the prediction made in the second tier.

In this study, teachers initially attended a one-day inservice training. Afterwards there was a teacher baseline phase (teacher implementing the function-based intervention), a coaching phase, followed by a maintenance phase. The first teacher began the baseline phase and subsequent teachers were introduced in a staggered fashion once a stable baseline was established. Once a minimum of five data points and a stable or decreasing trend was established, the teacher began intervention (coaching). A second teacher was introduced once a change in level or trend was identified for the initial teacher. Each subsequent teacher was added in the same manner. Teachers moved to the maintenance phase once a minimum of five data points in intervention were collected and each had scored minimally $80 \%$ accuracy in the final three consecutive probe sessions.

For the student behavior, this was a single subject experimental study using a multiple baseline across participants' design (Cooper et al., 2007). For the students, there was an initial baseline phase (occurring after the teacher inservice training), followed by the teacher implemented function-based intervention (teacher baseline phase), followed by the coaching phase, and finally a maintenance phase. Additionally, the researcher conducted a FA using an alternative treatments design on each of the students' problem behaviors after completion of the workshop but prior to completion of the student baseline (Cooper et al., 2007). The purpose of this FA was to ensure that the hypothesis of the functions of their behaviors, and resulting replacement behaviors and function- 
based interventions, were correct (data were graphed separately). Students' behavioral data were collected to measure changes; however, phase changes were not dependent on student responding, instead phase changes occurred based on teachers' performance. General Procedures

Initial observation. Prior to beginning formal data collection, the researcher observed each teacher and student pair to familiarize herself with the students and ensure the behavior met the criteria for this study. During this period, which lasted approximately one week, the researcher collected direct observation data on the primary challenging behavior in the form of the $\mathrm{ABC}$ observation forms. These data were used during the second portion of the teacher inservice training to complete a function matrix and develop a function-based intervention.

Inservice. Participating teachers attended a one-day, six hour inservice prior to the baseline phase. The researcher provided basic training on development and implementation of FBAs. The inservice began in a lecture format, providing the necessary information on how to conduct FBAs and relevant information on ABA. The lectures were provided via PowerPoint presentations that described the process of completing an FBA and developing/implementing function-based interventions as described by Umbreit et al. (2007). Topics included (a) identifying and defining challenging behaviors and replacement behaviors (b) FBA: interviews, (c) FBA: direct observation, (d) using the function matrix, (e) teaching replacement behavior, (f) improving the environment, (g) adjusting contingencies, and (h) identifying measurement systems. 
The second portion of the inservice moved to a workshop format where the researcher worked with the participants to begin completion of an FBA and develop function-based interventions for their paired students. Function-based interventions were developed for the primary challenging behavior. This included finalization of student behavior definitions, completion of an FAI form (O’Neill et al., 1997), function matrix (Umbreit et al, 2007), and Building a Support Plan form including competing pathways summary (O’Neill et al., 1997). The FAI took approximately 45-60 min to complete. The experimenter guided the teachers through the form by reading each question aloud, answering questions, and having them individually record their answers. After completion of the FAI, the experimenter provided each teacher the completed ABC forms reflecting the data collected on their paired student during the initial observation phase. The teachers had an opportunity to review the forms for accuracy, ask questions, and make any needed changes. The experimenter and the teachers then used the FAI and $\mathrm{ABC}$ forms to complete the function matrix. All of this information was then used to complete the Building a Support Plan form (including competing pathways summary) that identified the appropriate function-based intervention and replacement behavior(s). Teachers left the inservice with the technical information needed to implement the function-based interventions with their targeted student.

Student baseline. Baseline was conducted by observing the teacher work with the identified student during completion of a previously identified task or classroom activity. Duration of these sessions was held constant at 10 min for all sessions. This activity was selected by the teacher and researcher and was held constant throughout the study. The task/activity was one where the student had frequently exhibited the challenging behavior 
in the past. For Susan, sessions occurred during Circle Time, for Karla they occurred during English Language Arts small group resource room instruction, for Michael they occurring during one-on-one discrete trial implementation, and for Jack they occurred during small group English Language Arts instruction. Data were also taken on the frequency or percent intervals of the student challenging and replacement behaviors during this session.

During the student baseline data collection period, the researcher did not provide prompting, reinforcement, or corrective feedback for teachers. Teachers did not start implementation of the function-based intervention during this phase; instead continuing with their typical instruction as had been previously conducted. Once a minimum of five data points and a stable or decreasing trend was established across all included students, the teachers were brought into the teacher baseline phase (with teachers implementing the function-based interventions without researchers support or feedback).

Functional analysis. Prior to conducting the teacher baseline phase, the experimenter tested the effectiveness of the intervention developed by conducting a brief alternating treatments design (Cooper et al., 2007). The researcher used free play conditions alternating with conditions designed to test the hypothesized function of each students' problem behavior (i.e., attention for Susan, and escape for all other participants). Completion of the alternating treatments design served to confirm that the hypothesized function was accurate and that the designed intervention would be more likely to be effective. The alternating treatments design was conducted for brief alternating intervals so that each student was exposed to each condition until a divergent 
data path emerged. Once the function of the problem behavior was confirmed for each student by the researcher, the teacher baseline phase was introduced for all teachers.

Teacher baseline. After completion of the student baseline and completion of the alternating treatments design confirm the function of the problem behaviors, data were collected on accuracy of implementation of the function-based intervention by observing the teacher work with the identified student during completion of a previously identified task/activity. The teacher was scored on the accuracy of each step of the fidelity checklist. Data were also taken on the frequency or percent intervals of the student challenging behavior and replacement behavior during these sessions. The researcher did not provide prompting, reinforcement, or corrective feedback for teachers during the teacher baseline phase. When a minimal of five data points were collected and a stable or decreasing trend is established, each teacher began intervention (coaching) in a staggered fashion.

Coaching. The intervention consisted of the researcher implementing side-by-side coaching with the teacher as they worked with the target student during the identified task. The coaching intervention consisted of three mains parts: (a) a preconference meeting, (b) the coaching session, and (c) a post-coaching feedback meeting. During the preconference meeting, which lasted approximately 5-10 min, the experimenter provided specific instructions as to how to implement the function-based intervention. During the coaching process, the researcher provided an initial model on how to implement the function-based intervention and then provided immediate feedback on the teachers' performance of implementation of the function-based intervention with the student. The coaching process took approximately the same amount of time it typically takes the 
teacher to complete the session (i.e., $10 \mathrm{~min}$ ). No teacher implementation data were collected during the coaching. During the post-coaching feedback meeting, which typically lasted less than $5 \mathrm{~min}$, the experimenter reviewed the teacher's progress, highlighting steps that were correctly implemented and reviewing steps where errors were made.

Once the coaching was provided, the researcher immediately observed the teacher implementing the same task with the student and recorded the percentage of accuracy on the fidelity checklist. The second teacher was introduced once a change in level and/or trend was identified for the initial teacher. The third and fourth teachers were added in the same manner. Data were taken on student performance (frequency or percent intervals of challenging and replacement behavior) to observe if a reduction in challenging behavior was noted; however, phase changes were not dependent on student behavior.

Teachers were provided with coaching sessions until they scored minimally $90 \%$ accuracy in two consecutive sessions. After teachers scored at this high level of accuracy, the coaching session was no longer provided, instead the researcher simply observed the teacher implementing the function-based intervention. If the teachers' accuracy had fallen below 90\%, coaching would have been reintroduced (however, this did not occur during this study).

Generalization and maintenance. Generalization data were taken by observing each teacher work with the same student during a different task where the student was likely to exhibit the same behavior. This behavior went through the FBA process and had a function-based intervention developed along with replacement behavior identified during the inservice. For the students in this study, their problem behaviors demonstrated 
the same functions across the settings, and replacement behaviors were held constant. Data were collected on the teachers' accuracy of implementation of the function-based intervention based on the fidelity checklist. For example, if the intervention occurred during the students reading instruction, generalization took place when the teacher and student were engaged in math instruction. Generalization data were collected once during baseline and once during maintenance phases. For participants completing the coaching phase ahead of other participants, maintenance data were collected once per week until all participants had completed the coaching phase. After all participants had completed the coaching phase, maintenance were collected two and a half weeks later (after the students and teacher returned from the winter break and students had a chance to get back into the school routine).

Procedural reliability. Procedural reliability served as the primary method of demonstrating accuracy of implementation of the intervention. It was conducted by having a second doctoral student from UNC Charlotte or the school psychologist observe the sessions and complete the procedural reliability checklist during the coaching session, ensuring that the researcher delivered coaching with fidelity. Procedural reliability was conducted in $50 \%$ of all sessions, with a minimum of $90 \%$ agreement being acceptable. Procedural reliability data collection was evenly distributed across sessions and phases of the study. 


\section{CHAPTER 4: RESULTS}

The results for interobserver agreement and fidelity data are reported below. Afterwards, the results for each research question are presented. Interobserver Agreement

Teachers' implementation of function-based interventions. The second observer collected interobserver agreement on $32.2 \%$ of sessions across all phases of the study of the teachers' implementation of the function-based interventions. Interobserver agreement averaged $100 \%$ across all sessions for all teachers. Interobserver agreement was collected in $40.0 \%$ of teacher baseline sessions (e.g., teacher implementation of function-based interventions), $46.7 \%$ of sessions during the coaching phase, $33.3 \%$ of maintenance sessions, and $25 \%$ of generalization sessions.

Student behavior. Interobserver agreement was collected by the second observer to ensure that all student behavior was being recorded consistently. Interobserver agreement is reported below.

Functional analysis. The second observer collected observer collected interobserver agreement on $25 \%$ of all functional analysis sessions. Interobserver agreement averaged $100 \%$ across all sessions for all students.

Problem behavior. For the student problem behaviors, the second observer collected interobserver agreement on $31.3 \%$ of the total sessions of observations of student behavior. Interobserver agreement averaged $99.7 \%$, with a range of $90 \%$ to $100 \%$. Interobserver agreement was collected in $28.2 \%$ of student baseline sessions and 
averaged $99.1 \%$ with a range of $90 \%$ to $100 \%$. Interobserver agreement was collected in $40.0 \%$ of sessions during teacher implementation of the function-based intervention (e.g., teacher baseline) and averaged $100 \%$ across all sessions for all students. Interobserver agreement was collected in $53.3 \%$ of sessions during the coaching phase and averaged $100 \%$ across all sessions for all students. Interobserver agreement was collected in $33.3 \%$ of maintenance sessions and averaged $100 \%$.

Replacement behaviors. For the student replacement behaviors, the second observer collected interobserver agreement on $31.1 \%$ of the total sessions of observations of student behavior. Interobserver agreement averaged $96.0 \%$, with a range of $90 \%$ to $100 \%$. Interobserver agreement was collected in $28.2 \%$ of student baseline sessions and averaged $99.4 \%$ with a range of $90 \%$ to $100 \%$. Interobserver agreement was collected in $40.0 \%$ of sessions during teacher implementation of the function-based intervention (e.g., teacher baseline) and averaged $100 \%$ across all sessions for all students. Interobserver agreement was collected in $53.3 \%$ of sessions during the coaching phase and averaged $100 \%$ across all sessions for all students. Interobserver agreement was collected in $33.3 \%$ of maintenance sessions and averaged $100 \%$.

Procedural Fidelity

In order to ensure that coaching sessions were implemented as designed, the second observer collected data on the fidelity of the investigator's implementation of the coaching session with the teacher using a coaching fidelity checklist (see Appendix $\mathrm{H}$ ). Fidelity data were collected across $50 \%$ of coaching sessions and averaged $100 \%$ accuracy. 


\section{Dependent Variables}

Research Question 1: What are the effects of coaching on special education teachers' accuracy of implementation of function-based interventions?

Results showing the effects of coaching on the three participant teachers' implementation of function-based interventions are shown in Figure 4.1. The graph shows participants' results across teacher baseline (teacher implemented function-based interventions), during the coaching phase, and throughout maintenance. Each of the three teachers showed low baselines, which required the implementation of the coaching procedure to increase to higher levels. Results indicated a functional relationship between coaching and an increase in teachers' accurate implementation of function-based interventions. The fourth participant's results (Mrs. Green) are shown in Figure 4.2. The fourth teacher, Mrs. Green, had a high, stable baseline and therefore did not require coaching.

Mrs. Yacht. Mrs. Yacht's baseline showed a stable, decreasing trend. Her scores ranged from $47.8 \%$ accuracy to $7.7 \%$ accuracy and steadily declined throughout baseline. Her baseline mean was $29.4 \%$ accuracy. Once coaching was introduced, the data showed an immediate change in level and trend. The data for the coaching phase are stable at a high level, with little variability. Her scores ranged from $95.8 \%$ accuracy to $100 \%$ accuracy, with a mean of $99.2 \%$ accuracy. It is also important to note that Mrs. Yacht required only two coaching sessions before meeting the criteria to stop implementing coaching sessions. Probe sessions continued to be conducted until five sessions of data 
were collected to meet the minimum data required per phase. During maintenance, her data remained stable at a high level of $100 \%$ accuracy.

Mrs. Williams. Mrs. Williams' baseline showed a low, slightly variable data path with no trend. Her scores ranged from $17.2 \%$ accuracy to $4.0 \%$ accuracy. Her baseline mean was $11.0 \%$ accuracy. Once coaching was introduced, there was an immediate change to a high level with no variability or trend. Mrs. Williams consistently scored $100 \%$ accuracy during the coaching phase and also required only two coaching sessions. During maintenance, Mrs. Williams' data path continued to remain stable with a high level of $100 \%$ accuracy.

Mr. Carlisle. Mr. Carlisle's baseline data were low and slightly variable with no trend. His scores ranged from $10.5 \%$ accuracy to $21.3 \%$ accuracy. His mean score during baseline was $15.8 \%$ accuracy. Once coaching was introduced, there was an immediate change to a high level, stable data path with no trend. His scores ranged from $98.4 \%$ accuracy to $100 \%$ accuracy with a mean of $99.7 \%$ accuracy. Mr. Carlisle also required only two coaching sessions. During maintenance, Mr. Carlisle also continued to perform at $100 \%$ accuracy.

Mrs. Green. Mrs. Green's data were at a stable, high level with no trend during baseline. Her scores ranged from $94.3 \%$ accuracy to $100 \%$ accuracy with a mean of 98.2\% accuracy. Due to Mrs. Green's high performance during baseline, coaching was not introduced. During maintenance Mrs. Green also continued to maintain her performance at $100 \%$ accuracy. 


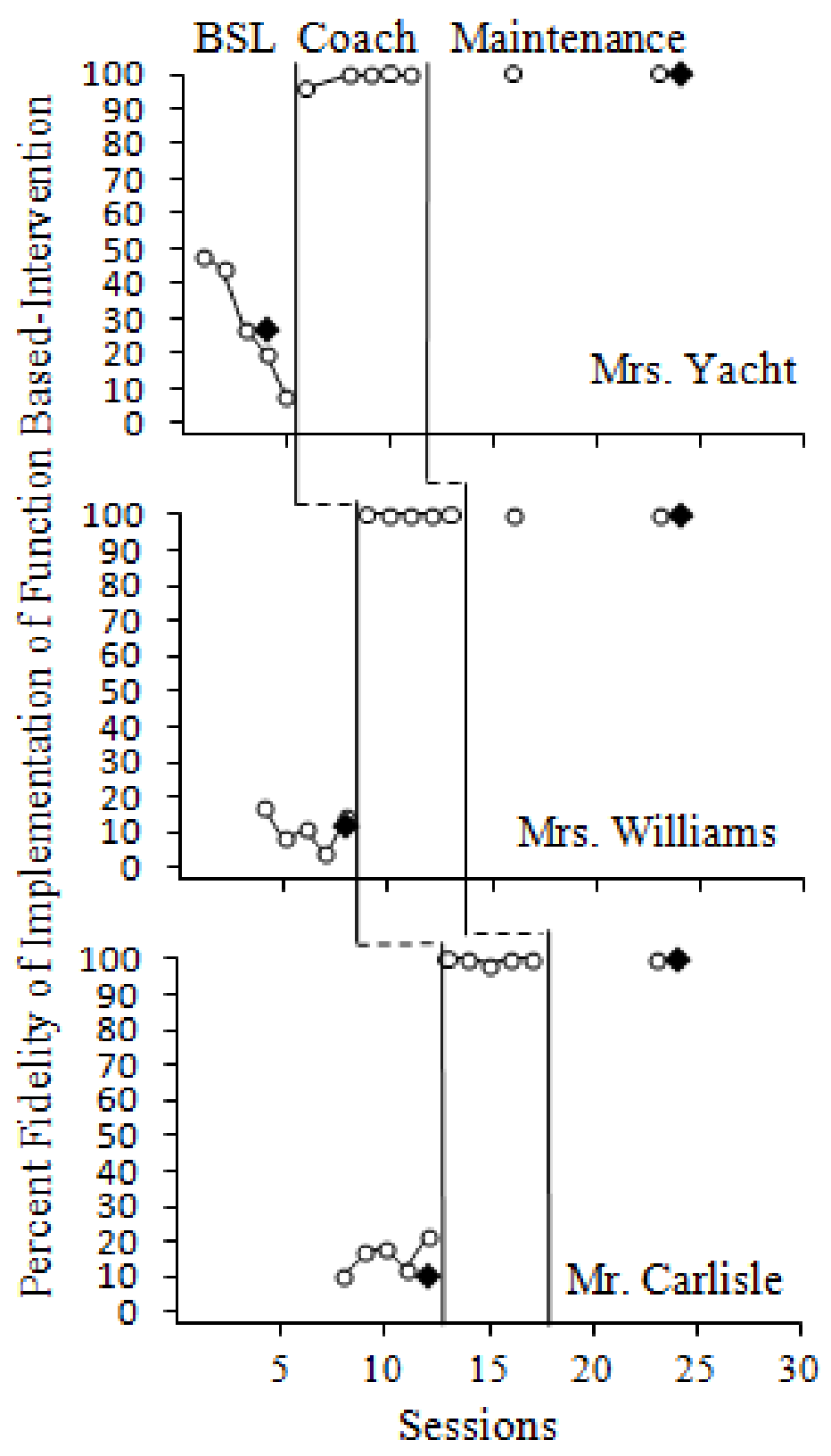

Figure 4.1 Teachers Percent Accuracy Implementing Function-Based Interventions Note: $\mathrm{BSL}=$ baseline, Coach $=$ coaching phase. Open circles represent the accuracy of the teachers' implementation of the function-based interventions. Closed diamonds represent their accuracy on generalization measures. 


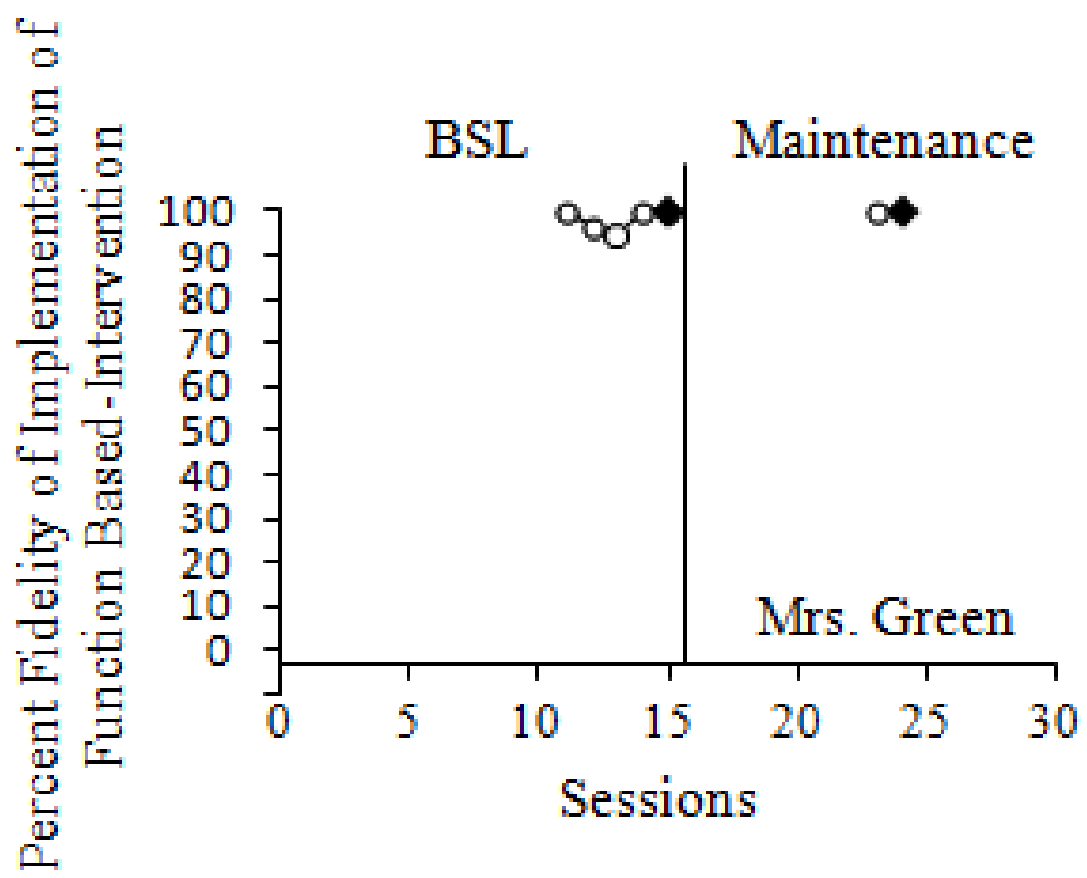

Figure 4.2 Fourth Participant's Percent Accuracy Implementing Function-Based Interventions

Note: $\mathrm{BSL}=$ baseline Coach $=$ coaching phase . Open circles represent the accuracy of the teachers' implementation of the function-based interventions. Closed diamonds represent their accuracy on generalization measures. The data path begins at session 11, where the teacher would have entered into the delayed multiple baseline as the fourth participant. 
Research Question 2: What is the effect of coaching on teachers' ability to generalize a function-based intervention (developed using the same process) to a second identified challenging behavior and/or setting with their students?

Results of generalization data points are shown in Figure 4.1 and Figure 4.2 as black diamonds. Results indicated that coaching improved teachers' ability to generalize the function-based intervention to another situation with the same student when the behavior served the same function. Additionally, data were collected on student performance during the teachers' generalization probes. These results are reported in Table 4.1. It is important to note that generalization probes were conducted during the teacher implementation of function-based intervention phase (e.g., teacher baseline) and maintenance phases. Generalization probes were not conducted during student baseline.

Mrs. Yacht. During baseline, Mrs. Yacht's generalization data point was similar to her primary data path. She scored $27.3 \%$ accuracy implementing the function-based intervention with Susan during lunchtime in the school cafeteria. During the maintenance period, Mrs. Yacht was able to generalize the function-based intervention procedure with $100 \%$ accuracy.

Susan. During both the generalization probe during teacher baseline and maintenance, Susan demonstrated zero instances of problem behavior and displayed appropriate use of materials in $90 \%$ of intervals. Her rates of problem behavior are consistent with her rates during the data collection during daily probes. Her percentage of intervals of appropriate use of materials is higher than during daily probes. This may be due to the nature of the activity where generalization data were collected (e.g., lunch). 
Susan may be more naturally reinforced by appropriate use of lunch materials than materials during her daily probe which occurred during a morning circle time activity.

Mrs. Williams. During baseline, Mrs. Williams' generalization data point was also similar to her primary data path. She scored $12.0 \%$ accuracy when implementing the function-based intervention with Karla during a one-on-one library activity. During the maintenance period, Mrs. Williams was able to generalize the function-based intervention procedure with $100 \%$ accuracy.

Karla. During the generalization probe conducted during teacher implementation of function-based intervention, Karla displayed the problem behavior in $10 \%$ of intervals, the primary replacement behavior during $90 \%$ of intervals, and the secondary replacement behavior zero times. During the generalization probe conducted during the maintenance phase, Karla did not display the problem behavior. She displayed the primary replacement behavior in $100 \%$ of intervals and did not exhibit the secondary replacement behavior. These data are consistent with her performance during daily probes.

Mr. Carlisle. During baseline, Mr. Carlisle's generalization data point was similar to his lowest data point in his primary data path. He scored $10.3 \%$ accuracy when implementing the function-based intervention with Michael during morning circle time. During the maintenance period, he was able to generalize the function-based intervention procedure with $100 \%$ accuracy.

Michael. During the generalization probe conducted during teacher implementation of function-based intervention, Michael displayed the problem behavior in $20 \%$ of intervals, the primary replacement behavior during $20 \%$ of intervals, and the 
secondary replacement behavior two times. During the generalization probe conducted during the maintenance phase, Michael displayed the problem behavior in 5\% of intervals, the primary replacement behavior in $95 \%$ of intervals, and the secondary replacement behavior eight times. The data for his problem behavior and primary replacement behavior are consistent with his data during daily probes during the same phases. His secondary replacement behavior occurred less frequently than expected (e.g., it was occurring at higher rates during daily probes in this phase), however rose to expected rates during the maintenance generalization probe. This may represent difficulty generalizing the functional communication response to a second situation, however was overcome during the maintenance generalization probe.

Mrs. Green. Mrs. Green's primary data path demonstrated the highest scores during her baseline. She scored as well when generalizing the function-based intervention to work with Jack during math class. She was able to generalize the function-based intervention with $100 \%$ accuracy. Her performance during maintenance was $100 \%$.

Jack. During the generalization probe conducted during teacher implementation of function-based intervention, Jack displayed the problem behavior in $20 \%$ of intervals, the primary replacement behavior during $80 \%$ of intervals, and did not display the secondary replacement behavior. During the generalization probe conducted during the maintenance phase, Jack displayed the problem behavior in $10 \%$ of intervals, the primary replacement behavior in $90 \%$ of intervals, and did not display the secondary replacement behavior. The data for his problem behavior, primary replacement behavior, and secondary replacement behavior are consistent with his data during daily probes during the same phases. 
Table 4.1 Student Data During Generalization Probes

\begin{tabular}{|c|c|c|c|c|c|c|}
\hline \multirow[b]{2}{*}{ Student } & \multicolumn{3}{|c|}{$\begin{array}{c}\text { Teacher Implementation of } \\
\text { Function-Based Intervention } \\
\text { (Teacher Baseline) }\end{array}$} & \multicolumn{3}{|c|}{ Maintenance Phase } \\
\hline & $\begin{array}{l}\text { Problem } \\
\text { Behavior }\end{array}$ & $\begin{array}{c}\text { Replacement } \\
\text { Behavior A }\end{array}$ & $\begin{array}{c}\text { Replacement } \\
\text { Behavior B }\end{array}$ & $\begin{array}{l}\text { Problem } \\
\text { Behavior }\end{array}$ & $\begin{array}{c}\text { Replacement } \\
\text { Behavior A }\end{array}$ & $\begin{array}{c}\text { Replacement } \\
\text { Behavior B }\end{array}$ \\
\hline Susan & 0 & $90 \%$ & N/A & 0 & $90 \%$ & N/A \\
\hline Karla & $10 \%$ & $90 \%$ & 0 & $0 \%$ & $100 \%$ & 0 \\
\hline Michael & $20 \%$ & $80 \%$ & 2 & $5 \%$ & $95 \%$ & 8 \\
\hline Jack & $20 \%$ & $80 \%$ & 0 & $10 \%$ & $90 \%$ & 0 \\
\hline
\end{tabular}


Research Questions 3: To what extent do students' challenging behaviors decrease and replacement behaviors increase as teachers implement function-based interventions with increasing fidelity?

Functional analysis. Prior to implementing any function-based interventions with students, it was important to verify the hypothesis about the function of each student's problem behavior. In order to do this, functional analyses were implemented comparing a condition designed to test the hypothesized function with a play condition for each student. The results of the functional analysis are shown in Figure 4.3.

Susan. Susan's data path for problem behavior during the attention conditions is higher than the data path for the play condition. There is no overlap between the data paths. The problem behavior occurred from a range of one to two times per session during attention conditions with a mean of 1.25 times per session. The problem behavior occurred zero times during the play conditions. This confirms that Susan's problem behavior was maintained by access to attention.

Karla. Karla's data path for problem behavior during the escape conditions was at a much higher level than the level for the play condition. There was no overlap between the data paths. The problem behavior ranged of $70 \%$ to $100 \%$ of intervals with a mean of $87.5 \%$ of intervals during the escape conditions. The problem behavior occurred zero times during the play conditions. This confirms that Karla's problem behavior was maintained by escape from unpreferred activities.

Michael. Michael's data path for his problem behavior during the escape conditions was at a higher level than for the play conditions with no overlap between the data paths. The problem behavior during the escape conditions ranged from $80 \%$ to $100 \%$ 
of intervals with a mean of $87.5 \%$ of intervals per session. The data for the play conditions ranged from $0 \%$ to $30 \%$ of intervals with a mean of $10.0 \%$ of intervals per session. This confirms that Michael's problem behavior was maintained primarily by escape from unpreferred activities.

Jack. Jack's data path for his problem behavior during the escape condition was at a much higher level than the data path for the problem behavior during the play condition. The problem behavior ranged from $70 \%$ to $100 \%$ of intervals with a mean of $87.5 \%$ of intervals during the escape condition. The problem behavior did not occur during any of the play conditions. This confirms that Jack's problem behavior was maintained by escape from unpreferred activities. 

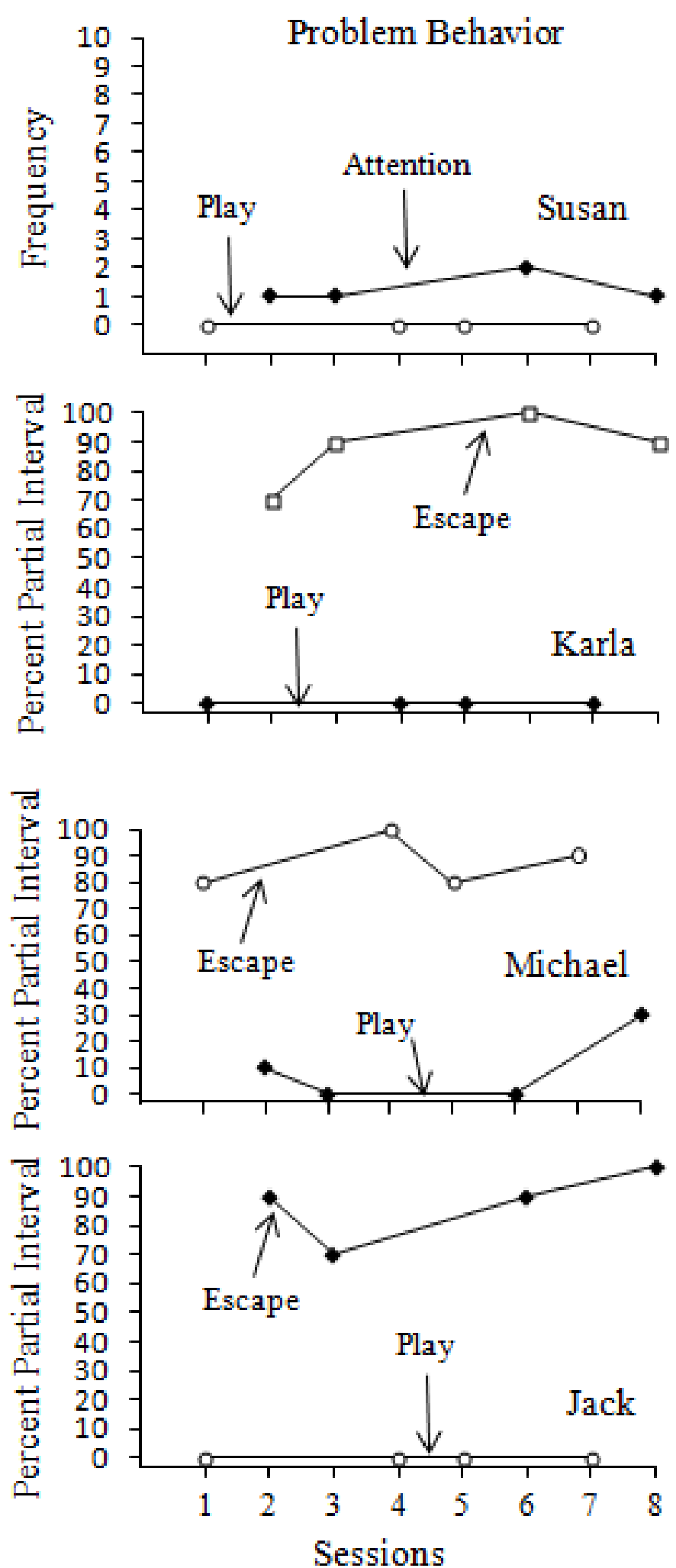

Figure 4.3 Functional Analysis Results 
Intervention data. Results on the effects of the function-based interventions and the function-based interventions plus coaching on student behavior are shown in Figure 4.4. The graphs on the left show the results of the implementation of function-based interventions and implementation of function-based interventions plus coaching on the students' challenging behaviors. The graphs on the right show the results of the implementation of function-based interventions and implementation of function-based interventions plus coaching on the students' replacement behaviors. The graphs show student baseline, teacher implementing function-based interventions (teacher baseline), function-based interventions plus coaching, and maintenance phases.

Results show improvement for all students' challenging behaviors either upon implementation of the function-based intervention (teacher baseline) or upon functionbased intervention plus coaching. Additionally, increases in students' primary replacement behaviors are seen either upon implementation of the function-based intervention (teacher baseline) or upon function-based intervention plus coaching. There is a functional relationship demonstrated between implementation of the function-based intervention plus coaching and an increase students' primary replacement behaviors.

Susan. During baseline, Susan's data for her problem behavior were highly variable at midlevel with no clear trend. Her problem behavior ranged from one per session to eight per session with a mean of 3.0 behaviors per session. Her replacement behavior was at zero, with no variability or trend. Her percentage of appropriate use of materials in baseline was $0.0 \%$.

Once the teacher implemented the function-based intervention, Susan's problem behavior dropped to zero rates, with no trend or variability. No problem behaviors were 
observed during this phase. Her replacement behavior demonstrated in immediate change in level, with some variability and no trend. Susan's appropriate use of materials ranged from $30 \%$ to $50 \%$ of intervals per session during this phase.

Once the coaching phase began, Susan's problem behavior remained at zero and showed no change. Her replacement behavior demonstrated an immediate change in level and remained slightly variable with no trend. Susan's replacement behavior ranged from $60 \%$ to $80 \%$ of intervals with a mean of $66.0 \%$.

During the maintenance phase, Susan's problem behavior remained at zero. Her replacement behavior had a slightly lower level than in the coaching phase; however, it remained at a slightly higher level than with the function-based intervention alone. Susan's replacement behavior ranged from $40-50 \%$ of intervals with a mean of $45 \%$.

Karla. During baseline, Karla's problem behavior was highly variable with no clear trend and a fairly high level. Her problem behavior ranged from $0 \%$ to $90 \%$ of intervals with a mean of $52.5 \%$ of intervals. Her primary replacement behavior (compliance) was also highly variable with no clear trend and was at a midlevel. Compliance ranged from $10 \%$ to $100 \%$ of intervals with a mean of $47.5 \%$ of intervals. Her secondary replacement behavior (functional communication) was at zero and did not occur at any point during baseline.

During the teacher implemented function-based intervention phase (teacher baseline), Karla's behavior showed a lower level, more stability, and decreased before stabilizing. Her problem behavior ranged from $0 \%$ of intervals to $30 \%$ of intervals with a mean of $10.0 \%$. Her primary replacement behavior demonstrated a higher level, with increased stability and increased before stabilizing. Compliance ranged from $70 \%$ to 
$100 \%$ of intervals with a mean of $90 \%$ of intervals. Her secondary replacement behavior occurred one time on the first session of the teacher implemented function-based intervention however did not occur during future sessions (range of 1 to 0 with a mean of 0.2 occurrences).

Once teacher coaching began, Karla's problem behavior showed a lower level with no trend or variability. She exhibited zero noncompliant behaviors during this phase. Karla's primary replacement behavior showed an increase in level to $100 \%$ of intervals with no trend or variability. Her secondary replacement behavior (functional communication) did not occur during this phase. It is worth noting that Karla expressed being highly motivated to stay engaged in the activities to earn her reinforcer as quickly as possible, and therefore stopped using her functional communication phrases.

In maintenance, Karla's problem behavior remained at zero. Her primary replacement behavior remained at $100 \%$ with no variability or trend. Karla's secondary replacement behavior (functional communication) did not occur during maintenance phase.

Michael. During baseline Michael's problem behavior was initially stable at a midlevel with no trend. Then, Michael's problem behavior showed a change in level to a lower level, but did stabilize at the new lower level. It is unclear what caused this change in his behavior; however, because his behavior did stabilize the function-based intervention phase (teacher baseline) was introduced. Michael's problem behavior ranged from $15 \%$ to $60 \%$ of intervals during baseline with a mean of $39.2 \%$. His primary replacement behavior (on-task) showed a reverse pattern, with stable behavior initially at a midlevel, then a change to a higher level where it stabilized. On task behavior ranged 
from $40 \%$ to $85 \%$ of intervals with a mean of $60.8 \%$ of intervals. His secondary replacement behavior (functional communication) occurred zero times during baseline.

Once the teacher began the function-based intervention, Michael's problem behavior demonstrated a slightly lower level with low variability. The problem behavior ranged from $10 \%$ of intervals to $25 \%$ of intervals and had a mean of $19 \%$. His primary replacement behavior demonstrated a slight increase in level with low variability and no trend. It ranged from $75 \%$ of to $90 \%$ of intervals with a mean of $81.0 \%$ of intervals. His secondary replacement behavior (functional communication) showed an increasing trend with low variability. Functional communication ranged from 0 to 13 occurrences per session with a mean of 6.4 .

Once the coaching phase began, Michael's problem behavior decreased to a lower level and was fairly stable with no trend. The problem behavior ranged from $0 \%$ to $10 \%$ of intervals with a mean of $4.0 \%$. His primary replacement behavior showed an immediate change to a higher level, was relatively stable, and no trend. It ranged from $90 \%$ to $100 \%$ of intervals with a mean of $96.0 \%$. His secondary replacement behavior (functional communication) was stable and variable. Functional communication ranged from 5 to 10 occurrences per session with a mean of 7.4 occurrences per session.

During maintenance, Michael did not display any problem behavior, which is reflected in his data path. His primary replacement behavior occurred in $100 \%$ of intervals. Michael's secondary replacement behavior remained consistent with previous levels with a frequency of 6.0 occurrences of functional communication.

Jack. During the baseline phase, Jack's problem behavior was highly variable, at a high level and no clear trend. The problem behavior ranged from $30 \%$ to $100 \%$ of 
intervals with a mean of $65.0 \%$. His primary replacement behavior (on-task behavior) also showed a high amount of variability with a midlevel and no clear trend. It ranged from $0 \%$ to $70 \%$ of intervals and had a mean of $35.0 \%$. His secondary replacement behavior (functional communication) had zero occurrences during baseline.

During the function-based intervention phase (teacher baseline), Jack's problem behavior showed a decreasing trend, with a lower level, and less variability. It ranged from $10 \%$ to $50 \%$ of intervals with a mean of $36.0 \%$ of intervals. His primary replacement behavior had an increased level, with an increasing trend, and less variability. It ranged from $50 \%$ to $90 \%$ of intervals with a mean of $64 \%$ of intervals. His secondary replacement behavior (functional communication) did not occur during this phase.

During maintenance, Jack's problem behavior occurred in $10 \%$ of intervals, which is as low as his lowest data point during the function-based intervention phase. His primary replacement behavior occurred for $90 \%$ of intervals, and his secondary replacement behavior did not occur, which remains consistent with the function-based intervention phase. 

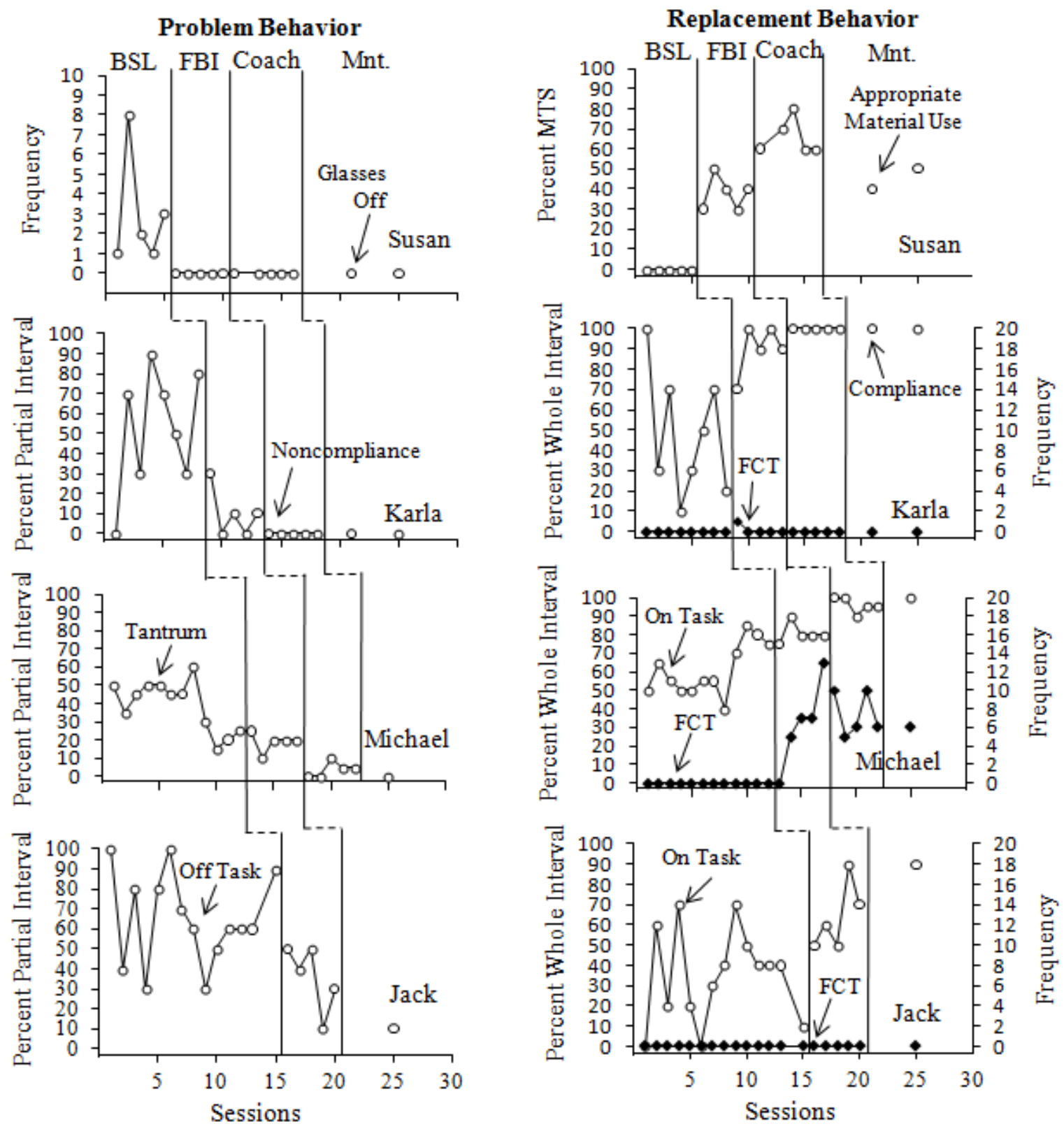

Figure 4.4 Student Problem and Replacement Behavior

Note: $\mathrm{BSL}=$ baseline, $\mathrm{FBI}=$ function-based intervention (teacher baseline) , Coach $=$ coaching phase, Mnt. = maintenance phase. On the replacement behavior graphs, open circles represent the primary replacement behavior, closed diamonds represent the secondary replacement behavior. 
Research Question 4: Do teachers and administrators find the use of coaching appropriate and efficient?

The teachers who participated in the study answered a social validity questionnaire to determine their perception of the effectiveness of the function-based interventions, the feasibility of implementing function-based interventions, the effectiveness of coaching, and if coaching was a socially acceptable method for improving accuracy of implementation of function-based interventions. Teachers also had the opportunity to write additional comments in an open-ended comments section. The results of the teachers' social validity survey are located in Table 4.2. Only the three teachers who received coaching answered questions that asked about the coaching procedure. Teachers rated the degree to which the agreed or disagreed to statements on a Likert scale. The rating scale was labeled with numbers one through five, with one being strongly disagree and five being strongly agree.

Each of the four teachers strongly agreed with the following statements: "Implementing function-based interventions are important when working with students with challenging behaviors," "I will use function-based interventions with other students in the future," and "I will continue to implement the designed function-based intervention with the target student." Of the three teachers who responded to the following statements, all three strongly agreed: “Coaching helped me better implement function-based interventions with this student," "The coaching sessions were not intrusive to my daily routine," "Coaching was cost efficient," and "Using coaching is a socially acceptable way to provide additional training beyond the workshop model." Three of the teachers strongly agreed and one teacher scored a 3 for the following two statements: "The student 
demonstrated an increase in his/her adaptive behavior" and "The student demonstrated a decrease in his/her challenging behavior." Finally, one teacher wrote the following response in the comments section: "I learned a lot from the coaching and implementing function-based interventions. I am going to try and implement these interventions in the regular education classroom. I am going to provide coaching to the regular education teacher. I am very happy with the coaching and results."

Additionally, the school psychologist completed a different questionnaire that included a question about the intrusiveness of the coaching procedure on the school schedule and whether she would recommend coaching as a follow training method to a workshop training. The results of the school psychologist's social validity questionnaire are located in Table 4.3.

The school psychologist strongly agreed with each of the following statements: "Implementing function-based interventions are important when working with students with challenging behaviors," "Coaching helped the teachers implement the functionbased interventions with students with challenging behaviors," "Coaching was cost efficient," "The students demonstrated an increase in their adaptive behavior," "The students demonstrated a decrease in their challenging behavior," "I would consider recommending coaching as a way to help teachers implement new strategies following a workshop training," and "Using coaching is a socially acceptable way to provide additional training beyond the workshop model." She rated a four for the following statement: "The coaching sessions were not intrusive to the school's daily routine." 
Table 4.2 Teacher Social Validity Data $(\mathrm{N}=4)$

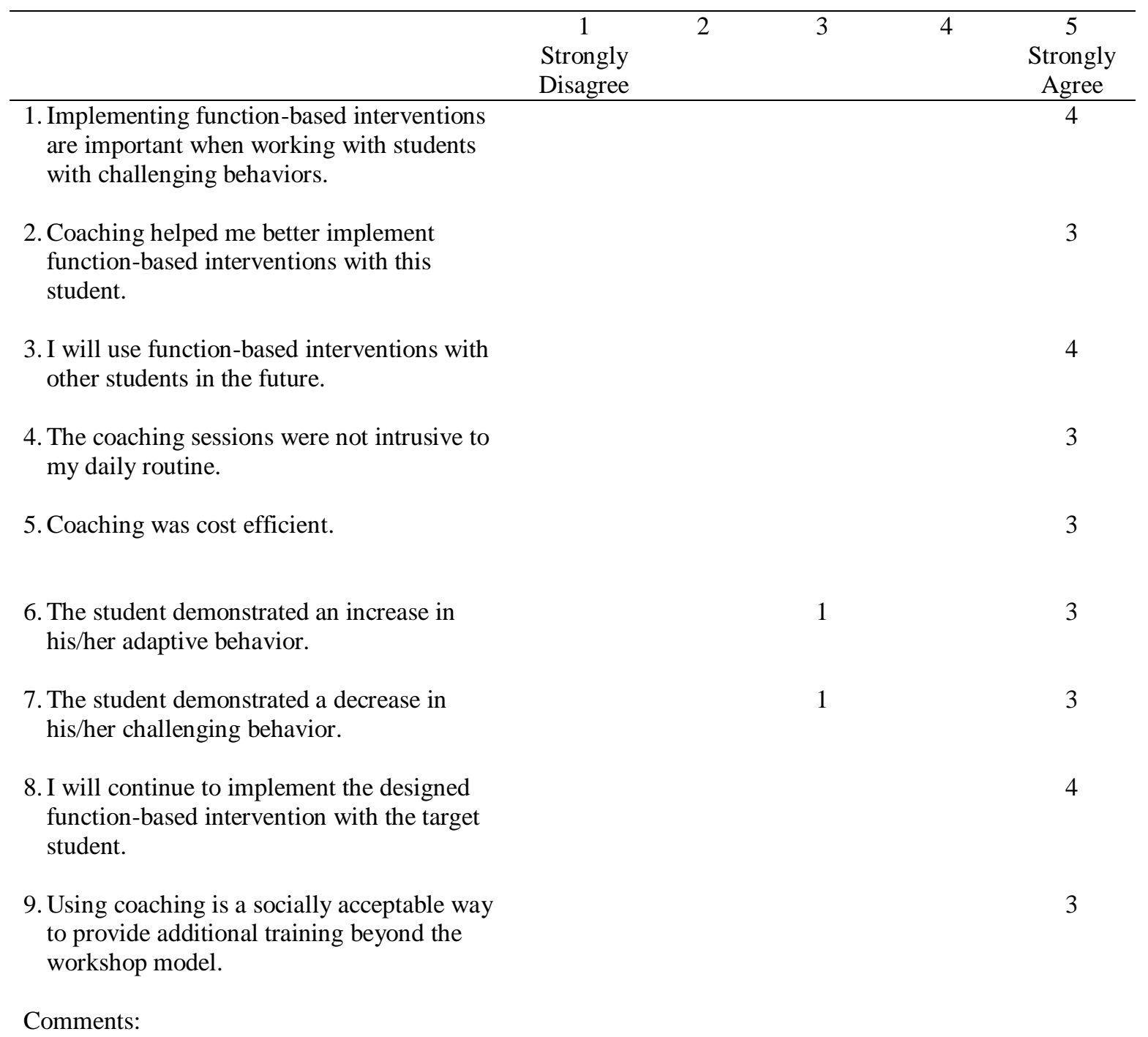

"I learned a lot from the coaching and implementing function-based interventions. I am going to try and implement these interventions in the regular education classroom. I am going to provide coaching to the regular education teacher. I'm very happy with the coaching and results." 
Table 4.3 School Psychologist Social Validity Data $(\mathrm{N}=1)$

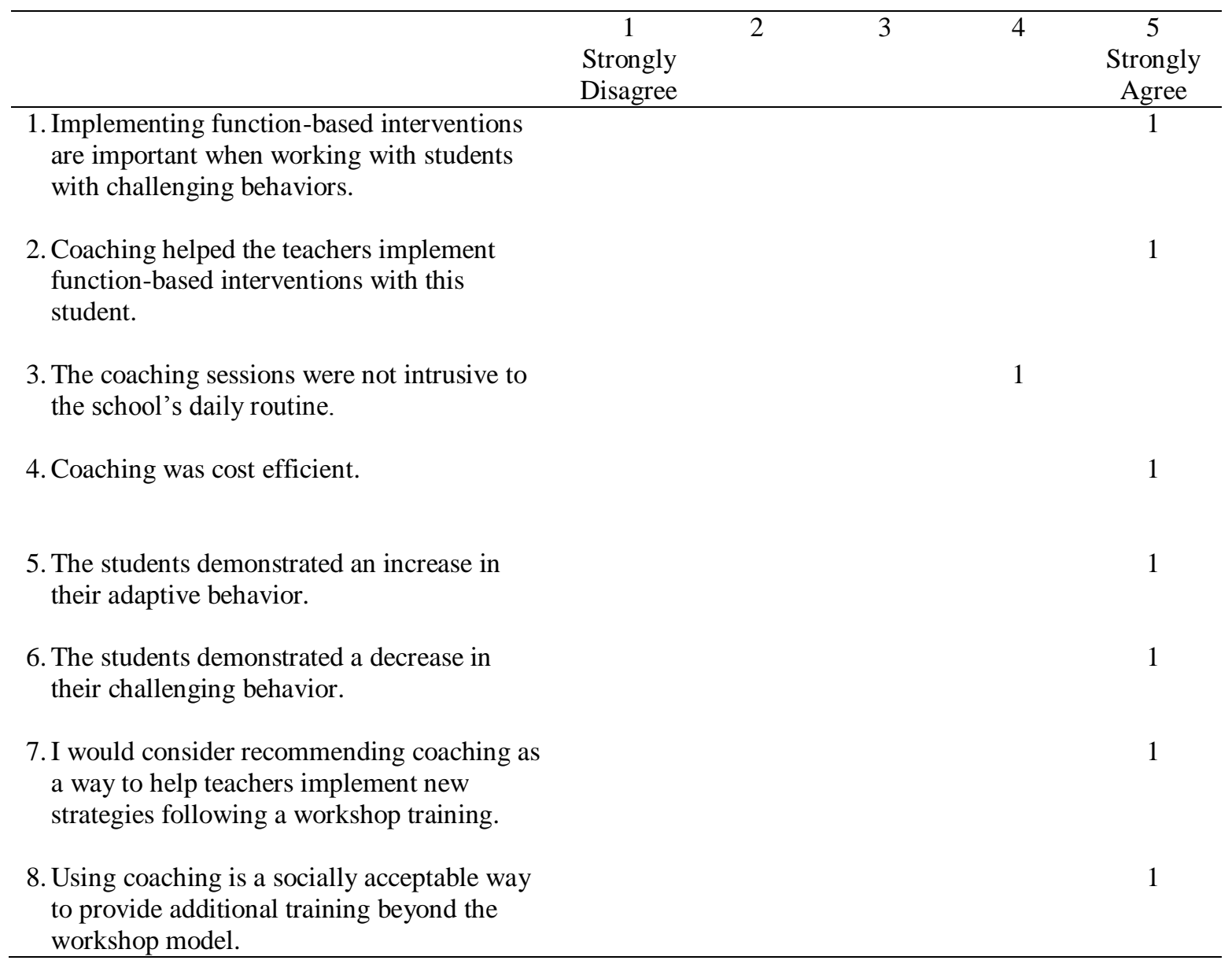




\section{CHAPTER 5: DISCUSSION}

The purpose of this study was to evaluate the effects of coaching on special education teachers' implementation of function-based interventions with students with severe disabilities through the use of a delayed multiple baseline across participants design. This study also sought to examine if teachers could generalize the ability to implement function-based interventions to different situations with their students. Additionally, this study examined the effect of the function-based intervention on the students' problem and replacement behaviors.

After an initial training on completion of FBAs and implementation of functionbased interventions, coaching was provided by the researcher to each teacher. Results indicated that there was a functional relationship between implementation of the coaching procedure and an increase in teacher fidelity scores. Teachers demonstrated the ability to generalize the strategies to another situation with the target student. A functional relationship was also found between accurate implementation of the function-based interventions and an increase in the students' primary replacement behaviors. Research Question 1: What are the effects of coaching on special education teachers' accuracy of implementation of function-based interventions?

The results of this study demonstrate a functional relationship between coaching and an increase in fidelity of teachers' implementation of function-based interventions. Three of the teachers had low levels of accuracy during baseline (e.g., after the workshop training alone). These teachers' data each have an immediate change in level after 
coaching to very stable and high data paths. Each of the three teachers' behavior show immediate increases after the implementation of the coaching procedure. The fourth teacher (Mrs. Green) was able to implement the function-based intervention with high accuracy after the workshop alone. Her data path demonstrated a high level of accuracy and therefore she was not introduced to the coaching intervention. It is important to note that Mrs. Green had previous experience and training in ABA and FBA.

These results indicate that some teachers (e.g., Mrs. Green) may be able to attend a workshop on function-based interventions and apply the procedures and interventions appropriately with their students. However, this raises the question about why the teacher had not already implemented a function-based intervention for the student. The workshop training and afternoon spent designing the function-based interventions may have provided the assistance needed to prepare the teacher to apply the function-based intervention. Because completion of FBAs and development of function-based interventions in schools are commonly completed as a team, this model may be sufficient for some teachers.

Three of the four teachers were unable to accurately implement the functionbased intervention after the workshop training alone. For these teachers, implementation of coaching produced rapid behavior change. This behavior change was noted after one coaching session and was maintained throughout the data collection for the study. 
Research Question 2: What is the effect of coaching on teachers' ability to generalize a function-based intervention (developed using the same process) to a second identified challenging behavior and/or setting with their students?

The results of the study demonstrate that all teachers were able to generalize their skills to a different activity with the target students. Each of the three teachers who required coaching had low levels of generalization during baseline. Their generalization scores during the baseline period were similar to their baseline data. After the coaching phase was complete, the teachers each demonstrated the ability to generalize to a different activity with $100 \%$ accuracy. This change in fidelity can be attributed to the coaching intervention, as generalization data remained at unacceptable levels during the baseline phase, but rose to acceptable levels after the teachers received the coaching intervention. The fourth teacher was able to generalize the function-based intervention during baseline and maintained this skill when observed again during the maintenance phase. This indicates that once teachers have been coached on how to implement function-based interventions during one activity, they may be able to generalize those procedures to similar activities throughout the school day for that specific student.

Student data collection during generalization probes yielded consistent patterns of student behavior in most cases. Students performance during generalization probes conducted during teacher baseline phase showed similar rates of behavior as those that occurred during daily probes with a few notable exceptions. First, the nature of the generalization activity for Sarah (e.g., lunch time) may have contributed to higher rates of appropriate use of materials. Simply put, eating lunch is more naturally reinforcing than engaging in circle time activities. For Michael, his frequency of functional 
communication responses was lower during the generalization probe that occurred during the teacher baseline phase. This may represent difficulty generalizing the skill to a different activity; however his frequency jumped to a higher frequency during the maintenance phase. Student behavior during generalization probes that occurred during maintenance phases were similar to data collected during daily probe data during the maintenance phase.

Research Questions 3: To what extent do students' challenging behaviors decrease and replacement behaviors increase as teachers implement function-based interventions with increasing fidelity?

The results of the study demonstrate a functional relationship between the accurate implementation of the function-based intervention (e.g., coaching phase) and an increase in each students' primary replacement behavior. All students' data paths for their primary replacement behaviors indicate an immediate change in level upon accurate implementation of the function-based intervention. Additionally, each student's problem behavior decreased during implementation of the study, however some students' problem behavior decreased upon initial implementation of the function-based intervention (teacher baseline) even when the intervention was not implemented accurately. However other students' problem behavior did not decrease until the coaching procedure was implemented (corresponding with accurate implementation of the function-based intervention).

Susan's problem behavior immediately decreased to zero once the teacher implemented the function-based intervention and remained at zero throughout the coaching and maintenance phases. Susan's data for her primary replacement behavior 
(appropriate use of materials) showed an increase in level from baseline (0\%) to the teacher's implementation of the function-based intervention (teacher baseline; $30 \%-50 \%$ of intervals), but this increase was not to acceptable levels as identified by her teacher. Once the coaching procedure was implemented (along with accurate implementation of the function-based intervention), Susan's data demonstrates another immediate increase to a higher, and more acceptable, level (60\%-80\% of intervals).

Karla's problem behavior showed an immediate decrease once the teacher implemented the function-based intervention (teacher baseline); however, it continued to have some variability and occurrences of noncompliance. Once the coaching phase started, Karla's problem behavior decreased to zero and remained at zero throughout maintenance. Karla's data for her replacement behavior (compliance) showed an increase in level upon the teacher implementing the function-based intervention (teacher baseline). While the behavior had significantly less variability than previously, there did continue to be some variability in the data. Once the coaching was implemented Karla's data immediately rose to $100 \%$ across all sessions. It is interesting to note that Karla's functional communication (secondary replacement behavior) occurred only one time after implementation of the function-based intervention. This may indicate her problem behavior was occurring due to a lack of appropriate reinforcement, rather than the inability to perform the primary replacement behavior (e.g., compliance). Karla's reinforcement system was designed so that she received zero stickers if she displayed noncompliant behavior, one sticker for asking for a break or help, and received two stickers for completing the activity compliantly without taking a break or asking for help (five stickers earned her computer time). After the first time Karla requested a break and 
received only one sticker, she stated to the teacher that she wanted to always earn two stickers and would not be taking anymore breaks.

Michael's problem behavior (tantrum) decreased during baseline; however, it did stabilize at an unacceptable level (as identified by the teacher) prior to implementation of the function-based intervention. Once the teacher implemented the function-based intervention, Michael's problem behavior did not show a significant change. However, once the coaching phase began, along with accurate implementation of the function-based intervention, Michael's problem behavior immediately decreased to a lower level. Michael's primary replacement behavior (on task behavior) did not show a change upon teacher implementation of the function-based intervention; however, it showed an immediate change in level once the coaching was introduced. Michael's secondary replacement behavior (functional communication) showed an increasing trend once the teacher implemented the function-based intervention (0-13 occurrences per session) and remained at a similar level during (5-10 occurrences per session). Michael's functional communication response was to exchange an icon to request taking a break in his favorite classroom chair. This data suggest that Michael improved the amount of time he was able to stay on task once the function-based intervention was introduced; however, he continued to rely on the functional-communication response to access escape from the demands.

Jack's problem behavior (off task) immediately demonstrated increased stability, a change in level, and a decreasing trend once the function-based intervention was implemented. It is important to note that Jack's teacher was able to accurately implement the function-based intervention during the teacher baseline phase. Jack's primary 
replacement behavior (on task behavior) demonstrated an immediate change to a higher level, with an increasing trend and increased stability. Jack did not utilize his functional communication response (appropriate break requests), preferring instead to complete the teacher led activity to earn access to computer time. Similar to Karla, this also suggests that Jack's low rates of the replacement behavior occurred due to a lack of reinforcement rather than an inability to perform the desired task.

There are a number of conclusions that can be drawn from these data. First, the data show that for some students, partial implementation of a function-based intervention is enough to produce a reduction in the problem behavior. However, for some students, accurate implementation is required before a reduction in problem behavior is observed. Second, accurate implementation of the function-based intervention is required to create sufficient changes in the students' primary replacement behavior. This has important implications towards the potential for students to maintain behavioral decreases over time. Interventions that focus solely on reducing problem behaviors, but do not teach replacement behaviors, do not maintain strongly when the intervention is removed because students have not been taught an appropriate way to fulfill the function of their problem behaviors (Cooper et al., 2007). This indicates the reductions observed in the students' problem behaviors upon occurrence of the partially implemented functionbased interventions (during the teacher baseline phase) may not have maintained over time.

These results indicate that attempting to implement portions of a function-based intervention may be better than not implementing an intervention; however, accurate implementation of function-based intervention produces the best student outcomes. 
Research Question 4: Do teachers and administrators find the use of coaching appropriate and efficient?

Results of both the teacher and psychologist surveys indicated that coaching was a socially appropriate method for teaching teachers how to accurately implement FBAs and function-based interventions. Teachers reported they agreed that implementing functionbased interventions are important when working with students who display challenging behavior and that coaching helped them implement the function-based interventions. They also reported that coaching was not intrusive to their daily routines and was cost effective. Three of the teachers reported observing a change in student behavior, while one teacher was neutral. All of the teachers agreed that coaching was a socially acceptable way to provide additional training beyond a workshop model.

The school psychologist also reported that function-based interventions are important, coaching helped the teachers implement the function-based interventions, student behavior improved, coaching was cost efficient, and socially acceptable. The psychologist also agreed that she would consider recommending coaching in the future.

This suggests that not only is coaching effective in increasing accuracy of implementation of function-based interventions, but also that coaching was viewed as effective and acceptable to the participants. This information, along with the rapid behavior change observed during the coaching phase, suggests that coaching may be an affordable, simple to implement method that can be used by school systems to follow up on workshop trainings to increase teachers' implementation of function-based interventions. 
Specific Contributions of this Study

This study has contributed to the literature on teacher implemented function-based interventions in a number of important ways: (a) this study shows that coaching is a successful method for improving teacher implementation of function-based interventions when workshops alone are insufficient; (b) it provides a model for the type and quantity of coaching required to observe the teachers' behavior change; (c) it adds to the literature on coaching, showing that coaching is also successful improving application of functionbased interventions; (d) this study is the first to measure both teacher and student behavior when implementing function-based interventions; and (e) it includes a measure of generalization maintenance to examine if teachers could continue performing the function-based interventions over time and in different settings.

Previous research stated that there is a need for additional special education support and ongoing training of special education teacher (Jenkins \& Yoshimura, 2010); however, workshop training is often insufficient to train school personnel to develop and implement function-based interventions (Scott et al., 2004; Scott et al., 2005; Van Acker et al., 2004). Furthermore, even though there is ample research published on the effectiveness of function-based interventions, there is a lack of research on the development and implementation of function-based interventions (Iwata et al., 1982, 1994; Scott et al., 2005). Nahgahgwon et al. (2010) specifically suggest that future research should examine the type of training procedures that would results in accurate implementation of function-based interventions. This study specifically addresses these issues by collecting data on teacher implementation of function-based interventions, 
confirming that workshop training alone was insufficient for three of the four teachers, and then showing that coaching was a successful way to improve the teachers' accuracy.

Second, previous research on coaching has suggested that future studies should examine the type and quantity of coaching that is required to improve teacher score (Menzies et al., 2008; Myers et al., 2011; Tschannen-Moran \& McMaster, 2009). This study showed that the coaching procedure produced changes in the teachers' behavior after only one session. Additionally, each teacher received only two coaching sessions before meeting the mastery criteria. Each coaching session lasted approximately $10 \mathrm{~min}$, meaning that each teacher received a total of approximately $20 \mathrm{~min}$ of coaching. This shows that the coaching procedure can be implemented in a brief time period and still produce positive results.

Third, the body of literature on coaching has shown that coaching can be effective in improving teachers' behavior when implementing classwide positive behavior supports (Filcheck et al., 2004), reading interventions (Jager et al., 2002; Kohler et al., 1999; Lignugaris-Kraft \& Marchand-Martella, 1993; Morgan et al., 1994), explicit math instruction (Kretlow, Cooke, \& Wood, 2011; Kretlow, Wood, \& Cooke, 2011), and teacher praise in an RTI model (Myers, Simonsen, \& Sugai, 2011). This study expands the areas where coaching has been shown to be effective to include teacher implementation of function-based interventions.

Fourth, this study made a significant contribution as the first study to measure both student and teacher behavior during implementation of function-based intervention as the primary dependent measures. Menzies et al. (2008) stated that future research needs to measure the effects of coaching on the students' performance as well as the 
teachers' performance. Changing teacher behavior is important only if those effects in turn can have a positive effect on student behavior. This study measured student behavior and showed the effects that the changes in teacher implementation of the function-based interventions had on their students' behavior.

Finally, Tschannen-Moran and McMaster (2009) suggested that research also need to focus on the sustainability of the changes in teacher behavior resulting from the coaching interventions. This study measured teacher and student maintenance data. For teacher completing the coaching phase before other teachers, maintenance data were collected once a week. For all teachers, maintenance data were collected after a two and a half week period. All teachers maintained their high scores during all maintenance observations. Maintenance data were also collected on student behavior, which showed that students were also able to maintain their behavioral changes. 
Limitations and Recommendations for Future Research

There are several noted limitations to the current study. First, the study did not examine removal of the expert (i.e., the researcher) from initial completion of the FBA process. The researcher worked with each teacher during the workshop training to develop the hypothesis for the function of each student's problem behavior and develop the corresponding function-based interventions. The researcher also conducted the FA to confirm the hypothesis. Teachers working with students on a daily basis may not need to confirm the hypothesis through use of an FA; however, conclusions cannot be drawn regarding teachers' ability to complete FAs from the results of this study. This prevents the researcher from drawing conclusions about how to fade expert support from completion of the FBA process and limits conclusions to accuracy of teacher implementation of function-based interventions. Teachers in schools often work as part of a team to develop FBAs for students with problem behaviors, therefore future research should focus on accuracy of completion of FBAs by school teams in addition to teacher implementation of function-based interventions.

A second limitation of this study is the use of relatively long intervals when measuring student behavior using partial and whole interval or momentary time sampling (1 min or 30s intervals). The intervals needed to be long enough that teachers could reasonably take data while instructing the student or a group of students during normally scheduled classroom activities. Use of longer intervals could lead to over or underestimation of behavioral occurrences as compared to shorter intervals (Cooper et al., 2007). For example, when tracking Karla's noncompliant behavior using one minute partial intervals, she may exhibit the problem behavior during the first $5 \mathrm{~s}$ of a $1 \mathrm{~min}$ 
interval, but then she may have been on task for the remainder of the interval. This means that the teacher and researcher would record that the behavior did occur for the $1 \mathrm{~min}$ interval, however if shorter 10s intervals were used, the data would reflect that she was noncompliant during the first 10 s interval, but on task for the remaining five $10 \mathrm{~s}$ intervals. Future research could use alternate methods for data collection, such as videotaping student behavior, that may allow for the use of shorter intervals while not sacrificing teacher accuracy of data collection.

A third limitation of this study is the inability to generalize the results to a wide range of teachers. This study was designed using single-subject research methodology; however, because this is the first study that examines the use of coaching to increase teacher accuracy implementing function-based interventions and includes only three participants who received the coaching procedure, there is insufficient evidence to generalize the results across a wide range of teachers in other schools. Horner et al. (2005) state that in order to generalize the effects of an intervention there need to be at least five replications across minimally three settings, three different researchers, and 20 participants. Future research should focus on replication of these results to meet the criteria outlined by Horner et al. (2005).

A fourth potential limitation relates to use of the delayed multiple baseline design across participants for teacher behavior. When using a delayed multiple baseline design, participants enter tiers in a staggered fashion, as was done in this study for the teachers. This means that all three teachers do not have their first data point on the same day. Additionally, delayed multiple baseline designs may present a limitation if baseline periods for each participant do not overlap; this would mean that baseline periods from 
the second and third tier could not be used to verify the predictions of previous phases (Cooper et al., 2007). This potential limitation can be overcome by making sure that each baseline period overlaps the previous tier's baseline period by several sessions (Cooper et al., 2007). In this study the first and second participants' baseline periods overlap by two data points and the same is true for the second and third participants' baseline periods. This allows the prediction of the first participant's baseline data path to be verified by the second participant's baseline data path. The same is true when comparing the second participant's baseline data path with the third participant's baseline data path.

The final limitation of this study was the use of the researcher as the coach. Because the researcher acted as the coach, it is unclear how and if the coaching procedure could be transferred to another professional within the school system. It may be possible to train psychologists, BCBAs, or teachers who perform well in baseline to act as coaches; however, this study does not examine how much or what type of training would be required to ensure that the coaching procedure could be successfully taught to other professionals. Future research should examine what type of professional would best translate into future coaches and what type of training and preparation is required. Implications for Practice

The results of this study indicate a number of implications for practice. First, inservice/workshop training alone is not sufficient to train most teachers to accurately implement FBAs and function-based interventions. School districts and administrators might consider adopting a training model based on expert coaching to provide teachers additional individualized support. Workshop and inservice trainings should include time 
for teachers to work with experts to actually plan for implementation of FBAs and function-based interventions with their individual students.

A second recommendation for practice is for school systems interested in adopting this model to work with a small group of qualified professionals who have demonstrated success in developing and implementing FBAs and function-based interventions. The school should create protocols for observing teachers implementing function-based interventions to identify which teachers would benefit from the coaching procedures. The coaches can then organize their time to spend a short amount of time with each teacher in need to provide targeted coaching. This will hopefully allow school systems to utilize coaching methods in a time and cost efficient manner.

A third recommendation arises from the fourth teacher participant in this study. This teacher demonstrated the ability to implement the function-based intervention accurately with her student after the workshop training alone; however, this teacher was not implementing a function-based intervention for this problem behavior with this student prior to the workshop. This suggests that some level of support is still required to help teachers complete FBAs and develop appropriate function-based interventions. It might be helpful for schools to develop an FBA team that meets regularly to review cases and help teachers complete FBAs and implement function-based interventions. These teams could consist of administrators, teachers, school counselors, and/or school psychologists. 


\section{REFERENCES}

Accardo, P. J., \& Whitman, B. Y. (2011). Dictionary of developmental disabilities terminology ( $3^{\text {rd }}$ ed.). Baltimore, MD; Paul H. Brookes Publishing Co.

Alberto, P. A., \& Troutman, A. C. (2009). Applied behavior analysis for teachers $\left(8^{\text {th }}\right.$ ed.). Upper Saddle River, NJ; Pearson.

Blacher, J., \& McIntyre, L. L. (2006). Syndrome specificity and behavioural disorders in young adults with intellectual disability: Cultural differences in family impact. Journal of Intellectual Disability Research, 50, 184-198. doi: 10.1111/j.13652788.2005.00768.

Blood, E., \& Neel, R. S. (2007). From FBA to implementation: A look at what is actually being delivered. Education \& Treatment of Children, 30, 67-80.

Carr, E. G. (1977). The motivation of self-injurious behavior - A review of some hypotheses. Psychological Bulletin, 64, 600-616.

Carr. E. G., \& Durand, V. M. (1985). Reducing behavior problems through functional communication training. Journal of Applied Behavior Analysis, 18, 111-126.

Centers for Disease Control. Retrieved from http://www.cdc.gov/ncbddd/autism/data.html

Chandler, L. K., \& Dahlquist, C. M., (2006). Functional assessment: Strategies to prevent and remediate challenging behavior in school settings $\left(2^{\text {nd }}\right.$ ed.). Upper Saddle River, NJ: Pearson.

Cooper, J. O., Heron, T. E., \& Heward, W. L. (2007). Applied behavior analysis (2 ${ }^{\text {nd }}$ ed.). Upper Saddle River, NJ: Pearson.

Dunlap, G., Kern-Dunlap, L., Clarke, S., \& Robbins, F. R. (1991). Functional assessment, curricular revision, and severe behavior problems. Journal of Applied Behavior Analysis, 24, 387-397.

Emerson, E., Kiernan, C., Alborz, A., Reeves, D., Mason, H... Hatton, C. (2001). The prevelance of challenging behaviors: A total population study. Research in Developmental Disabilities, 22, 77-93. doi:10.1016/S0891-4222(00)00061-5

Ervin, R. A., DuPaul, G. J., Kern, L., \& Friman, P. C. (1998). Classroom-based functional and adjunctive assessments: Proactive approaches to intervention selection for adolescents with attention deficit hyperactivity disorder. Journal of Applied Behavior Analysis, 31, 65-78. 
Evenson, A., Justinger, B., Pelischek, E., \& Schulz, S. (2009). Zero tolerance policies and the public schools: When suspension is no longer effective. Communique, 37(5), $1-7$.

Filcheck, H. A., McNeil, C. B., Greco, L. A., \& Bernard, R. S. (2004). Using a wholeclass token economy and coaching of teacher skills in a preschool classroom to manage disruptive behavior. Psychology in the Schools, 41, 351-361.

Filter, K. J., \& Horner, R. H. (2009). Function-based academic interventions for problem behavior. Education \& Treatment of Children, 32, 1-19.

Foster-Johnson, L., Ferro, J., \& Dunlap, G. (1994). Preferred curricular activities and reduced problem behaviors in students with intellectual disabilities. Journal of Applied Behavior Analysis, 27, 493-405.

Gast, D. L. (2010). Single subject research methodology in behavioral sciences. New York, NY: Routledge Taylor \& Francis Group.

Heward, W. L. (2009). Exceptional children: An introduction to special education $\left(9^{\text {th }}\right.$ ed.). Upper Saddle River, NJ: Pearson.

Horner, R. H. (1994). Functional assessment: Contributions and future directions. Journal of Applied Behavior Analysis, 27, 401-404.

Horner, R. H., Carr, E. G., Halle, J., McGee, G., Odom, S., \& Wolery, M. (2005). The use of single-subject research to identify evidence-based practice in special education. Exceptional Children, 71, 165-179.

Iwata, B. A., Dorsey, M. F., Slifer, K. J., Bauman, K. E., \& Richman, G. S. (1982). Toward a functional analysis of self-injury. Journal of Applied Behavior Analysis, 27, 3-20.

Iwata, B. A., Pace, G. M., Dorsey, M. F., Zarcone, J. R., Vollmer, T. R, Smith, R. G... Willis, K. D. (1994). The functions of self-injurious behavior: An experimentalepidemiological analysis. Journal of Applied Behavior Analysis, 27, 215-240.

Jager, B., Reezigt, G. J., \& Creemers, B. P. (2002). The effects of teacher training on new instructional behavior in reading comprehension. Teaching and Teacher Education, 18, 831-842.

Janssen, M. J., Riksen-Walraven,J. M., van Dijk, J. P., \& Ruijssenaars, W. A. (2010). Interaction coaching with mothers of children with congenital deaf-blindness at home: Applying the diagnostic intervention model. Journal of Visual Impairment \& Blindness, 1, 15-29. 
Jenkins, A. A., \& Yoshimura, J. (2010). Not another inservice! Meeting the special education professional development needs of elementary general educators. TEACHING Exceptional Children, 42(5), 36-43.

Kamps, D., Wendland, M., \& Culpepper, M. (2006). Active teacher participation in functional behavior assessment for students with emotional and behavioral disorder risks in general education classrooms. Behavioral Disorders, 31, 128146.

Kern, L., Childs, K. E., Dunlap, G., Clarke, S., \& Falk, G. D. (1994). Using assessmentbased curricular intervention to improve the classroom behavior of a student with emotional and behavioral challenges. Journal of Applied Behavior Analysis, 27, 7-19.

Kretlow, A. G., \& Bartholomew, C. C. (2010). Using coaching to improve the fidelity of evidence-based practices. Teacher Education and Special Education, 33, 279-299. doi: $10.1177 / 0888406410371643$

Kretlow, A. G., Cooke, N. L., \& Wood, C. L. (2011). Using in-service and coaching to increase teachers' accurate use of research-based strategies. Remedial and Special Education. Advance online publication. doi: 10.1177/0741932510395397

Kretlow, A. G., Wood, C. L., \& Cooke, N. L. (2011). Using inservice and coaching to increase kindergarten teachers' accurate delivery of group instructional units. The Journal of Special Education, 44, 234-246.

Kohler, F. W., Ezell, H. K., \& Paluselli, M. (1999). Promoting changes in teachers' conduct of student pair activities: An examination of reciprocal peer coaching. The Journal of Special Education, 33, 154-165.

Lane, K. L., Smither, R., Huseman, R., Guffey, J. \& Fox, J. (2007). A function-based intervention to decrease disruptive behavior and increase academic engagement. Journal of Early and Intensive Behavior Intervention, 4, 348-364.

Liaupsin, C. J., Umbreit, J., Ferro, J. B., Urso, A., \& Upreti, G. (2006). Improving academic engagement through systematic, function-based intervention. Education \& Treatment of Children, 4, 573-591.

Lignugaris-Kraft, B., \& Marchand-Martella, N. (1993). Evaluation of preservice teachers' interactive teaching skills in a Direct Instruction practicum using student teachers as supervisors. Teacher Education and Special Education, 16, 309-318.

Loiacono, V., \& Valenti, V. (2010). General education teachers need to be prepared to co-teach the increasing number of children with autism in inclusive settings. International Journal of Special Education, 25(3), 25-32. 
Lynch, J., \& Ferguson, K. (2010). Reflections of elementary school literacy coaches on practice: Roles and perspectives. Canadian Journal of Education, 33, 199-227.

Menzies, H. M, Mahdavi, J. N., \& Lewis, J. L. (2008). Early intervention in reading: From research to practice. Remedial and Special Education, 29, 67-77. doi: $10.1177 / 0741932508315844$

Mustian, A. L. (2010). The comparative effects of function-based verses nonfunctionbased interventions on the social behavior of African American students. Unpublished doctoral dissertation, University of North Carolina at Charlotte.

Myers, D. M., Simonsen, B., \& Sugai, G. (2011). Increasing teachers' use of praise with a response-to-intervention approach. Education \& Treatment of Children, 34, 3559.

Nahgahgwon, K. N., Umbreit, J., Liaupsin, C. J., \& Turton, A. M. (2010). Function-based planning for young children at risk for emotional and behavioral disorders. Education \& Treatment of Children, 33, 537-559.

O’Neill, R. E., Horner, R. H., Albin, R. W., Sprague, J. R., Storey, K., \& Newton, J. S. (1997). Functional assessment and program development for problem behavior: A practical handbook ( $2^{\text {nd }}$ ed.). Pacific Grove, CA: Brooks/Cole.

Onchwari, G., \& Keengwe, J. (2008). The impact of a mentor-coaching on teacher professional development. Journal of Early Childhood Education, 36, 19-24. doi: 10.1007/s10643-007-0233-0

Peterson, D. S., Taylor, B. M., Burnham, B., \& Schock, R. (2009). Reflective coaching conversations: A missing piece. The Reading Teacher, 62, 500-509. doi: 10.1598/RT.62.6.4

Powell, D. R., Diamond, K. E., Burchinal, M. R., \& Koehler, M. J. (2010). Effects of an early literacy professional development intervention on head start teachers and children. Journal of Educational Psychology, 102, 299-312. doi: 10.1037/a0017763

Repp, A. C., Felce, D., \& Barton, L. E. (1988). Basing the treatment of stereotypic and self-injurious behaviors on hypotheses of their causes. Journal of Applied Behavior Analysis, 21, 281-289.

Rock, M. L, Gregg, M., Thead, B. K., Acker, S. E., Gable, R. A., \& Zigmond, N. P. (2009). Can you hear me now? Evaluation of an online wireless technology to provide real-time feedback to special education teachers-in-training. Teacher Education and Special Education, 32, 64-82. doi: 10.1177/0888406408330872 
Rojahn, J., Wilkins, J., Matson, J. L., Boisjoli, J. (2010). A comparison of adults with intellectual disabilities with and without ASD on parallel measures of challenging behavior: The behavior problems inventory-01 (BPI-01) and autism spectrum disorders-behavior problems for intellectually disabled adults (ASD-BPA). Journal of Applied Research in Intellectual Disabilities, 23, 179-185.

Roscoe, E. M., Kindle, A. E., \& Pence, S. T. (2010). Functional analysis and treatment of aggression maintained by preferred conversational topics. Journal of Applied Behavior Analysis, 43, 723-727.

Rudd, L. C., Lambert, M. C., Satterwhite, M. \& Smith, C. H. (2009). Professional development + coaching $=$ enhanced teaching: Increasing usage of math mediated language in preschool classrooms. Journal of Early Childhood Education, 37, 6369. doi: 10.1007/s10643-009-0320-5

Sailors, M., \& Price, L. R. (2010). Professional development that supports the teaching of cognitive reading strategy instruction. The Elementary School Journal, 110, 301322. doi: 0013-5984/20101/11003-0003

Sasso, G. M., Reimers, T. M., Cooper, L. J., Wacker, D., Berg, W., Steege, M... Allaire, A. (1992). Use of descriptive and experimental analysis to identify the functional properties of aberrant behavior in school settings. Journal of Applied Behavior Analysis, 25, 809-821.

Scheeler, M. C., Congdon, M., \& Stansbery, S. (2010). Providing immediate feedback to co-teachers through bug-in-ear technology: An effective method of peer coaching in inclusion classrooms. Teacher Education and Special Education, 33, 83-96. doi: 10.1177.0888406409357013

Scott, T. M., Liaupsin, C. C., Nelson, C. M., \& McIntyre, J. (2005). Team-based functional behavior assessment as a proactive public school process: A descriptive analysis of current barriers. Journal of Behavioral Education, 14, 57-71. doi: $10.1007 / \mathrm{s} 10864-005-0961-4$

Scott, T. M., McIntyre, J., Liaupsin, C., Nelson, C. M., \& Conroy, M. (2004). An examination of functional behavior assessment in public school settings: Collaborative teams, experts, and methodology. Behavioral Disorders, 29, 384395.

Scott, T. M., McIntyre, J., Liaupsin, C., Nelson, C. M., Conroy, M., \& Payne, L. D. (2005). An examination of the relation between functional behavior assessment and selected intervention strategies with school-based teams. Journal of Positive Behavior Interventions, 7, 205-215. 
Shanley, J. R., \& Niec, L. N. (2010). Coaching parents to change: The impact of in vivo feedback on parents' acquisition of skills. Journal of Clinical, Child, \& Adolescent Psychology, 39, 282-287. doi: 10.1080/15374410903532627

Shidler L., \& Fedor, K. (2010). Teacher-to-teacher: The heart of the coaching model. Young Children, 7, 70-75.

Sigafoos, J., Arthur, M., \& O’Reilly, M. (2003). Challenging behaviour and developmental disability. London, England: Whurr Publishers.

Skinner, B. F. (1938). The behavior of organisms: An experimental analysis. Oxford, England: Appleton Century.

Sugai, G., Horner, R. H., Dunlap, G., Hieneman, M., Lewis, T. J., Nelson, C. M... Wilcox, B. (2000). Applying positive behavioral support and functional behavior assessment in schools. Journal of Positive Behavioral Interventions, 2, 131-143.

Touchette, P. E., MacDonald, R. F., \& Langer, S. N. (1985). A scatter plot for identifying stimulus control of problem behavior. Journal of Applied Behavior Analysis, 18, 343-351.

Tschannen-Moran, M., \& McMaster, P. (2009). Sources of self-efficacy: Four professional development formats and their relationship to self-efficacy and implementation of a new teaching strategy. The Elementary School Journal, 110, 228-245.

Turton, A. M., Umbreit, J., Liaupsin, C. J., \& Bartley, J. (2007). Function-based intervention for an adolescent with emotional behavioral disorders in Bermuda: Moving across culture. Behavioral Disorders, 33(1), 23-32.

Umbreit, J., Ferro, J. B., Liaupsin, C. J., \& Lane, K. L. (2007). Functional behavioral assessment and function-based intervention. Upper Saddle River, NJ: Pearson.

Van Acker, R., Boreson, L., Gable, R. A., \& Potterton, T. (2004). Are we on the right course? Lessons learned about current FBA/BIP practices in schools. Journal of Behavioral Education, 14, 35-56. doi: 10.1007/s10864-005-0960-5

Vismara, L. A., Young, G. S., Stahmer, A. C., McMahon-Griffith, E., \& Rogers, S. J. (2009). Dissemination of evidence-based practice: Can we train therapists from a distance? Journal of Autism and Developmental Disorders, 39, 1636-1651. doi: 10.1007/s10803-009-0796-2

Watson, P. J., \& Workman, E. A. (1981). The non-concurrent multiple baseline acrossindividuals design: An extension of the traditional multiple baseline design. Journal of Behavior Therapy and Experimental Psychiatry, 12, 257-259. 
Yoon, K. S., Duncan, T., Lee, S. W.-Y., Scarloss, B., \& Shapley, K. (2007). Reviewing the evidence on how teacher professional development affects student achievement (Issues \& Answers Report, REL 2007-No. 033). Washington, DC: U.S. Department of Education, Institute of Education Sciences, National Center for Education Evaluation and Regional Assistance, Regional Educational Laboratory Southwest. Retrieved from http://ies.ed.gov/ncee/edlabs

Zakierskiy, M., \& Siegal, A. (2010). Creating collaborative literacy teams to increase reading achievement in urban settings. Journal of College Teaching \& Learning, 7(4), 25-28. 


\section{APPENDIX A: FUNCTIONAL ASSESSMENT INTERVIEW FORM}

\section{FUNCTIONAL ASSESSMENT INTERVIEW (FAI)}

\begin{tabular}{|c|c|}
\hline Person of concern "Karla" & Age $\frac{8^{\prime}}{}$ Sex M (F) \\
\hline Date of interview $\quad \mid 1-4-\|$ & Interviewer Keri stephensiolbthou \\
\hline
\end{tabular}

A. DESCRIBE THE BEHAVIORS.

1. For each of the behaviors of concern, define the topography (how it is performed), frequency (how often it occurs per day, week, or month), duration (how long it lasts when it occurs), and intensity (how damaging or destructive the behaviors are when they occur).

Behavior Topography Frequency Intensity

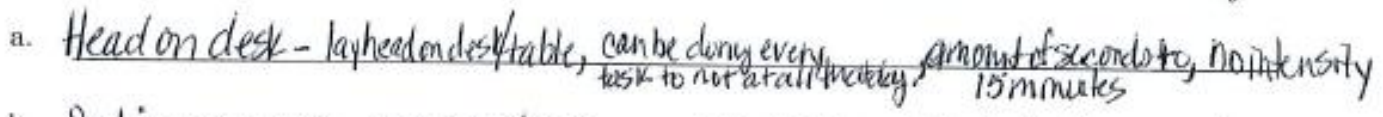

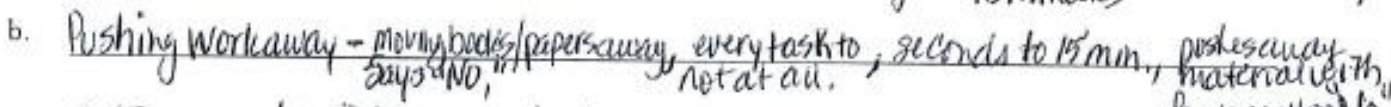

c. Gettig up andmeving tocarpet, standup waik tr carpet, 2-3triesa dain, $0-15$ forde, yelles $\mathrm{NO}^{\circ}$

d. Self lay doun to notatain min. Is none

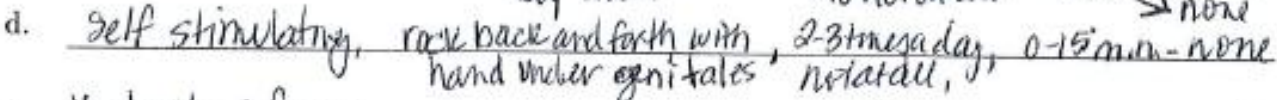

e. Verbally fefosily - "

f.

g.

h.

i.

j.

2. Which of the behaviors described above are likely to occur together in some way? Do they occur about the same time? In some kind of predictable sequence or "chain"? In response to the same type of situation? 
B. DEFINE ECOLOGICAL EVENTS (SETTING EVENTS) THAT PREDICT OR SET UP THE PROBLEM BEHAVIORS.

1. What medications is the person taking (if any), and how do you believe these may affect his or her behavior?

None

2. What medical or physical conditions (if any) does the person experience that may affect his or her behavior (e.g., asthma, allergies, rashes, sinus infections, seizures, problems related to menstruation)?

When sick behavion is mone presunt.

3. Describe the sleep patterns of the individual and the extent to which these patterns may affect his or her behavior.
When tired "Karla" "vants When tired "Karla" ora to on carpot mov, pots trigurs in month, refuses work.

4. Describe the eating routines and diet of the person and the extent to which these may affect his or her behavior.
"Karla" requests a snack early in the morning. we have increased snack do to her asicing formore.

5a. Briefly list below the person's typical daily schedule of activities. (Check the boxes by those activities the person enjoys and those activities most associated with problems.)
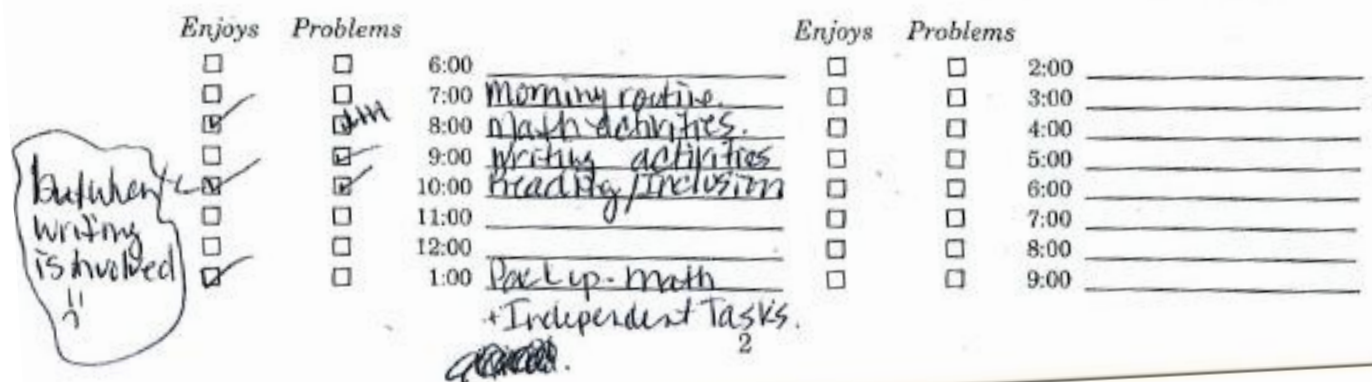
5b. To what extent are the activities on the daily schedule predictable for the person, with regard to what will be happening, when it will occur, with whom, and for how long?

Solvedule is revy predictable. Howerer, achrities vary with anoust of handuriting/writing with in

5c. To what extent does the person have the opportunity during the day to make choices about his or her activities and reinforcing events? (e.g., food, clothing, social companions, leisure activities)

structived activitics, but choies with in the activities. torexample: which perciel, pietere, paper.

6. How many other persons are typically around the individual at home, school, or work (including staff, classmates, and housemates)? Does the person typically seem bothered in situations that are more crowded and noisy?
RegEd classrom - Iteaches - 27 students Resource - 2.7 studenty and 1 teaches

7. What is the pattern of staffing support that the person receives in home, school, work, and other settings (e.g., 1:1, 2:1)? Do you believe that the number of staff, the training of staff, or their social interactions with the person affect the problem behaviors?

Restrurce-setting - striggles more when more
studentt at in class.

C. DEFINE SPECIFIC IMMEDIATE ANTECEDENT EVENTS THAT PREDICT WHEN THE BEHAVIORS ARE LIKELY AND NOT LIKELY TO OCCUR.

1. Times of Day: When are the behaviors most and least likely to happen?

Most likely: Writing actwatics, transitions, mid-morn iny,

Least likely: Afternoon, before dissmissal, working $1 / 1$
with reading. 
2. Settings: Where are the behaviors most and least likely to happen?

Most likely: At the table durence onvil gromp woik, Indepadent tasks.with Writing involked, All setting, Reg Ed, Spact, Sorcials,

Least likely: Ion I reading taske, Snad time. Cafetera.

3. People: With whom are the behaviors most and least likely to happen?

Most likely: All teachera, + parents.

Least likely:

$?$

4. Activity: What activities are most and least likely to produce the behaviors?

Most likely: Writing, Independent tasks. Anytrie she does not

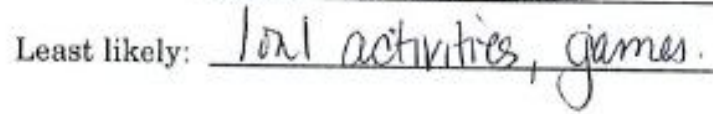

5. Are there particular or idiosyncratic situations or events not listed above that sometimes seem to "set off" the behaviors, such as particular demands, noises, lights, clothing?

Assemblies, Transition - unexpected.

6. What one thing could you do that would most likely make the undesirable behaviors occur?

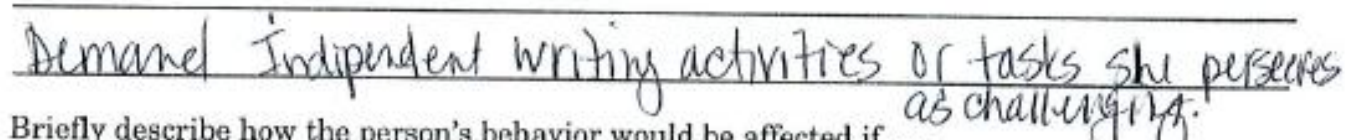

7. Briefly describe how the person's behavior would be affected if ...

a. You asked him or her to perform a difficult task.

heral, put head donn, wark away, "no"

b. You interrupted a desined activity, such as eating ice cream or watching TV,

c. You unex́pectedly chapged his or her typical routihe or schedulg offactivities.

You unexpectedly chapged his or her typical routihe or schedulg of activities.


d. She or he wanted something but wasn't able to get it (e.g., a food item up on a shelf). Put head dolm, cries, walls avey to canpet, refores to more.

e. You didn't pay attention to the person or left her or him alone for a while (e.g., 15 minutes). yell Teaches name, refuses to move.

D. IDENTIFY THE CONSEQUENCES OR OUTCOMES OF THE PROBLEM BEHAVIORS THAT MAY BE MAINTAINING THEM (I.E., THE FUNCTIONS THEY SERVE FOR THE PERSON IN PARTICULAR SITUATIONS).

1. Think of each of the behaviors listed in Section A, and try to identify the specific consequences or outcomes the person gets when the behaviors occur in different situations.
What exactly
What exactly

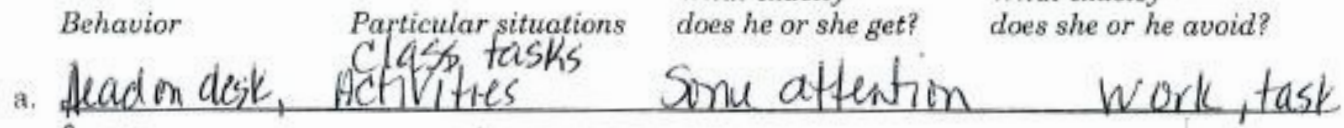
b. lishily urrewas
c. Cetting uptmoin
d.
e. Self stimulatiog
to concept.
f.
g.
h.
i.
j.
E. CONSIDER THE OVERALL EFFICIENCY OF THE PROBLEM BEHAVIORS. EFFICIENCY IS THE COMBINED RESULT OF (A) HOW MUCH PHYSICAL EFFORT IS REQUIRED, (B) HOW OFTEN THE BEHAVIOR IS PERFORMED BEFORE IT IS REWARDED, AND (C) HOW LONG THE PERSON MUST WAIT TO GET THE REWARD.

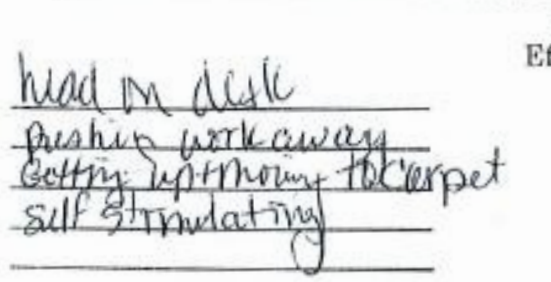

\section{Low}

Efficiency

1
1
1
1
1

High

Efficiency
(5)
(5)
(5)
(5) 
F. WHAT FUNCTIONAL ALTERNATIVE BEHAVIORS DOES THE PERSON ALREADY KNOW HOW TO DO?

1. What socially appropriate behaviors or skills can the person already perform that may generate the same outcomes or reinforcers produced by the problem behaviors?

raises hard.

G. WHAT ARE THE PRIMARY WAYS THE PERSON COMMUNICATES WITH OTHER PEOPLE?

1. What are the general expressive communication strategies used by or available to the person? These might include vocal speech, signs/gestures, communication boards/books, or electronic devices. How consistently are the strategies used? rocal spench

2. On the following chart, indicate the behaviors the person uses to achieve the communicative outcomes listed:

\begin{tabular}{|c|c|c|c|c|c|c|c|c|c|c|c|c|c|c|c|c|c|}
\hline $\begin{array}{l}\text { Communicative } \\
\text { Functions }\end{array}$ & 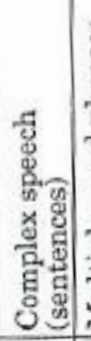 & 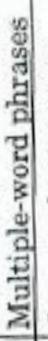 & 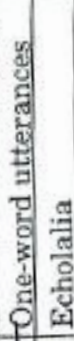 & 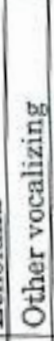 & 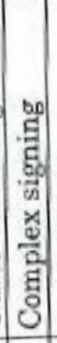 & 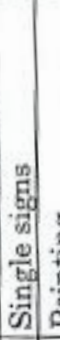 & $\begin{array}{c} \\
\text { no } \\
.5 \\
.5 \\
.9 \\
0 .\end{array}$ & 㗁 & 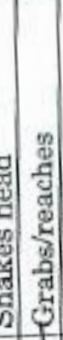 & \begin{tabular}{|c|} 
\\
\\
5 \\
0 \\
0 \\
0 \\
$\vdots$ \\
0 \\
$\vdots$ \\
5 \\
5 \\
0 \\
0 \\
\end{tabular} & 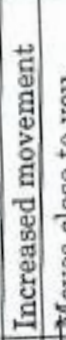 & 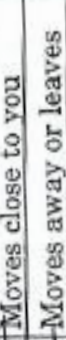 & 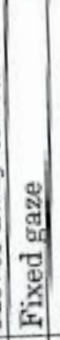 & 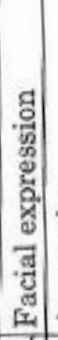 & 명. & 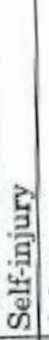 & $\frac{4}{\dddot{g}}$ \\
\hline Request attention & 1 & & $\sqrt{1}$ & & & & & & 1 & & 1 & 515 & & $\sqrt{1}$ & & & \\
\hline Request help & $\checkmark$ & $\sqrt{1}$ & $\sqrt{1}$ & & & & & & $J$ & & & $\sqrt{1}$ & & & & & \\
\hline $\begin{array}{l}\text { Request preferred } \\
\text { food/objects/activities }\end{array}$ & $J$ & $\sqrt{ }$ & $\sqrt{2}$ & & & & & & $\sqrt{ }$ & & & & & & & & \\
\hline Request break & & & 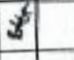 & & & & & & & & & J & & & & & \\
\hline $\begin{array}{l}\text { Show you something } \\
\text { or some place }\end{array}$ & & & & & & & & & & & & & & & & & \\
\hline $\begin{array}{l}\text { Indicate physical pain } \\
\text { (headache, illness) }\end{array}$ & & & & & & & & & & & & $\checkmark$ & & & & & \\
\hline $\begin{array}{l}\text { Indicate confusion } \\
\text { or unhappiness }\end{array}$ & & & $\checkmark$ & & & & & & & & & 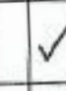 & & & & & \\
\hline $\begin{array}{l}\text { Protest or reject a } \\
\text { situation or activity }\end{array}$ & & & $\sqrt{ }$ & & & & & & & & & & & & & & \\
\hline
\end{tabular}


3. With regard to the person's receptive communication, or ability to understand other persons ...

a. Does the person follow spoken requests or instructions? If so, approximately how many? (List if only a few.) Yes, if prefenred.

b. Does the person respond to signed or gestural requests or instructions? If so, approximately how many? (List if only a few.) Yes, if preferred

c. Is the person able to imitate if you provide physical models for various tasks or activities? (List if only a few.)

Yes

d. How does the person typically indicate yes or no when asked if she or he w ants something, wants to go somewhere, and so on?

Hskis, or just mowes on her onen with out asking.

H. WHAT ARE THINGS YOU SHOULD DO AND THINGS YOU SHOULD AVOID IN WORKING WITH AND SUPPORTING THIS PERSON?

1. What things can you do to improve the likelihood that a teaching session or other activity will go well with this person?

Give choices, Support, break tasks into swaul steps, Model

2. What things should you avoid that might interfere with or disrupt a teaching session or activity with this person?

Give Indipendent tasks with no suppizt Give a directive not choice

I. WHAT ARE THINGS THE PERSON LIKES AND ARE REINFORCING FOR HIM QR HER?

1. Food items: Treasere box, sand box, compulter, Music read book, attention 
2. Toys and objects: Sond box, beads, coils on rug

3. Activities at home: Attention, Molucs, jobs

4. Activities/outings in the community:

$$
?
$$

5. Other:?

J. WHAT DO YOU KNOW ABOUT THE HISTORY OF THE UNDESIRABLE BEHAVIORS, THE PROGRAMS THAT HAVE BEEN ATTEMPTED TO DECREASE OR ELIMINATE THEM, AND THE EFFECTS OF THOSE PROGRAMS?

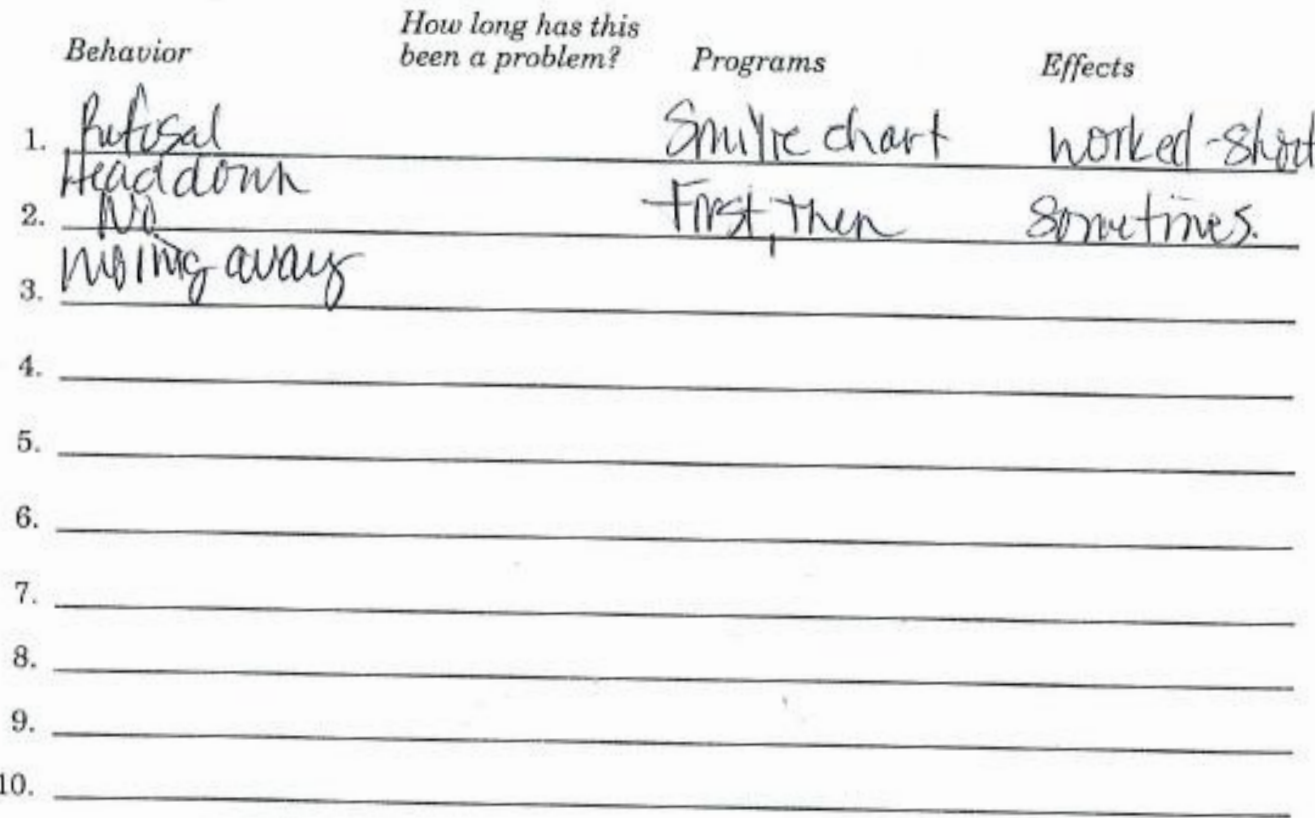


APPENDIX B: FUNCTION MATRIX

\begin{tabular}{|c|c|c|}
\hline & $\begin{array}{c}\text { Positive Reinforcement } \\
\text { (Access Something) }\end{array}$ & $\begin{array}{c}\text { Negative Reinforcement } \\
\text { (Avoid Something) }\end{array}$ \\
\hline Attention & & \\
\hline $\begin{array}{l}\text { Tangibles/ } \\
\text { Activities }\end{array}$ & & \\
\hline Sensory & & \\
\end{tabular}




\section{APPENDIX C: BUILDING A SUPPORT PLAN}

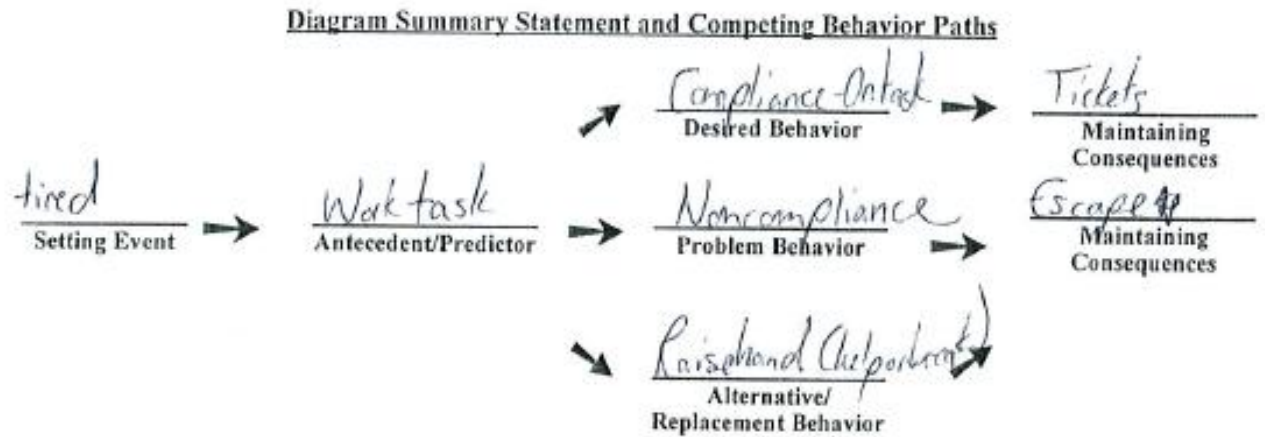

List Strategies that Make the Problem Behavior Irrelevant, Ineffective, \& Inefficient

\begin{tabular}{|c|c|c|}
\hline $\begin{array}{l}\text { - Give } 5 \mathrm{~mm} \text {. } \\
\text { to lay down. } \\
\text { cut work to } 50 \% \text {. }\end{array}$ & 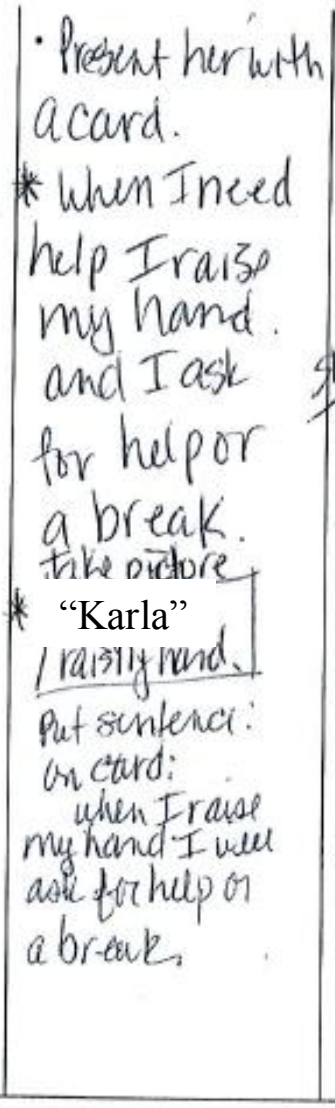 & 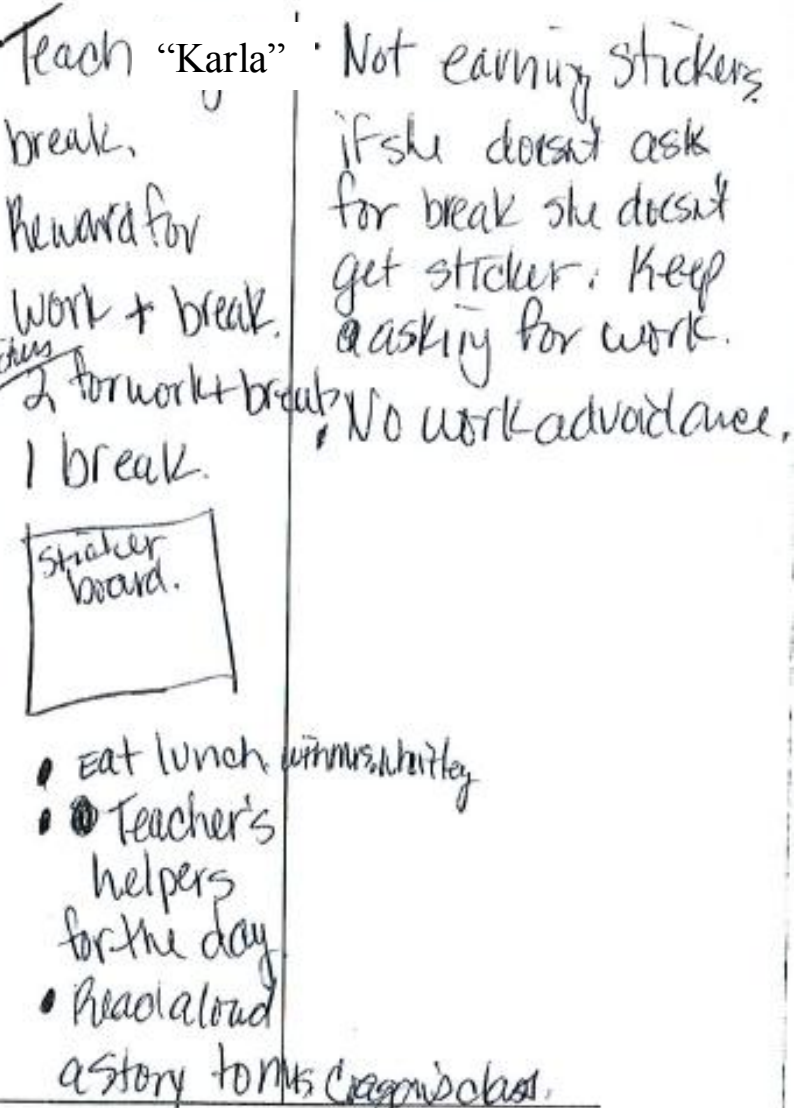 \\
\hline & & $\begin{array}{l}\text { Teaching } \\
\text { Strategies }\end{array}$ \\
\hline
\end{tabular}




\section{APPENDIX D: POWERPOINT SAMPLES}

\section{Definition \& Principles of FBA}

C. FBA is based on the assumption that

- All behavior is functional and/or communicative

- Then it is legitimate - it has message or functional value

- Intervention should be designed to teach acceptable way to communicate or accomplish function

\section{Overview of Procedures of FBA}

STEP 3. Verify hypotheses (VERIFY)

- hypotheses are tested through experimental manipulations to confirm or disconfirm the hypotheses

STEP 4. Develop, implement, and evaluate intervention (INTERVENE)

- assessment-based interventions are developed, implemented, and monitored

\section{Define the Problem Behavior}

A. Three criteria for the definition of a behavior

- Observable 票

- Measurable 분

- Precise

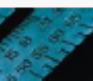

\section{Overview of Procedures of FBA}

STEP 1. Describe and identify problem (DESCRIBE) - information regarding the problem behavior is collected through indirect and direct measures

STEP 2. Interpret and develop hypotheses (CATEGORIZE)

- collected data are interpreted and hypotheses about the problem behavior are generated

STEP 1:

DESCRIBE AND IDENTIFY PROBLEM

The purpose of this step is to:

obtain information from various sources

(through indirect and direct strategies)

in order to describe and identify the problem

Informant

assessment

Descriptive assessment

\section{Define the Problem Behavior}

B. To define in OMP terms, we need to "pinpoint" the behavior

- Pinpointing refers to the process of refining broad generalizations into specific. observable. measurable behaviors

- To pinpoint the behavior, fill in the following phrase:

will be counted when ....

Adapted from SPED 4270/5270 Course Materials, University of North Carolina at

Charlotte, Dr. Ya-yu Lo. 


\section{APPENDIX E: FUNCTION-BASED INTERVENTION PROCEDURE FIDELITY CHECKLIST}

IOA: $\quad \mathrm{Y} / \mathrm{N}$ (IOA Score $=$

\section{Function-Based Intervention Procedure Fidelity Checklist}

Teacher:

Session:

Date:

Recorder:

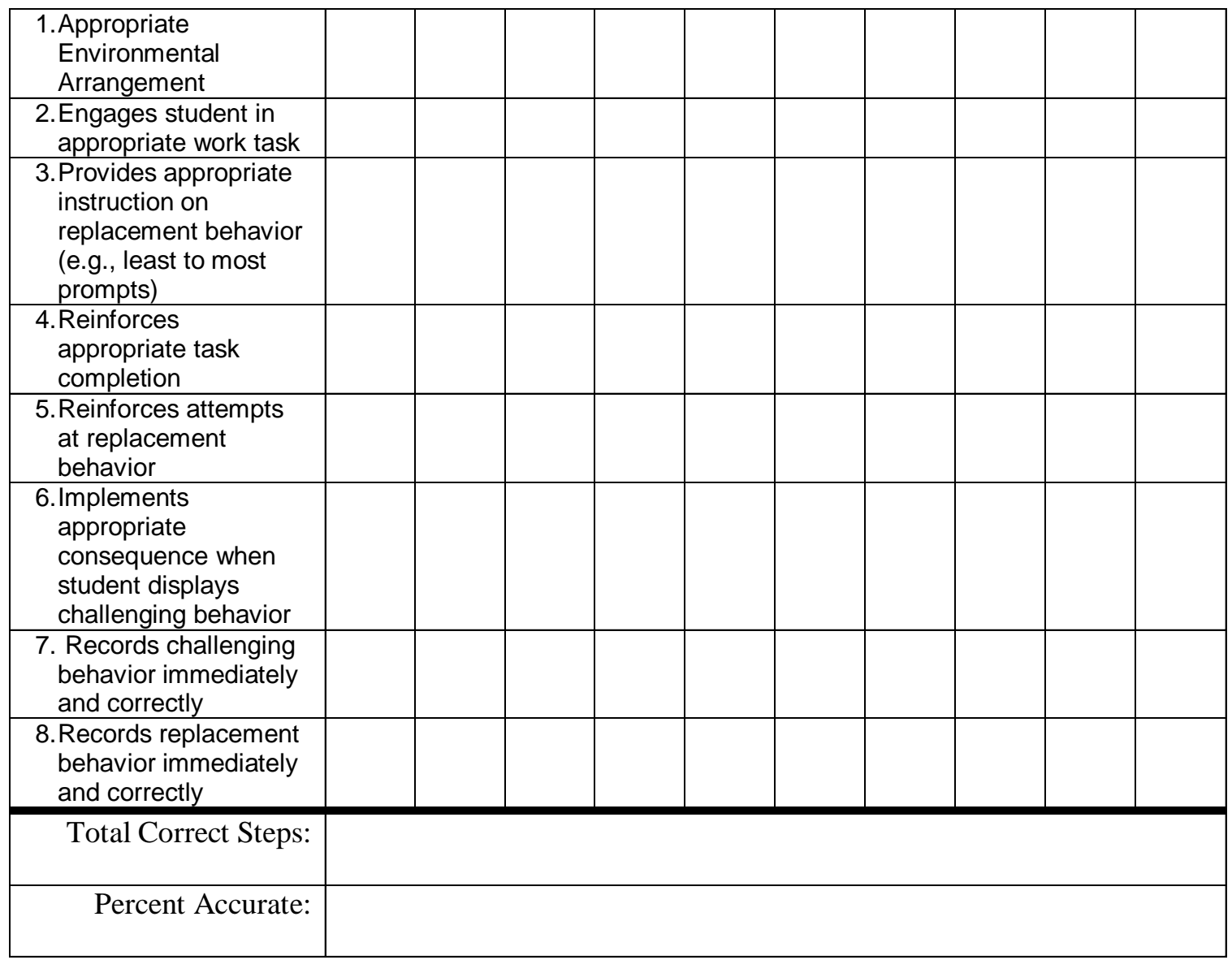

$+=$ Step performed correctly

- = Step not performed or performed incorrectly 


\section{APPENDIX F: TEACHER SPECIFIC FUNCTION-BASED INTERVENTION PROCEDURE FIDELITY CHECKLIST}

IOA: $\quad \mathrm{Y} / \mathrm{N}$ (IOA Score $=$

Teacher 1 Function-Based Intervention Procedure Fidelity Checklist

Teacher:

$+=$ Step performed correctly

Session:

- = Step not performed or performed

Date:

incorrectly

Recorder:

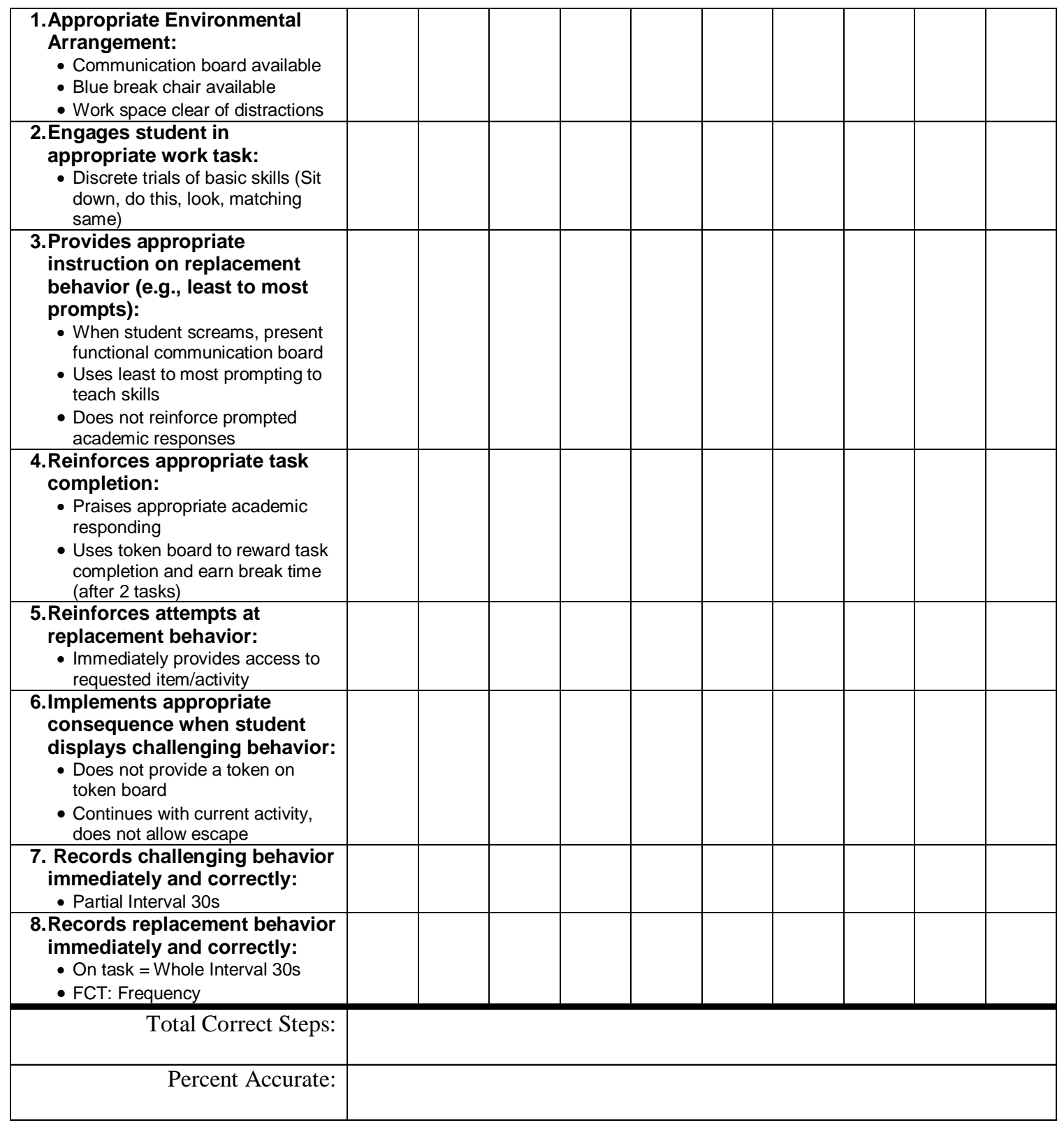




\section{APPENDIX G: PARTIAL INTERVAL RECORDING SHEET FOR STUDENT BEHAVIOR}

IOA: $\quad \mathrm{Y} / \mathrm{N} \quad($ IOA Score $=$ )

Student Interval Recording Sheet

\begin{tabular}{|l|l|}
\hline Date: & Problem Behavior: \\
\hline Student Name: & Replacement Behavior A: \\
\hline Session: & Replacement Behavior B: \\
\hline Recorder: & \\
\hline
\end{tabular}

\begin{tabular}{|c|c|c|}
\hline & $\begin{array}{c}\text { Problem } \\
\text { Behavior }\end{array}$ & $\begin{array}{c}\text { Replacement } \\
\text { Behavior (A) }\end{array}$ \\
\hline Date: & & \\
\hline Session: & & \\
\hline $\begin{array}{c}\text { Time in } \\
\text { min \& s }\end{array}$ & $\begin{array}{l}\text { + = Behavior occurred } \\
0=\text { Behavior did not occur }\end{array}$ \\
\hline $0: 30$ & & \\
\hline 1:00 & & \\
\hline $1: 30$ & & \\
\hline $2: 00$ & & \\
\hline $2: 30$ & & \\
\hline $3: 00$ & & \\
\hline $3: 30$ & & \\
\hline $4: 00$ & & \\
\hline $4: 30$ & & \\
\hline $5: 00$ & & \\
\hline $5: 30$ & & \\
\hline $6: 00$ & & \\
\hline $6: 30$ & & \\
\hline $7: 00$ & & \\
\hline $7: 30$ & & \\
\hline $8: 00$ & & \\
\hline $8: 30$ & & \\
\hline $9: 00$ & & \\
\hline $9: 30$ & & \\
\hline $10: 00$ & & \\
\hline Total & & \\
\hline Percent & & \\
\hline & & \\
\hline
\end{tabular}

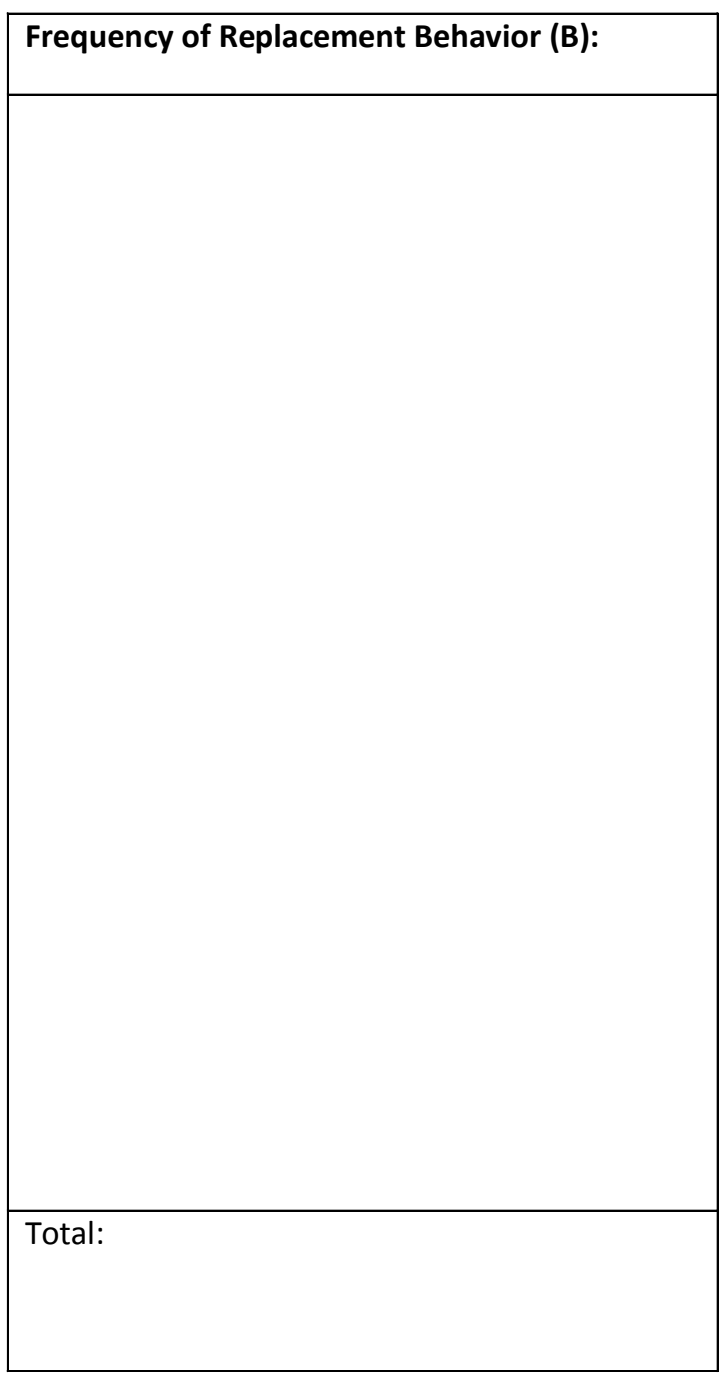

$+=$ Behavior occurred

$\theta=$ Behavior did not occur 
APPENDIX H: COACHING FIDELITY CHECKLIST

\section{Coaching Fidelity Checklist}

Teacher:

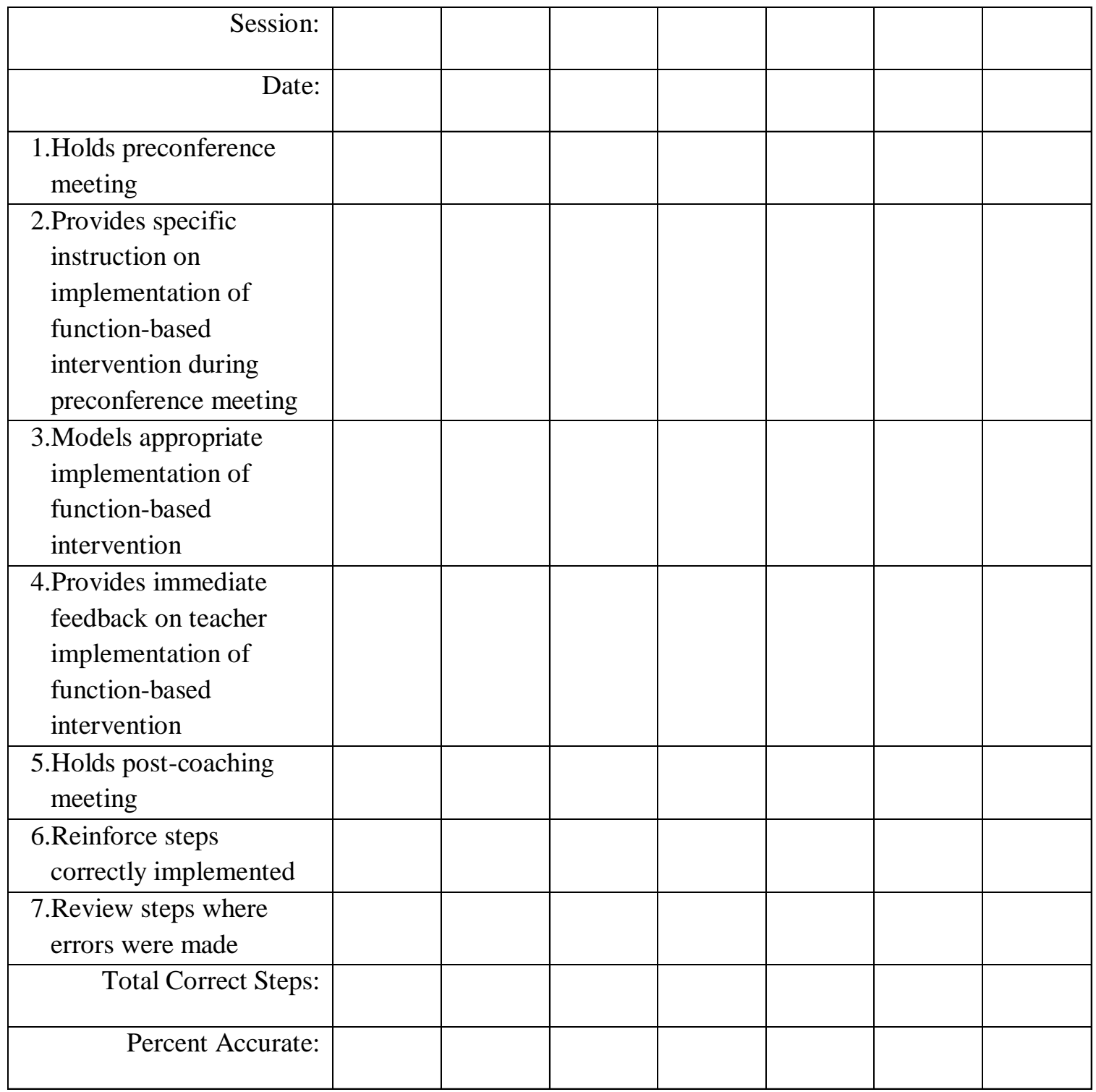

$+=$ Step performed correctly

- = Step not performed or performed incorrectly 
APPENDIX I: STUDENT DATA COLLECTION

\begin{tabular}{|c|c|c|c|}
\hline Student & Teacher & Behavior (function) & Data Collection Method \\
\hline \multirow[t]{3}{*}{ Susan } & Mrs. Yacht & Glasses off (attention) & Frequency \\
\hline & & Appropriate Use of & MTS: 1 min \\
\hline & & Materials & \\
\hline \multirow[t]{4}{*}{ Karla } & Mrs. Williams & Noncompliance (escape) & Partial Interval: 1 min \\
\hline & & Compliance & Whole Interval: $1 \mathrm{~min}$ \\
\hline & & Functional Communication: & Frequency \\
\hline & & Break or Help Request & \\
\hline \multirow[t]{4}{*}{ Michael } & Mr. Carlisle & Tantrum (escape) & Partial Interval: 30s \\
\hline & & On Task & Whole Interval: $30 \mathrm{~s}$ \\
\hline & & Functional Communication: & Frequency \\
\hline & & Break Request & \\
\hline \multirow[t]{3}{*}{ Jack } & Mrs. Green & Off-task (escape) & Partial Interval: $1 \mathrm{~min}$ \\
\hline & & On-task & Whole Interval: 1 min \\
\hline & & Appropriate Break Request & Frequency \\
\hline
\end{tabular}




\section{APPENDIX J: SOCIAL VALIDITY QUESTIONNAIRES}

Please rate the following on a scale of 1 (strongly disagree) to 5 (strongly agree).

\begin{tabular}{|c|c|c|c|c|c|}
\hline & $\begin{array}{c}1 \\
\text { Strongly } \\
\text { disagree }\end{array}$ & 2 & 3 & 4 & $\begin{array}{c}5 \\
\text { Strongly } \\
\text { Agree }\end{array}$ \\
\hline $\begin{array}{l}\text { 1. Implementing function-based interventions } \\
\text { are important when working with students } \\
\text { with challenging behaviors. }\end{array}$ & & & & & \\
\hline $\begin{array}{l}\text { 2. Coaching helped me better implement } \\
\text { function-based interventions with this } \\
\text { student. }\end{array}$ & & & & & \\
\hline $\begin{array}{l}\text { 3. I will use function-based interventions } \\
\text { with other students in the future. }\end{array}$ & & & & & \\
\hline $\begin{array}{l}\text { 4. The coaching sessions were not intrusive } \\
\text { to my daily routine. }\end{array}$ & & & & & \\
\hline 5. Coaching was cost efficient. & & & & & \\
\hline $\begin{array}{l}\text { 6. The student demonstrated an increase in } \\
\text { his/her adaptive behavior. }\end{array}$ & & & & & \\
\hline $\begin{array}{l}\text { 7. The student demonstrated a decrease in } \\
\text { his/her challenging behavior. }\end{array}$ & & & & & \\
\hline $\begin{array}{l}\text { 8. I will continue to implement the designed } \\
\text { function-based intervention with the target } \\
\text { student. }\end{array}$ & & & & & \\
\hline $\begin{array}{l}\text { 9. Using coaching is a socially acceptable } \\
\text { way to provide additional training beyond } \\
\text { the workshop model. }\end{array}$ & & & & & \\
\hline Comments: & & & & & \\
\hline
\end{tabular}




\section{Psychologist Social Validity Questionnaire}

Function-based interventions are interventions and intervention packages that are developed from the FBA data that address the identified function of the challenging behavior (Umbreit et al., 2007). Functional behavior assessment (FBA) is a set of strategies designed to identify the function of a given behavior through identification of altering antecedent variables, altering consequence variables, and alternative behaviors (Cooper et al., 2007).

Please rate the following on a scale of 1 (strongly disagree) to 5 (strongly agree).

\begin{tabular}{|c|c|c|c|c|c|}
\hline & $\begin{array}{c}1 \\
\text { Strongly } \\
\text { disagree }\end{array}$ & 2 & 3 & 4 & $\begin{array}{c}5 \\
\text { Strongly } \\
\text { Agree }\end{array}$ \\
\hline $\begin{array}{l}\text { 1. Implementing function-based interventions } \\
\text { are important when working with students } \\
\text { with challenging behaviors. }\end{array}$ & & & & & \\
\hline $\begin{array}{l}\text { 2. Coaching helped the teachers implement } \\
\text { function-based interventions with this } \\
\text { student. }\end{array}$ & & & & & \\
\hline $\begin{array}{l}\text { 3. The coaching sessions were not intrusive } \\
\text { to the school's daily routine. }\end{array}$ & & & & & \\
\hline 4. Coaching was cost efficient. & & & & & \\
\hline $\begin{array}{l}\text { 5. The students demonstrated an increase in } \\
\text { their adaptive behavior. }\end{array}$ & & & & & \\
\hline $\begin{array}{l}\text { 6. The students demonstrated a decrease in } \\
\text { their challenging behavior. }\end{array}$ & & & & & \\
\hline $\begin{array}{l}\text { 7. I would consider recommending coaching } \\
\text { as a way to help teachers implement new } \\
\text { strategies following a workshop training. }\end{array}$ & & & & & \\
\hline $\begin{array}{l}\text { 8. Using coaching is a socially acceptable } \\
\text { way to provide additional training beyond } \\
\text { the workshop model. }\end{array}$ & & & & & \\
\hline Comments: & & & & & \\
\hline
\end{tabular}

